\title{
Boosting gas separation performance and suppressing the physical aging of polymers of intrinsic microporosity (PIM- 1) by nanomaterial blending. DOI:
}

10.1039/D0NR07042D

\section{Document Version}

Accepted author manuscript

Link to publication record in Manchester Research Explorer

Citation for published version (APA):

Ahmad, M. Z., Castro-muñoz, R., \& Budd, P. M. (2020). Boosting gas separation performance and suppressing the physical aging of polymers of intrinsic microporosity (PIM-1) by nanomaterial blending. Nanoscale, 12(46), 2333323370. https://doi.org/10.1039/D0NR07042D

\section{Published in:}

Nanoscale

\section{Citing this paper}

Please note that where the full-text provided on Manchester Research Explorer is the Author Accepted Manuscript or Proof version this may differ from the final Published version. If citing, it is advised that you check and use the publisher's definitive version.

\section{General rights}

Copyright and moral rights for the publications made accessible in the Research Explorer are retained by the authors and/or other copyright owners and it is a condition of accessing publications that users recognise and abide by the legal requirements associated with these rights.

\section{Takedown policy}

If you believe that this document breaches copyright please refer to the University of Manchester's Takedown Procedures [http://man.ac.uk/04Y6Bo] or contact uml.scholarlycommunications@manchester.ac.uk providing relevant details, so we can investigate your claim.

\section{OPEN ACCESS}




\title{
Boosting gas separation performance and suppressing the physical aging of polymers of intrinsic microporosity (PIM-1) by nanomaterial blending.
}

\author{
Mohd Zamidi Ahmad ${ }^{1 *}$, Roberto Castro-Muñoz ${ }^{2}$, Peter M. Budd ${ }^{1}$ \\ ${ }^{1}$ Organic Materials Innovation Center (OMIC), Department of Chemistry, University of Manchester, \\ Oxford Road, M13 9PL, United Kingdom. \\ ${ }^{2}$ Tecnologico de Monterrey, Campus Toluca. Avenida Eduardo Monroy Cárdenas 2000 San Antonio \\ Buenavista, 50110 Toluca de Lerdo, Mexico.
}

*Corresponding Author: mohdzamidi.ahmad@manchester.ac.uk; zamidi.ahmad@gmail.com

\begin{abstract}
In recent decades, Polymers of Intrinsic Microporosity (PIMs) especially the firstly introduced PIM1 , have been actively explored for various membrane-based separation purposes and widely recognized as the next generation membrane materials of choice for gas separation due to their ultra-permeable characteristics. Unfortunately, the polymers suffer substantially the negative impacts of physical aging, a phenomenon that is primarily noticeable in high free volume polymers. The phenomenon occurs at the molecular level, which leads to changes in the physical properties, and consequently the separation performance and membrane durability. This review discusses the strategies that have been employed to manage the physical aging issue, with a focus on the approach of blending with nanomaterials to give mixed matrix membranes. A detailed discussion is provided on the types of materials used, their inherent properties, the effects on gas separation performance, and their benefits in the suppression of the aging problem.
\end{abstract}

\section{Keywords:}

Polymers of intrinsic microporosity, physical aging, mixed matrix membrane, metal-organic frameworks, nanomaterials 


\section{Table of Contents}

Abstract

1.0. Introduction

1.1. Polymer physical aging

1.2 Aging in superglassy high performance polymers

1.3 Strategies for controlling the aging

1.3.1. Mixed matrix membrane (MMM)

1.3.2. Role of fillers in MMMs in gas separation

2.0. MMMs for performance enhancement and aging suppression of PIM-1

2.1. PIM-1 with metal-organic frameworks (MOFs)

2.1.1. Zeolitic imidazolate frameworks (ZIFs)

2.1.2. Zirconium-based MOFs

2.1.3. Chromium-based MOFs

2.1.4. Photo-responsive MOFs

2.1.5. Post synthetically modified MOFs

2.1.6. Two-dimensional (2D) MOFs

2.1.7. Modification of MOF-MMM fabrication procedure

2.2 PIM-1 with nanotubes and 2D fillers

2.2.1 Carbon nanotubes (CNTs)

2.2.2. Graphene

2.2.3. Graphene oxide (GO)

2.2.4. Graphitic carbon nitride $\left(\mathrm{g}-\mathrm{C}_{3} \mathrm{~N}_{4}\right)$

2.3 PIM-1 with inorganic fillers

2.4. PIM-1 with other fillers

2.4.1. Polyhedral oligomeric silsesquioxane (POSS)

2.4.2. Organic cage molecules

2.4.3. Triptycene-based porous organic polymers (POPs)

2.4.4. Covalent organic frameworks (COFs)

2.4.5. Porous aromatic frameworks (PAFs)

2.4.6. Hypercrosslinked polymers (HCPs) and porous carbons

2.4.7. Network PIMs

3.0. MMM standpoints

3.1. Separation performance

3.2. Aging behavior

4.0. Perspective and conclusion 


\section{Introduction}

Nowadays, the application of membrane technology to separate high-quality gases $\left(\mathrm{H}_{2}, \mathrm{CH}_{4}, \mathrm{O}_{2}\right)$ from other impurities $\left(\mathrm{CO}_{2}, \mathrm{H}_{2} \mathrm{~S}, \mathrm{CO}\right)$ has proven its benefits over the thermodynamically controlled gas-separation methods, being a continuous energy-efficient operation, having a smaller ecological and physical footprint, and having a lower operational complexity [1-4]. Nevertheless, the scientific membrane separation community is bound to explore the next generation of ultra-permeable polymers, for higher separation productivity in industrial production $[5,6]$.

The theory of separating gas mixtures by means of membrane technology has been increasingly acknowledged and is likely to become more important, for example for biogas purification and processing of especially low-quality gas reservoirs [4,7]. Membrane permeability (inversely proportional to the membrane thickness) and selectivity, being the key performance indicators, remain the most significant challenges to ensure higher separation efficiency [5], among other required characteristics, such as excellent thermal stability, high tolerance to contaminants and plasticizing agents $\left(\mathrm{CO}_{2}, \mathrm{H}_{2} \mathrm{~S}\right.$, water vapor), high availability and good reproducibility [5]. Polymeric membranes, being one to three orders of magnitude cheaper than inorganic membranes [8], need to be further enhanced to compete with the chemically and thermally stable inorganic membranes, which are commonly produced from metals, ceramics or pyrolyzed carbon [9-11]. Inorganic membranes can have five to ten times higher perm-selectivity [8], but are prohibitively expensive and delicate to fashion into continuous and defect-free membranes [9,11].

Nearly two decades ago, the first polymers of intrinsic microporosity (PIMs) were reported by Budd and McKeown [12] and defined accordingly to IUPAC as microporous, with effective pore dimensions of $<2 \mathrm{~nm}$ [13]. Their high porosity is the direct consequence of the contortion sites and lack of single bonds in the polymer backbone, giving irregular and kinked polymer chains that lack conformational flexibility. The site of contortion is typically a spiro-center (a single tetrahedral carbon atom shared by two rings). A PIM's rigid and contorted molecular configuration causes it to pack inefficiently, trapping a sufficient amount of free volume [13] to give Brunauer-Emmett-Teller (BET) surface areas as high as $800 \mathrm{~m}^{2} \cdot \mathrm{g}^{-1}$. While the free volume gives high gas permeability, the bottlenecks or gates interconnecting the micropores behave as sieves for gas molecules with different sizes and shapes, giving rise to its separation selectivity. Benefiting from this high surface area and porosity, many researchers have tailored PIMs for various applications, such as gas separation, gas storage and catalysis. In terms of gas separation, PIMs have demonstrated a solution-processability amenable to the production of either thickor thin-films with superior gas permeability, far beyond conventional polymers, and have contributed to pushing the previous Robeson upper bound limits to new heights (Figure 1) [14,15]. Unfortunately, the commercial application of PIMs remains limited due to the aging problem, which consequently affects the membrane performance over time. In general, a PIM's inefficient packing places the polymer in a 
non-equilibrium state and, by nature, molecular relaxation will occur that drives the material closer to equilibrium. The phenomenon is referred to as polymer physical aging.
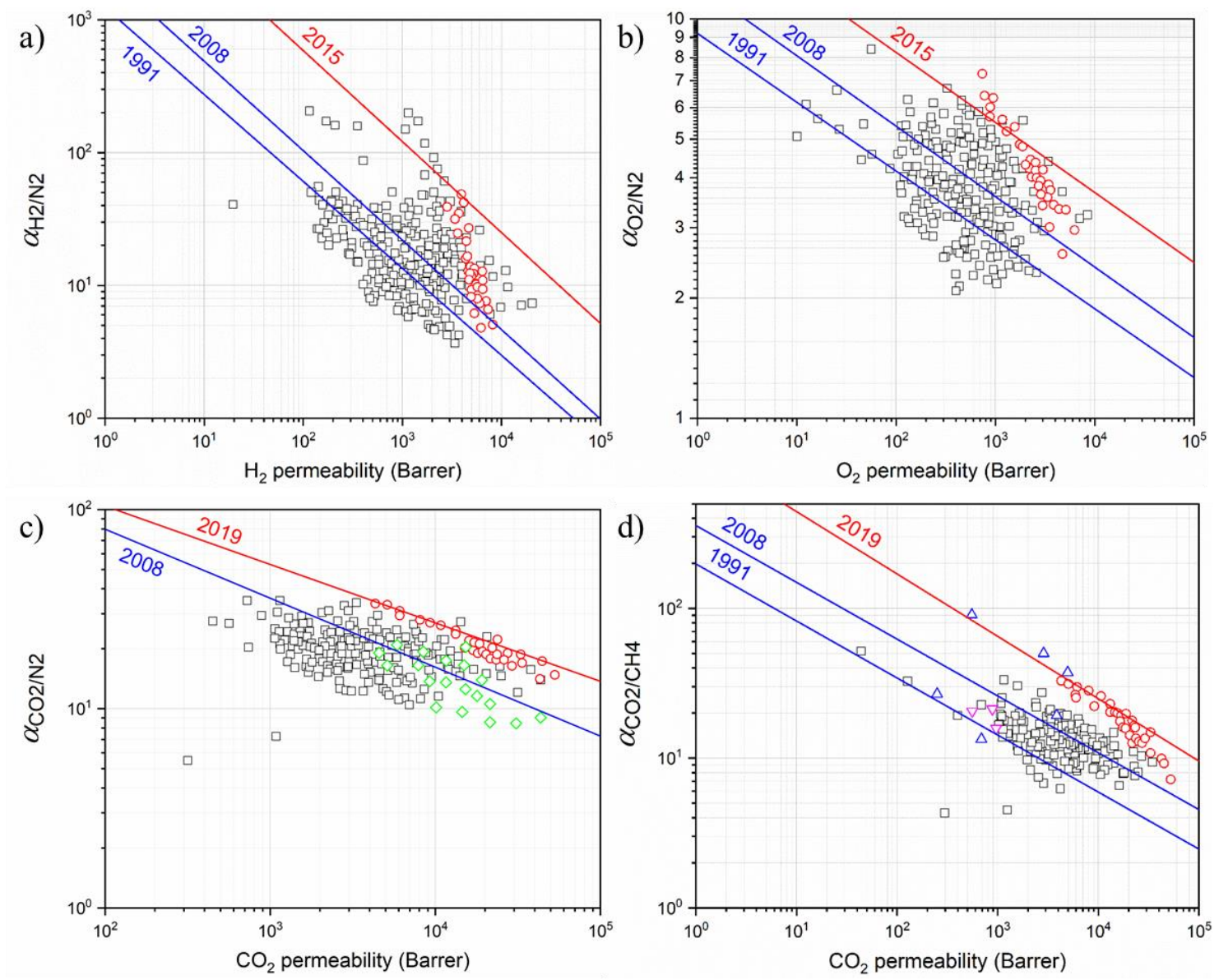

Figure 1: Double logarithmic plots of (a) $\mathrm{H}_{2} / \mathrm{N}_{2}$, (b) $\mathrm{O}_{2} / \mathrm{N}_{2}$, (c) $\mathrm{CO}_{2} / \mathrm{N}_{2}$, and (d) $\mathrm{CO}_{2} / \mathrm{CH}_{4}$ selectivity against the permeability of the most permeable gas of the pair, for as-synthesized PIMs and other high free volume polymer membranes (black squares). Also included; benzotriptycene-based PIMs (red circles), PIMs modified by fillers (green diamonds), carbon molecular sieve (CMS) membranes derived from high free volume polymers (blue triangles), and thermally rearranged PIMs membranes (inverted purple triangles). All were reviewed and discussed in [16,17], against the 1991 [14], 2008 [15], 2015 [18] and 2019 [17] performance upper bounds.

\subsection{Polymer physical aging}

Polymer physical aging is a phenomenon that occurs in most amorphous and semi-crystalline polymers, involving a reversible change in the polymer properties as a function of time [19]. This glassystate structural relaxation towards a thermodynamically more stable state occurs without permanent structure modification, chemical or physical. Although physical aging occurs without any external influence, its rate is dependent on several factors, such as temperature, gas environment, and polymer structure [20,21]. More importantly, it has been observed that physical aging occurs more rapidly in a thin polymer film (i.e., rate of aging in a film is inversely proportional to its thickness) [22-24], as evident in both conventional polymers such as polyimide (PI), polysulfone (PSF) and polyphenylene oxide (PPO), and high free volume polymers such as PIMs, poly(1-trimethylsilyl-1-propyne) (PTMSP) 
and the fluoropolymers Teflon ${ }^{\circledR} \mathrm{AF}$ and Hyflon ${ }^{\circledR} \mathrm{AD}$. The accelerated aging of thin films is attributed to enhanced mobility near the surface, or the diffusion of free volume to the surface of the film, which allows the polymer to reach a lower free volume state more quickly than in bulk samples [25].

Polymer free volume is best explained by the relationship between a polymer's specific volume and temperature (Figure 2) [16,26]. At a temperature below the glass transition $\left(T_{\mathrm{g}}\right)$, a polymer has reduced molecular mobility and its thermal expansion coefficient is less than in the liquid state, $\alpha_{1}$. The polymer reaches thermal equilibrium without being able to reorganise to the density expected from extrapolation of the equilibrium liquid line $\left(V_{1}\right)$, creating unrelaxed free volume (the shaded area in Figure 2). When the storage temperature $\left(T_{\mathrm{a}}\right)$ of the polymer is below $T_{\mathrm{g}}$, the limited polymer mobility allows for a slow loss of unrelaxed free volume over time (physical aging).

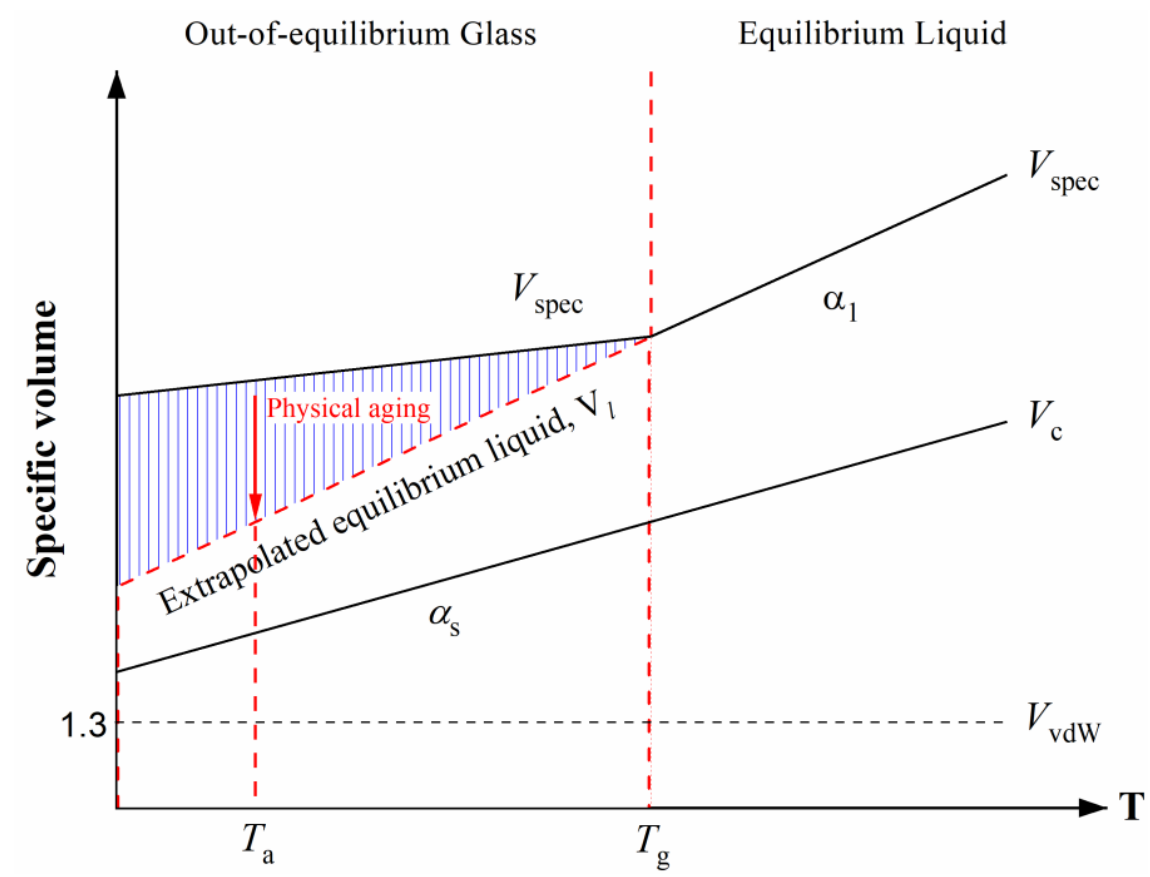

Figure 2: The temperature dependence of the specific volume of a glassy polymer, around the glass transition temperature $\left(T_{\mathrm{g}}\right)$. A similar plot can be constructed for thermodynamic quantities such as enthalpy and entropy. This figure has been adapted from ref. [27] with permission from American Chemical Society, copyright 2016.

The total free volume ( $V_{\text {free }}$ ) of a glassy polymer can be estimated from its solid density $\left(1 / V_{\text {spec }}\right)$ [28-30] in relation to the van der Waals molecular volume $\left(V_{\mathrm{vdW}}\right)$, which can be calculated by group contribution methods [31]. The closed packed hypothetical crystal volume $\left(V_{\mathrm{c}}\right)$ at $0 \mathrm{~K}$ is commonly taken as $1.3 V_{\mathrm{vdw}}$, as discussed by Horn [32], and thus the fractional free volume may be calculated as:

$$
\phi_{\mathrm{FV}}=\frac{V_{\text {free }}}{V_{\text {spec }}}=1.0-1.3 \times \frac{V_{\text {vdW }}}{V_{\text {spec }}}
$$

More accurate free-volume measurement techniques are made available by advanced instrumentation, including positron annihilation lifetime spectroscopy (PALS) [33], where positrons are 
injected and the lifetime of ortho-positronium (o-Ps) can be related to the size of free volume elements in the amorphous sample by assuming a spherical cavity shape [34]. Other techniques are inverse gas chromatography (IGC) [35,36], cryogenic physisorption ( $\mathrm{N}_{2}$ sorption) $[37,38],{ }^{129} \mathrm{Xe}$ NMR spectroscopy [33,39], molecular modelling and scattering methods (e.g., small-angle X-ray scattering (SAXS) [40] and X-ray diffraction (XRD) [40]). More details about each of these techniques can be found in the references.

\subsection{Aging in superglassy high performance polymers}

Besides PIMs, it should be noted that several other non-network polymers may also possess significant intrinsic microporosity, such as polyacetylenes, fluorinated polymers and poly(norbornenes), demonstrated by their very high gas permeabilities and often described as high free volume or ultrapermeable polymers [41]. Although polymer physical aging may occur in all glassy polymers, it is particularly noticeable in highly microporous polymers.

The porosity in PIMs is closely related to free volume, which as previously discussed arises from a chain structure combining rigid segments with sites of contortion, producing a high concentration of interconnected pores. In terms of gas separation, the changes in free volume during aging decreases the gas permeability. The most investigated PIM, PIM-1 (common synthesis routes presented in Figure 3), can show a tremendous loss in gas permeability over time, i.e., up to $75 \%$ in just 30-90 days [42-44]. The permeability loss is even more significant in thin-film composite (TFC) membranes, i.e., to almost 95\% [24]. In addition, molecular modelling of PIM-1 indicates that the spirobisindane unit and dioxane linkages are relatively flexible [45]. This amorphous and semi-flexible nature of PIM-1 polymer chains results in a broad size distribution of free volume elements (for example, 4-10 A) and significant aging effects.
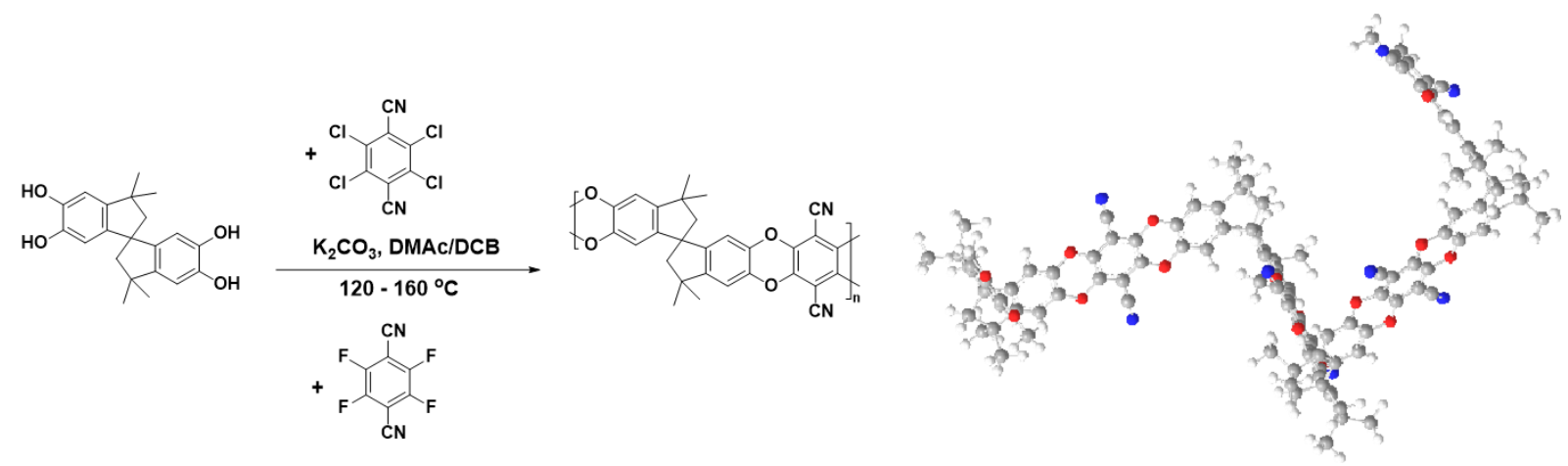

Figure 3: Synthesis routes of the most-investigated polymer of intrinsic microporosity, PIM-1, and a molecular fragment showing the contorted structure that causes inefficient packing, giving its intrinsic microporosity.

Due to the aging phenomenon, the commercial application of PIM-1 remains limited, as it translates into poor separation durability of the material. The effect of aging on the gas separation performance is demonstrated for PIM-1 and several other PIM derivatives for $\mathrm{H}_{2} / \mathrm{N}_{2}$ and $\mathrm{O}_{2} / \mathrm{N}_{2}$ separation in Figure 4(a) and Figure 4(b), respectively. While many researchers are investigating methods to reduce the loss of 
gas permeability, several others are studying the direct changes within the polymer by structural analysis, to understand the changes during physical aging (e.g., small-angle X-ray scattering (SAXS) analysis [46]) and how the phenomenon affects gas permeation and sorption [47]. As our understanding of the nature of physical aging develops, PIMs and other ultra-permeable polymers will hopefully reach their full commercial potential.
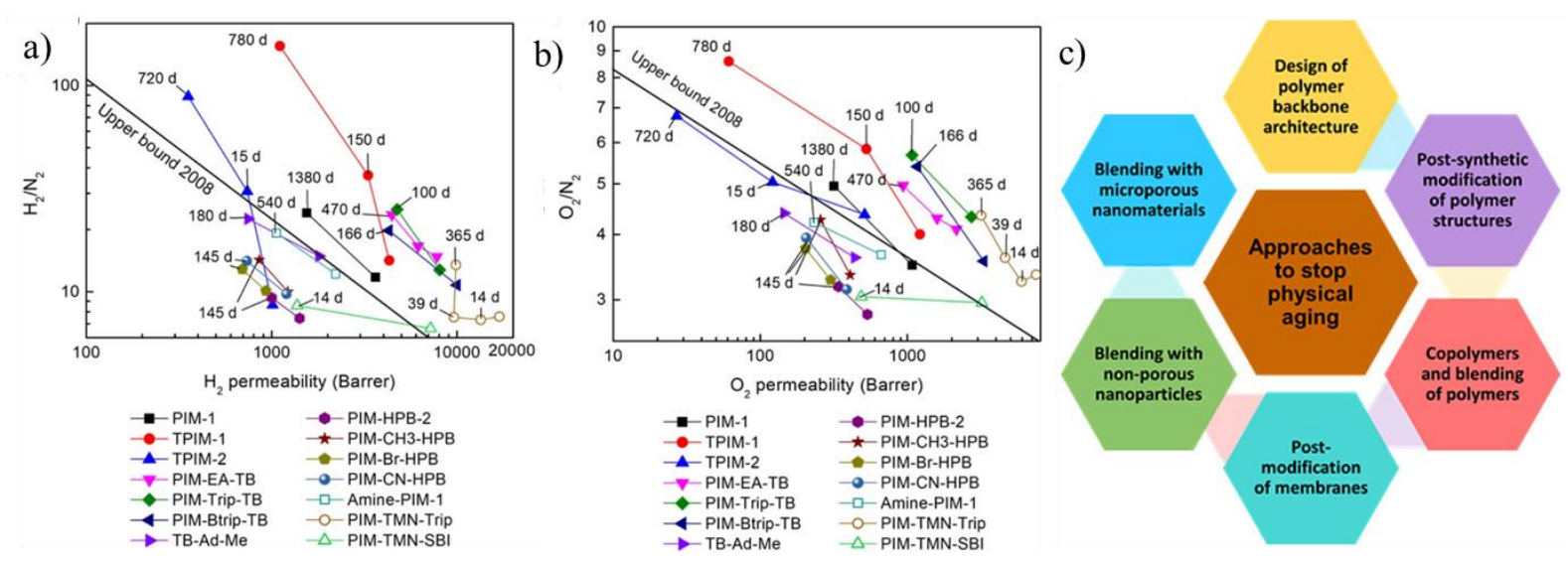

Figure 4: Selectivity versus permeability Robeson plots for (a) $\mathrm{H}_{2} / \mathrm{N}_{2}$ and (b) $\mathrm{O}_{2} / \mathrm{N}_{2}$ gas pairs, showing the aging effects in PIMs. (c) Methods currently employed to manage polymer physical aging. This figure has been reproduced from ref. [16] with permission from American Chemical Society, copyright 2018.

\subsection{Strategies for controlling physical aging}

Several techniques are currently being explored to tackle the physical aging problem in high free volume glassy polymers (illustrated in Figure 4(c)), such as (i) variation of polymer backbone design and architecture, (ii) polymer post-synthetic modification, (iii) post-modification of the finished membranes, (iv) the formation of copolymers and blending of polymers (v) the addition of non-porous nanoparticles and (vi) the addition of microporous nanomaterials. These techniques are proven to be useful to a certain degree in PIMs and other highly permeable polymers. Examples are thermal selfcrosslinking of PIM-1 $[48,49]$, the addition of non-porous (i.e., silica nanoparticles [50] and multiwalled carbon nanotubes [51] in PIM-1) and porous materials or even multivalent metal ions [52], treating PIM1 with supercritical $\mathrm{CO}_{2}$ [43] and polymer blending, creating dual-phase microporous with other highly microporous borazine-linked polymer BLP-101 [53] or non-microporous poly(ethylene imine) [54].

This review will focus on the approach of making PIM-1 mixed matrix membranes using nanoparticles as the fillers. The filler properties and their effects on the gas separation performance, as well as their benefits in reducing the aging phenomenon, are discussed accordingly. Synthetic design approaches in producing more advanced PIMs are not presented here.

\subsubsection{Mixed matrix membranes (MMMs)}

A proven technique to push the PIMs performance boundary is through the fabrication of mixed matrix membranes (MMMs). MMMs are defined as composite materials comprising solid or rigid 
phases dispersed in a continuous polymer phase [55-57]. The combination of the polymer with filler particles aims to exploit the synergistic advantages from each phase, such as high permeability of the dispersed fillers, high selectivity and easy processability of the polymers. The embedded filler adjusts the local polymer dynamic properties (i.e., stiffness, segmental chain motion and fractional free volume). Thus, MMMs may offer enhanced physical, thermal and mechanical properties for the aggressive and adverse environments in actual gas separation systems [8]. A great number of inorganic and organic/inorganic hybrid filler materials have been incorporated into continuous polymeric phases to facilitate gas transport. The filler material may be selected on the basis of its pore size, which allows fast diffusion and molecular sieving, according to the gas kinetic diameters. Additionally, the features of these materials are often adjustable (i.e., through functionalization or chemical exchange), giving a controlled pore size and diverse opportunities for gas permeability and selectivity fine-tuning [58]. However, the permeation and separation behavior in a MMM is not merely an additive property of the filler and polymer phases' intrinsic performance [9,55,59]. The morphology of the MMM strongly affects its gas transport properties [60-62]. Therefore, fabrication of an ideal MMM with no fillerpolymer interfacial defects and no particle agglomeration is crucial. Challenges encountered in MMM preparation relate to the need to control and maintain the chemical structure of the filler upon addition into the continuous polymer matrix and to understand their surface chemistry [63].

The fillers used in polymer-based MMMs are divided into several categories, including: (i) 2D and 3D metal-organic complexes or frameworks (MOFs), (ii) nanotubes and 2D fillers such as GO and graphitic carbon nitride $\left(\mathrm{g}-\mathrm{C}_{3} \mathrm{~N}_{4}\right)$, (iii) inorganic filler materials such as silica, and (iv) other emerging organic solid fillers such as polyhedral oligomeric silsesquioxane (POSS), covalent organic frameworks (COFs) and porous aromatic frameworks (PAFs). Their incorporation in MMMs has been reported using both low flux (e.g., PSF [64], polyvinyl acetate (PVAc) [65] and polybenzimidazole (PBI) [66]) and high flux (e.g., rubbery polydimethylsiloxane (PDMS) [67] and glassy hexafluoropropane dianhydridebased 6FDA-DAM $[68,69])$ polymers. Indeed, MOF-containing membranes have been reported to perform better than the 2008 Robeson upper bounds [15] for several gas pairs of great interest, $\mathrm{CO}_{2} / \mathrm{CH}_{4}$ (e.g. UiO-66 with 6FDA-DAM [29], ZIF-90 with 6FDA-DAM [70], ZIF-8 with PIM-1 [71]), $\mathrm{CO}_{2} / \mathrm{N}_{2}$ (e.g. ZIF-7 in Pebax ${ }^{\circledR} 1657$ [72], ZIF-8 in Pebax ${ }^{\circledR} 2533$ [73]), and $\mathrm{H}_{2} / \mathrm{CO}_{2}$ (e.g. $\mathrm{NH}_{2}-\mathrm{CAU}-1$ in PMMA [74], ZIF-8 in PBI [75]).

As for PIMs, the small size and readily available silica particles were first incorporated into PIMs [50] and subsequently cross-linked PIMs [76]. The report encouraged others to investigate other nonporous fillers, such as carbon nanotubes and carbon nitride [77,78], followed by a newer generation of carbon material, graphene [79]. The addition of non-porous fillers commonly aims to increase selectivity by increasing the gas molecules' diffusion pathway, primarily affecting the bigger and slower permeating gas (i.e., $\mathrm{CH}_{4}$ and $\mathrm{C}_{2} \mathrm{H}_{6}$ in natural gas separation), and to modulate its performance stability by increasing plasticization resistance and reducing physical aging. Further developments were later reported with various types of MOFs, the $2 \mathrm{D}$ or $3 \mathrm{D}$ crystalline COFs, among others. There is a broad 
spectrum of MMMs available, many of which have overcome the upper bound limit, giving superior performance to the conventional PSF and Matrimid® polymeric membranes.

In principle, fabrication of a MMM is more straightforward than a pure inorganic membrane, owing to the polymer continuous matrix's flexibility, the brittleness of an inorganic membrane could be avoided [9,80-82]. MMM research, on the other hand, has concentrated on dense, symmetric flat sheet membranes, due to their more facile fabrication compared to the asymmetric flat sheet and hollow fiber membranes. However, dense membranes present lower gas permeances than asymmetric membranes of the same polymer [63,83]. A comparative study by Basu et al. [83] exhibited higher fluxes in a Matrimid ${ }^{\circledR}-\mathrm{Cu}_{3}(\mathrm{BTC})_{2}$ asymmetric $\mathrm{MMM}$, due to a lower resistance for the specific gas to permeation across its thinner selective layer. Khayet [84] and Hasbullah et al. [85] also reported similar findings in polyvinylidene fluoride (PVDF) and in-house synthesised polyaniline-based membranes, respectively. Additionally, for the actual industrial application, dense flat sheet membranes will require a specific porous support or module system due to its lower mechanical strength compared to asymmetric membranes $[8,84]$. Regardless of this, the fundamental investigation of a new MMM system in the form of a flat sheet dense membrane is more suitable due to its easier processability and higher reproducibility.

Three methodologies have been reported to produce dope solutions that are cast to form MMMs: (i) Filler dispersion in a solvent, followed by polymer addition, (ii) dissolution of polymer in a solvent, before the addition of dry filler particles into the polymer solution, (iii) separate preparation of polymer solution and particle dispersion, followed by mixing of the two. Methods (i) and (iii) were reported to produce MMMs with better filler dispersions $[9,15,55]$. The dope solution was cast on a flat surface for solvent evaporation and thermally heated (with or without vacuum) to remove the remaining solvent. Final heat treatment is dependent on the polymer glass transition temperature, $T_{\mathrm{g}}$. Note that in this review, polymer blends are excluded as the polymer components are often soluble in typical solvents used in membrane fabrication, whereas the fillers discussed here (MOFs, COFs, GO and 2D nanomaterials) are insoluble in conventional solvents.

\subsubsection{Role of fillers in MMMs for gas separation}

Depending on the type of filler, the chemical structure, and its surface chemistry, the effects of a filler in a MMM will differ. Fillers can be classified according to whether they are porous or non-porous. For the porous fillers, the effects are primarily related to their structures and pore sizes, acting as a molecular sieve and separating the permeating gases according to their molecular shapes and kinetic sizes. Due to their precise apertures, MMMs with porous fillers usually exhibit high permeability and selectivity, i.e., the addition of Zr-based MOFs [29,86] and Zn-based MOFs [87,88] in 6FDA-based polyimides. For ease of understanding, a schematic illustration is presented in Figure 5Error! Reference source not found.(a), indicating a high permeability $\left(P_{\mathrm{a}}\right)$ porous filler phase and a low permeability $\left(P_{\mathrm{b}}\right)$ polymer phase. Additionally, in the case of fillers with large pore sizes (pore 
dimensions much larger than the permeating gases), the mechanism of selective surface flow should also be considered and may be important, especially when separating condensable gases (e.g., water vapor).

In contrast, non-porous fillers generally improve the gas separation properties of MMMs by increasing the tortuosity of the path through the matrix, giving the lowest permeability $\left(P_{\mathrm{c}}\right)$ phase in Figure 5(b). It is a result of a decrease in the diffusion rate of larger molecules, along the lengthier diffusion pathways. Often its addition also increases the MMMs separation factor, i.e., commercial Cabosil@ TR-530 fumed silica [50] in PIM-1. However, non-porous fillers may also disrupt the polymer chain packing, creating additional free volume between the polymer chains and thus increasing the permeability of the continuous phase $[89,90]$. In the case of non-porous fillers with low or no exterior functional groups, it can be a challenge to create an efficient interaction with the polymer phase, often creating non-optimum interfaces that, in some cases, lead to non-selective void formation.

a) Porous filler

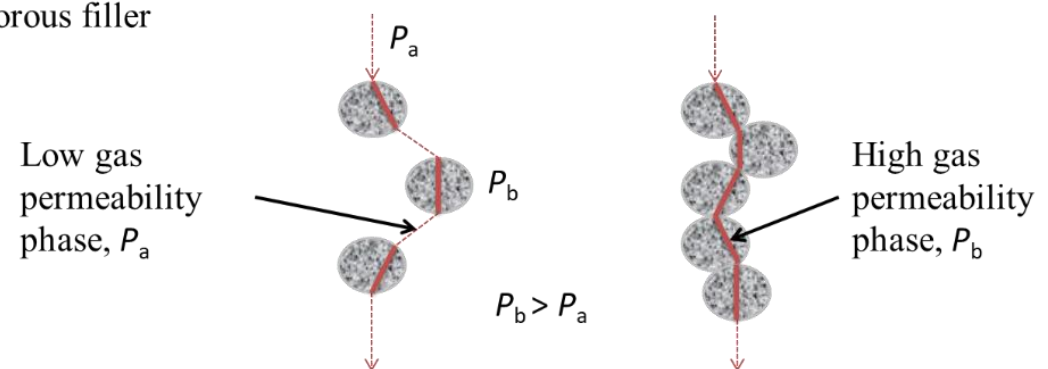

b) Non-porous filler

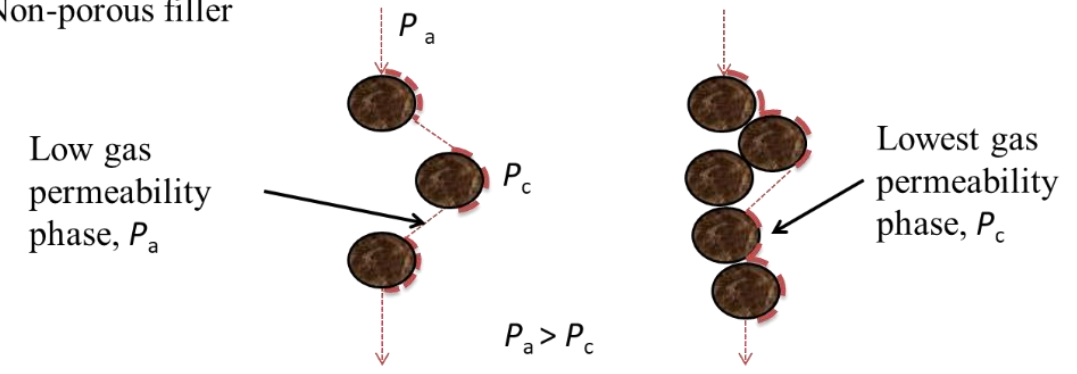

Figure 5: The diffusion pathways through (a) porous and (b) non-porous filler phases in the polymer matrix, where a discontinuous (left) or a continuous (right) particle distribution is formed. The permeability is in the order of $P_{\mathrm{b}}>P_{\mathrm{a}}>P_{\mathrm{c}}$.

Besides the conventional approaches of mechanical mixing with additional priming step (a step to optimize filler dispersion and minimize agglomeration [91,92]) and ultrasonic treatment to improve their interactions; surface functionalization has been employed in many polymer-filler MMM systems (i.e., $\mathrm{NH}_{2}$-CAU-1 in PMMA [74], $\mathrm{NH}_{2}$-MIL-(Al)-53 in 6FDA-DAM-HAB [93], $\mathrm{NH}_{2}$-UiO-66 in Matrimid® 9725 [94], UiO-66-NH-COCH 3 in 6FDA-DAM [95], $\mathrm{HSO}_{3}$-MIL-101(Cr) in SPEEK [96]). Furthermore, in the case of the separation of polar gases $\left(\mathrm{CO}_{2}, \mathrm{SO}_{2}\right.$, and $\left.\mathrm{H}_{2} \mathrm{~S}\right)$, the added functional groups may also interact with the gases and thus improve the penetrant solubility in the MMM. 
Another deciding aspect is the geometrical properties of the filler, e.g., particle size and shape. Johnson and Koros [97] stated that micron-sized cubic particles would limit the particle packing, especially within an asymmetric membrane skin layer (thickness range of 0.1 to $0.5 \mu \mathrm{m}$ ). The particles may also protrude and, consequently, produce highly defective surfaces. On the other hand, smaller nano-sized particles (which translates into a higher surface area) can provide better interfacial contact with the polymer matrix and hence be more appropriate for MMM preparation. However, in most cases, the degree of particle dispersion is reduced with an increase of nano-filler loading $[64,97,98]$. This is possibly due to the nanoparticles' nature, where they can be difficult to be broken down into smaller domains after their formation, or they tend to reassemble to form bulky aggregates. Many have reported experimental MMM studies [95,99-102] relating the influences of particle size and shape in comparison to the theoretical approaches, based on well-known Maxwell [103] and Lewis \& Nielsen [104,105], and their modified or extended models [106,107].

As discussed above, the effective permeability of a composite membrane is not only determined by each component's permeability and its volume fraction, but is also governed by the mixed-matrix-filler morphology [108]. Schneider et al. [109] recently published a study of the transport of guest molecules in a two-phase medium using Kinetic Monte Carlo (KMC) simulation. They simulated the effects of filler-particle volume fraction, particle size, shape (aspect ratio), and the spatial particle distribution, on gas transport properties through ideal MMMs (without interfacial voids or rigidified polymeric regions at the interfaces resulting from poor fabrication or compatibility $[60,110])$. The findings further emphasized the importance of well-distributed and non-aggregated filler, where the non-overlapping and randomly placed spherical filler particles (regardless of size) were found to be in good agreement with the analytical models (Maxwell [103] and Lewis \& Nielsen [104,105]) (see Figure 6(a)). Surprisingly, it is revealed that the rod-like particles deliver the highest effective permeability, due to its least transport inhibition effect (see Figure 6(d).

a)

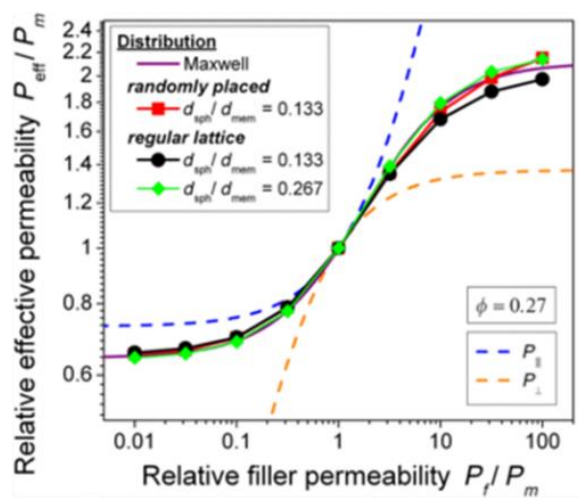

b)

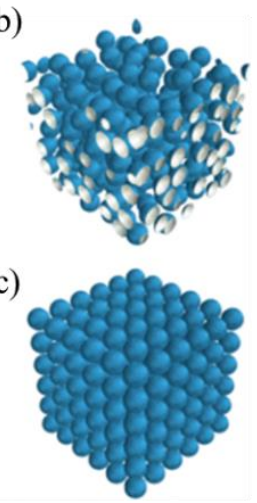

d)

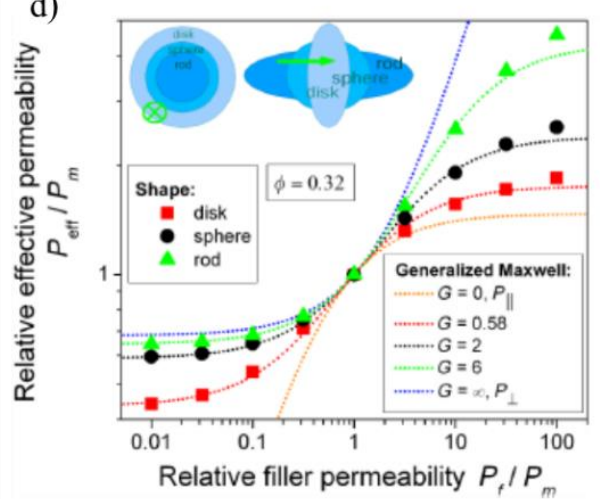

Figure 6: Effective permeability vs. filler permeability relative to the pure polymer permeability, $P_{m}$, for (a) MMMs with (b) random vs. (c) regular filler particle distributions, and (d) randomly placed particles of different shapes with a filler packing fraction of 0.32. This figure has been reproduced from ref. [109] with permission from American Physical Society, copyright 2019. 
Over the years, with the advance of high-level quantum calculation integrated with force field-based molecular dynamics simulation, several highly significant studies were reported focusing on the polymer/filler compatibility, providing crucial insights on intermolecular MOF/polymer interaction (polymer configuration adaptation and its end group penetration into the MOF surface pores) and its microscopic properties (the presence of interfacial micro-voids). The studies provide an understanding of MMM interface microscopic structures, by determining the interaction sites, as well as the polymer rigidity and conformation of the interfaces, in relation to the gas separation properties [111].

Among them are Zr-based MOF UiO-66 in poly(ethylene glycol) (PEG), PIM-1 and PVDF [111], UiO-66 in 6FDA-DAM [95] and ZIF-8 in several types of PIMs [112]. For example, Benzaqui et al. [113] performed a combination of multimodal experimental and computational methods to understand the complex microstructure of ZIF-8/PIMs (see Figure 7). They revealed that in PIM-1/ZIF-8, there is a main preferential interaction $(-\mathrm{CN})$ PIM-1 $\cdots(-\mathrm{NH})$ ZIF-8 of ZIF-8 imidazolate moieties, giving a smaller and more significant (than $(-\mathrm{OH})_{\mathrm{ZIF}-8)}$ ) characteristic distance of $2.6 \AA$. Meanwhile in PIM-EA-TB/ZIF8 , the $(-\mathrm{CN})$ PIM-EA-TB $\cdots(-\mathrm{NH})$ ZIF-8 interaction gives a bigger distance of $3.0 \AA$, ascribed to the fact that their $\mathrm{N}$ atoms are in the fused-ring system, making it geometrically less exposed than the $\mathrm{CN}$ group of PIM-1 to interact. Besides that, the overall interface region of PIM-EA-TB/ZIF-8 (region A $=9.0 \pm 1.0$ $\AA$ ) is determined to be significantly smaller than that of PIM-1/ZIF-8 (region $\mathrm{A}=13.0 \pm 2.0 \AA$ ). The PIM-EA-TB/ZIF-8 also showed lower maximum equivalent radii for the 'interfacial micro-voids' of 5.3 $\pm 0.5 \AA$, as compared to PIM-1/ZIF-8 $(6.3 \pm 0.5 \AA$ A). This crucial information directly aids many other researchers to understand the filler-polymer interaction, thus enabling highly effective MMMs to be created.

a)

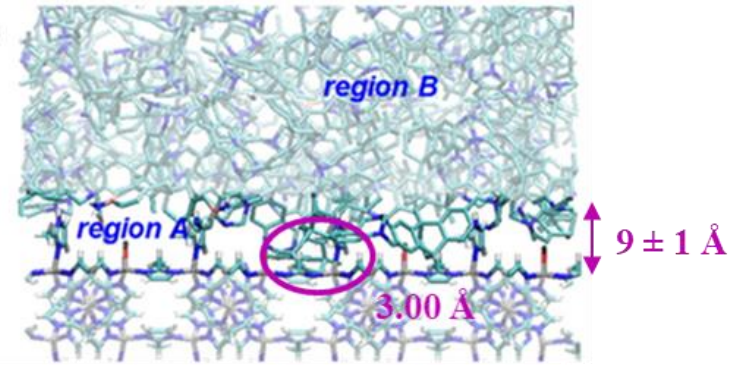

c)

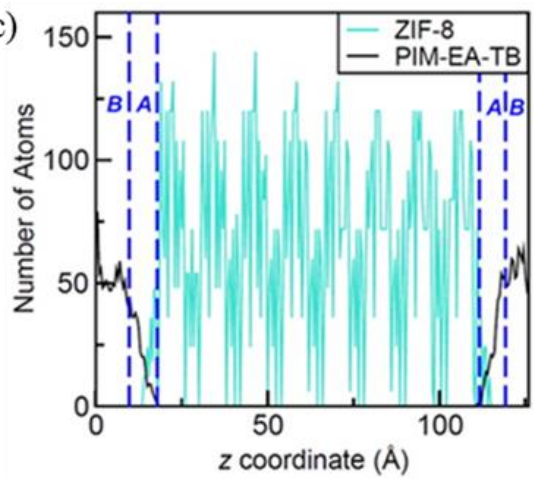

b)

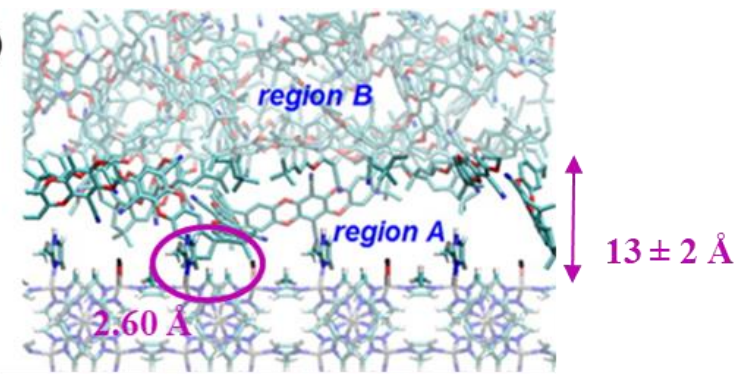

d)

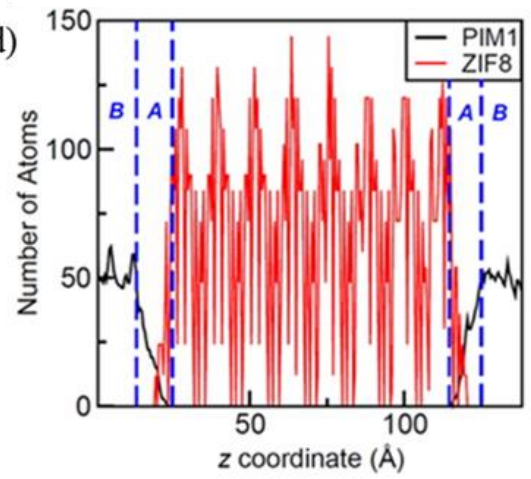

Figure 7: Snapshots of (a) PIM-EA-TB and (b) PIM-1 interfaces with ZIF-8, indicating the interface region A distances. The density of ZIF- 8 with polymer atoms as a function of the $z$-coordinate for a representative 
configuration of (c) PIM-EA-TB/ZIF-8 and (d) PIM-1/ZIF-8 systems are presented. This figure has been reproduced from ref. [113] with permission from American Chemical Society, copyright 2016.

Due to the vast abundance of available MOFs and the limitless options for metal and ligand pairing, the experimental investigation of MOF-based MMMs in gas separation becomes a challenge. For this reason, Sumer and Keskin [114] presented a computational study to accurately predict the selectivity and permeability of 70 different MOFs in 10 types of polymer (which includes common polymers such as Ultem ${ }^{\circledR}$, Matrimid ${ }^{\circledR}, 6$ FDA-DAM, PIM-1 and PIM-7), focusing specifically on MMMs for $\mathrm{CO}_{2} / \mathrm{N}_{2}$ separation. By combining atomically detailed simulations with continuum modeling [115] to assess gas separation performances of MOF-based MMMs, validated with the available experimental gas permeability in the literature, their findings are very valuable. For example, the $\mathrm{CO}_{2} / \mathrm{N}_{2}$ separation simulation of $70 \mathrm{MOF}$ in MMMs with the highly permeable but poorly selective PTMGP (poly(trimethylgermylpropyne)) showed that only three MOFs could simultaneously increase $\mathrm{CO}_{2}$ permeability and $\mathrm{CO}_{2} / \mathrm{N}_{2}$ selectivity. The rest of the MOFs improve only $\mathrm{CO}_{2}$ permeability with minor (19 MOFs) or very significant (48 MOFs) selectivity loss.

Please note that from this section onwards, the gas permeation data are presented according to their reported values in the literature, either as permeance, $K$, in Gas Permeance Units, GPU ( $1 \mathrm{GPU}=10^{-6}$ $\mathrm{cm}^{3}{ }_{\text {STP }} \mathrm{cm}^{-2} \mathrm{~s}^{-1} \mathrm{cmHg}^{-1}$ ) or as permeability, $P$, (permeance multiplied by the membrane thickness) in units of Barrer (1 Barrer $\left.=10^{-10} \mathrm{~cm}^{3}{ }_{\text {STP }} \mathrm{cm} \mathrm{cm}^{-2} \mathrm{~s}^{-1} \mathrm{cmHg}^{-1}\right)$.

\section{MMMs for performance enhancement and aging suppression of PIM-1}

\subsection{PIM-1 with metal-organic frameworks (MOFs)}

MOFs, classified by their three-dimensional crystalline frameworks with permanent porosity are emerging as versatile fillers [98]. The frameworks are metal-based clusters, linked by organic ligands [116]. They are gaining substantial attention due to their high $\mathrm{CO}_{2}$ uptake (e.g., HKUST-1 of $7.2 \mathrm{mmol}$ $\mathrm{g}^{-1}$ [117], MOF-74 of $4.9 \mathrm{mmol} \mathrm{g} \mathrm{g}^{-1}$ [118], at 1 bar, $273-298 \mathrm{~K}$ ), large apparent surface areas of up to $7000 \mathrm{~m}^{2} \mathrm{~g}^{-1}$ [119], well-defined selective pores due to their crystallinity, and high thermal and chemical stability [1], among other features. Compared with other adsorbents or porous materials, like activated carbon or zeolites, the MOFs' sorption properties can be designed and fine-tuned through their organic ligands, including their post-synthetic modification (PSM) [120-122]. These tunable pore geometries and flexible framework properties $[1,56]$ are useful for various gas separation purposes. Indeed, MOFcontaining membranes have been reported to perform better than the 2008 Robeson upper bounds [15] for several gas pairs of great interest, $\mathrm{CO}_{2} / \mathrm{CH}_{4}$ (e.g. UiO-66 with 6FDA-DAM [29], ZIF-90 with 6FDADAM [70], ZIF-8 with PIM-1 [71]), $\mathrm{CO}_{2} / \mathrm{N}_{2}$ (e.g. ZIF-7 in Pebax ${ }^{\circledR} 1657$ [72], ZIF-8 in Pebax ${ }^{\circledR} 2533$ [73]), and $\mathrm{H}_{2} / \mathrm{CO}_{2}$ (e.g. $\mathrm{NH}_{2}-\mathrm{CAU}-1$ in PMMA [74], ZIF-8 in PBI [75]).

\subsubsection{Zeolitic imidazolate frameworks (ZIFs)}


Zeolitic imidazolate frameworks (ZIFs), a subclass of MOFs, are constructed of imidazolate (im) anionic organic ligands tetrahedrally coordinated by transition metals (M). ZIF-8, the best-known ZIF, comprised of $\left[\mathrm{Zn}(\mathrm{mim})_{2}\right] \cdot n \mathrm{G}(\mathrm{mim}=2$-methylimidazole, $\mathrm{G}=$ guest) crystallites (see Figure 8(a)), possess the zeolite analogous O-Si-O sodalite topology (SOD), resulting in the M-im-M bridges being at $145^{\circ}$ [123], thus giving them highly stable permanent pore apertures and excellent gas separation improvement in many polymer membranes [86,87,124]. Bushell et al. [71] reported the use of nanoZIF-8 $\left(A_{\mathrm{BET}}=1,300 \mathrm{~m}^{2} \cdot \mathrm{g}^{-1}\right.$; average size of $\left.\sim 50 \mathrm{~nm}\right)$ into PIM-1. They improved the $\alpha_{\mathrm{H} 2 / \mathrm{N} 2}$ and $\alpha_{\mathrm{CO} 2 / \mathrm{CH} 4}$ by $110 \%$ and $192 \%$, respectively, with 43 vol. $\%$ loading (neat PIM-1, $P_{\mathrm{CO} 2}=4,390 ; P_{\mathrm{O} 2}=580 ; P_{\mathrm{H} 2}=$ 1,630 Barrer; $\left.\alpha_{\mathrm{CO} 2 / \mathrm{CH} 4}=14.2 ; \alpha_{\mathrm{O} 2 / \mathrm{N} 4}=3.2 ; \alpha_{\mathrm{H} 2 / \mathrm{N} 2}=9.1 ; \alpha_{\mathrm{H} 2 / \mathrm{CH} 4}=5.3\right)$. The improvement is ascribed to a tremendous increase in the permeability of smaller kinetic diameter gases (e.g., $P_{\mathrm{H} 2}$ increase up to $310 \%$ ), related to the effect of smaller components (kinetic diameters of $\mathrm{H}_{2}=2.89 \AA$ and $\mathrm{O}_{2}=3.46 \AA$, compared to $\mathrm{N}_{2}=3.64 \AA$ and $\mathrm{CH}_{4}=3.80 \AA$ ) penetrating more readily into the ZIF- 8 interior cavities of $\sim 11.6 \AA$ through its $\sim 3.4 \AA$ window openings, and to the nature of microvoids at the interface between polymer and MOF. Optimal interfaces, which only enhance the mobility of smaller gas components, are produced from an effective membrane fabrication method (i.e., no filler agglomeration, the formation

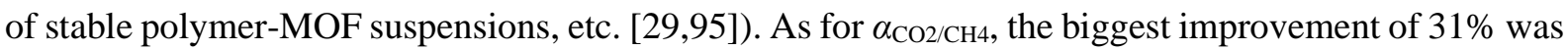
presented by a MMM with 28 vol.\% loading, where the $P_{\mathrm{CO} 2}$ and $P_{\mathrm{CH} 4}$ were increased by $20 \%$ and $6.5 \%$, respectively [71]. The higher increment in $P_{\mathrm{CO} 2}$ was contributed by the selective adsorption capacity of ZIF-8 metal ions towards $\mathrm{CO}_{2}$. Interestingly, the same MMM also presented an improvement in $\alpha_{\mathrm{O} 2 / \mathrm{N} 2}$ by $41 \%$, where $P_{\mathrm{O} 2}$ increased by $50 \%$, while $P_{\mathrm{N} 2}$ increased by only $8 \%$. In this case, the improvement is thought to be mainly contributed by the increased molecule diffusivities, according to their kinetic diameters. This hypothesis is supported by their PALS analysis, where they found no correlation between the increased diffusivity and permeability to the free volume elements (FVEs). One should note that the relationship is not only dependent on the size of the FVEs but also their connectivity.
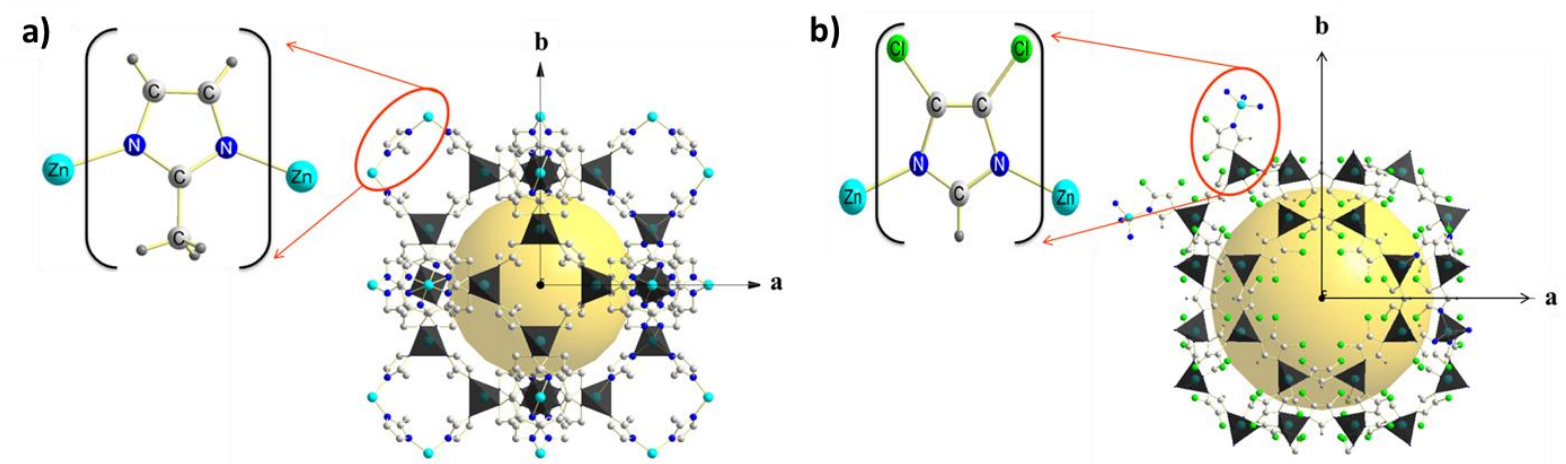

Figure 8: Three-dimensional presentation of (a) ZIF-8, tetrahedrally coordinated [ $\left.\mathrm{Zn}(\mathrm{mim})_{2}\right] \cdot \mathrm{nG}$, and (b) ZIF-71, $\left.\mathrm{Zn}(4,5 \text {-dichloroimidazole })_{2}\right)$. Highlighted are their respective anionic organic ligands.

Using an innovative computational methodology, Semino et al. [125] demonstrated that the interaction at the interface between PIM-1 and ZIF-8 is predominantly governed by PIM-1's nitrogen 
atom of the cyano group and the $-\mathrm{NH}$ group of the ZIF-8 surfaces, leading to a mean characteristic $(\mathrm{NH})_{\text {ZIF-8 }}-(\mathrm{N})_{\text {PIM-1 }}$ distance $\sim 2.57 \AA$ (Figure 9(a)). Secondarily, when located close to the vicinity of (NH) ZIF-8, PIM-1's aliphatic carbons interact, giving a mean distance of $\sim 3.00 \AA$ (Figure 9 (b)). The latter interaction is less influential, encountered only when the L-shape vertex of PIM-1 falls through the 'zigzag' conformation on ZIF-8's surface. It is also concluded that the interactions between the $(\mathrm{OH})_{\mathrm{ZIF}-8}$ group and the PIM-1 sites are less specific as they are less exposed to the polymer phase. The authors also considered the ZIF-8 flexibility and believed that the reorientation reduces the interaction between the methyl groups and the (NH) ZIF-8 functions (Figure 9(c)), compared to the most predominant interaction which occurred in the one chain PIM-1/rigid ZIF-8 system (Figure 9(d)). Nevertheless, the overall study indicates that there is no interpenetration between PIM-1 and ZIF-8, which may lead to the commonly observed rigidification and pore blockage phenomenon in MMMs $[59,60]$.

a)

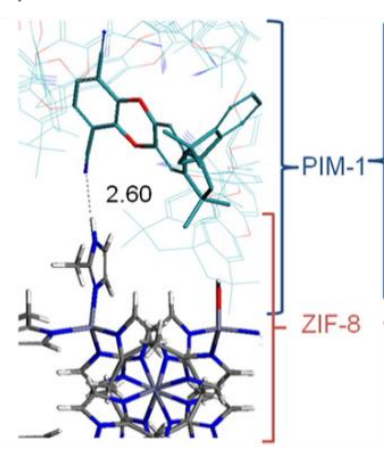

b)

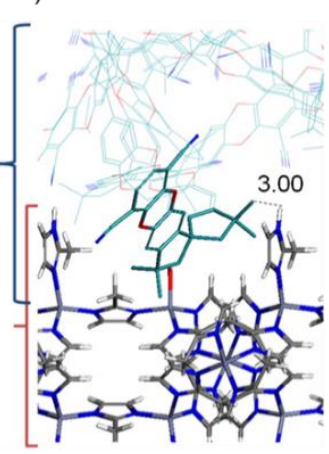

c)

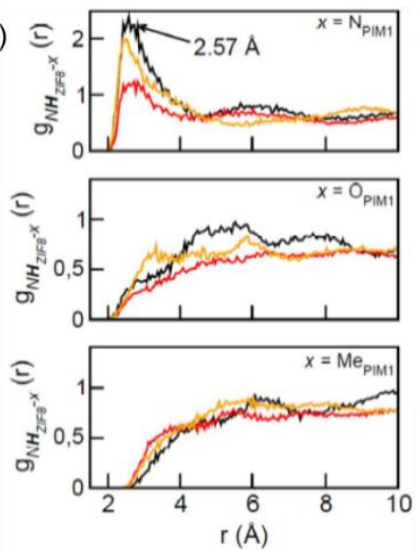

d)
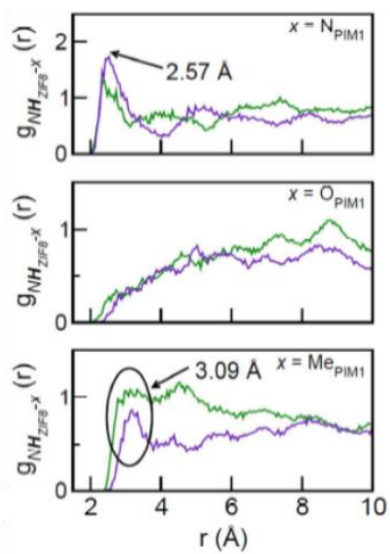

Figure 9: Illustration of (a) $(\mathrm{NH})_{\text {ZIF-8 }} \cdot(\mathrm{N})_{\text {PIM-1 }}$ and (b) (NH) $)_{\text {ZIF-8 }} \cdots$ (methyl) $)_{\text {PIM-1 }}$ interactions. The representation of radial distribution function of (NH) ZIF- $8 \cdot(\mathrm{X})_{\mathrm{PIM}-1}, \mathrm{X}=\mathrm{N}$ (top), $\mathrm{O}$ (middle) and methyl (bottom) pairs in the

(c) long-chain PIM-1/flexible ZIF-8 surface system, and (d) multiple chains PIM-1/rigid ZIF-8 surface. This figure has been reproduced from ref. [125] with permission from American Chemical Society, copyright 2016.

Recently, Sánchez-Laínez et al. [88] demonstrated that the incorporation of 10 wt.\% ZIF-8 into a composite of PIM-1 and 6FDA-DAM (90:10 blend ratio) increased the $P_{\mathrm{CO} 2}$ between 21-26\% but at the expense of its selectivity. The neat PIM-1/6FDA-DAM showed a $P_{\mathrm{CO} 2}$ of 8,364 Barrer and $\alpha_{\mathrm{CO} 2 / \mathrm{CH} 4}$ of 14.6 when tested with a $\mathrm{CO}_{2} / \mathrm{CH}_{4}(50 / 50 \mathrm{v} / \mathrm{v})$ mixture and $P_{\mathrm{CO} 2}$ of 7,678 Barrer and $\alpha_{\mathrm{CO} 2 / \mathrm{N} 2}$ of 15.9 when tested with a $\mathrm{CO}_{2} / \mathrm{N}_{2}(10 / 90 \mathrm{v} / \mathrm{v})$ mixture, at 3 bar feed pressure and $35{ }^{\circ} \mathrm{C}$. The ZIF-8 composite membranes presented a selectivity reduction of $27 \%$ for $\alpha_{\mathrm{CO} / \mathrm{CH} 4}$ and $9 \%$ for $\alpha_{\mathrm{CO} 2 / \mathrm{N} 2}$. The performance trade-off behavior (gaining $P$ while losing its $\alpha$ caused by interface voids of a size comparable to the penetrant species, which is also defined as 'leaking' MMM morphology [59,60]) is because 6FDADAM is not miscible with PIM-1, forming 3-5 $\mu \mathrm{m}$ lenticular particles. However, they are evenly distributed. ZIF-8 particles were positioned in the two-polymer interphase region.

Cobalt-substituted ZIF-8, referred to as ZIF-67, possesses a Co-N bond that is stiffer than ZIF-8's Zn-N, which contributes to ZIF-67's slightly smaller effective pore apertures (its tetrahedral SOD 
topology is similar to that of ZIF-8). Pure ZIF-67 shows $\alpha_{\mathrm{CO} 2 / \mathrm{CH} 4}$ of 45 with $P_{\mathrm{CO} 2}=8,000$ Barrer [126], higher than pure ZIF-8 $\left(\alpha_{\mathrm{CO} 2 / \mathrm{CH} 4}=24 ; P_{\mathrm{CO} 2}=9,650\right.$ Barrer [71]). Wu et al. [126] presented excellent gas separation improvements of several gas pairs in PIM-1 $\left(M_{\mathrm{w}}=118,000 \mathrm{~g} \cdot \mathrm{mol}^{-1} ; \bigoplus=2.5\right)$ with ZIF-67 $\left(A_{\mathrm{BET}}=1,481 \mathrm{~m}^{2} \cdot \mathrm{g}^{-1}\right.$, micropore volume $\left.=0.73 \mathrm{~cm}^{3} \cdot \mathrm{g}^{-1}\right)$. The neat PIM-1 $\left(P_{\mathrm{CO} 2}=4,521\right.$ and $P_{\mathrm{H} 2}=2,219$ Barrer; $\alpha_{\mathrm{CO} 2 / \mathrm{CH} 4}=12.5 ; \alpha_{\mathrm{CO} 2 / \mathrm{N} 2}=20.2 ; \alpha_{\mathrm{H} 2 / \mathrm{CH} 4}=6.1 ; \alpha_{\mathrm{H} 2 / \mathrm{N} 2}=9.9$, when tested at 2 bar and $30{ }^{\circ} \mathrm{C}$ ) were improved with an addition of 20 wt.\% ZIF-67, producing MMMs with $P_{\mathrm{CO} 2}$ and $P_{\mathrm{H} 2}$ of 5,206 and 3,452 Barrer, respectively. The selectivities were also improved to $\alpha_{\mathrm{CO} 2 / \mathrm{CH} 4}=16.8, \alpha_{\mathrm{CO} 2 / \mathrm{N} 2}=24.2, \alpha_{\mathrm{H} 2 / \mathrm{CH} 4}=$ 24.2 and $\alpha_{\mathrm{H} 2 / \mathrm{N} 2}=16.5$. Similarly to the other ZIFs, these improvements were also due to the molecular sieving property of the crystals and its large intrinsic pore apertures. To further improve the ZIF-67/PIM1 interfacial morphology, the same group further investigate nano-sized ZIF-67 (25-35 nm, $A_{\mathrm{BET}}=1,412$ $\mathrm{m}^{2} \cdot \mathrm{g}^{-1}$, micropore volume $=0.46 \mathrm{~cm}^{3} \cdot \mathrm{g}^{-1}$ ) incorporation into similar PIM-1 [127]. They showed that 15 wt.\% enhanced the $\alpha_{\mathrm{CO} 2 / \mathrm{CH} 4}$ of the neat PIM-1 (of 12.5) up to 21.1, translated into a 69\% improvement. They concluded that the significant $\alpha_{\mathrm{CO} / \mathrm{CH} 4}$ improvement is attributed to the fortified polymer-filler interfacial interaction and the improved polymer-filler interfacial morphology arising from the nanosized filler.

Meanwhile, Hao et al. [128] utilized a bigger and rhombic coordinated ZIF-71 [Zn(4,5dichloroimidazole) $)_{2}$ )] with a pore aperture size of $4.2 \AA$ and cavity size of $16.5 \AA$ (see Figure 8(b)), and successfully improved the gas separation performance, especially for $\mathrm{O}_{2} / \mathrm{N}_{2}, \mathrm{CO}_{2} / \mathrm{N}_{2}$ and $\mathrm{CO}_{2} / \mathrm{CH}_{4}$ gas pairs in PIM-1. They reported tremendous permeability improvements of $154 \%$ for $\mathrm{CO}_{2}$ and $185 \%$ for $\mathrm{O}_{2}$, while maintaining its $\alpha_{\mathrm{O} 2 / \mathrm{N} 2}=3.4-3.7, \alpha_{\mathrm{CO} 2 / \mathrm{CH} 4}=10.2-11.9$ and $\alpha_{\mathrm{CO} / \mathrm{N} 2}=18.3-20.1$, up to 30 wt. $\%$ ZIF-71 loading. The improvement is contributed by the higher adsorption capacity of ZIF-71 towards $\mathrm{O}_{2}$ and $\mathrm{CO}_{2}$, and the filler addition contributes to a higher free volume in their interphase region, effectively facilitating the gas transport without affecting gas pair selectivities. The same membranes, when treated with UV for $40 \mathrm{~min}$, presented even more significant selectivity improvement (at the expense of gas permeability). It is noteworthy that the MMMs presented lower gas permeability reductions (between 2-5 \%) after UV-crosslinking, compared to the neat PIM-1 (reduced by 51\% and $63 \%$ for $P_{\mathrm{O} 2}$ and $P_{\mathrm{CO} 2}$ respectively). There is no aging test reported for these ZIF-MMM systems.

\subsubsection{Zirconium-based MOFs}

Khdhayyer et al. [129] reported the fabrication and gas separation performances of PIM-1 MMMs with zirconium-terephthalate based MOFs; UiO-66 $\left[\mathrm{Zr}_{6} \mathrm{O}_{4}(\mathrm{OH})_{4}\left(\mathrm{O}_{2} \mathrm{CC}_{6} \mathrm{H}_{4} \mathrm{CO}_{2}\right)_{6}\right]$ and its carboxylic acid and amine derivatives (see Figure 10(a)). The MOFs presented a preferential $\mathrm{CO}_{2} / \mathrm{CH}_{4}$ adsorption selectivity in the order of their functionality $\left.(\mathrm{COOH})_{2}>-\mathrm{NH}_{2}>\mathrm{UiO}-66\right)$ and were expected to increase the gas pair selectivity when incorporated into a PIM-1 $\left(M_{\mathrm{w}}=112,000 \mathrm{~g} \cdot \mathrm{mol}^{-1} ; Ð=2.3\right)$ continuous phase. The gas separation performances of the neat PIM-1 $\left(P_{\mathrm{CO} 2}=4,770 ; P_{\mathrm{N} 2}=219 ; P_{\mathrm{CH} 4}=286\right.$ Barrer; $\left.\alpha_{\mathrm{CO} / \mathrm{N} 2}=21.8 ; \alpha_{\mathrm{CO} 2 / \mathrm{CH} 4}=16.7\right)$ were enhanced in MMMs with $9.1-28.9$ wt. $\%$ nanoparticle loadings. The best performances were achieved with $16.6 \mathrm{wt} \%$ of UiO-66, $28.6 \mathrm{wt} . \%$ of UiO-66-(COOH $)_{2}$ and 
28.6 wt. $\%$ of UiO-66- $\mathrm{NH}_{2}$, where the $\mathrm{CO}_{2}$ permeability was improved by $60 \%, 28 \%$ and $32 \%$, respectively, while maintaining its $\mathrm{CO}_{2} / \mathrm{N}_{2}$ selectivity of $\sim 20-22$. They concluded that the permeability improvements were due to the favorable diffusion path created in the MOF-polymer interface cavities. Their gas solubility coefficient calculation also suggested that the apparent solubilities of the gases were not affected by the presence of UiO-66 based fillers, and this hypothesis is questionable since the functionalized UiO-66 often shows higher $\mathrm{CO}_{2}$ adsorption [95,130]. Regrettably, in terms of $\mathrm{CO}_{2} / \mathrm{CH}_{4}$ selectivity, none of the MMMs presented any improvement due to relatively high $\mathrm{CH}_{4}(43-84 \%)$ and $\mathrm{N}_{2}$ (35-68\%) permeability increments.

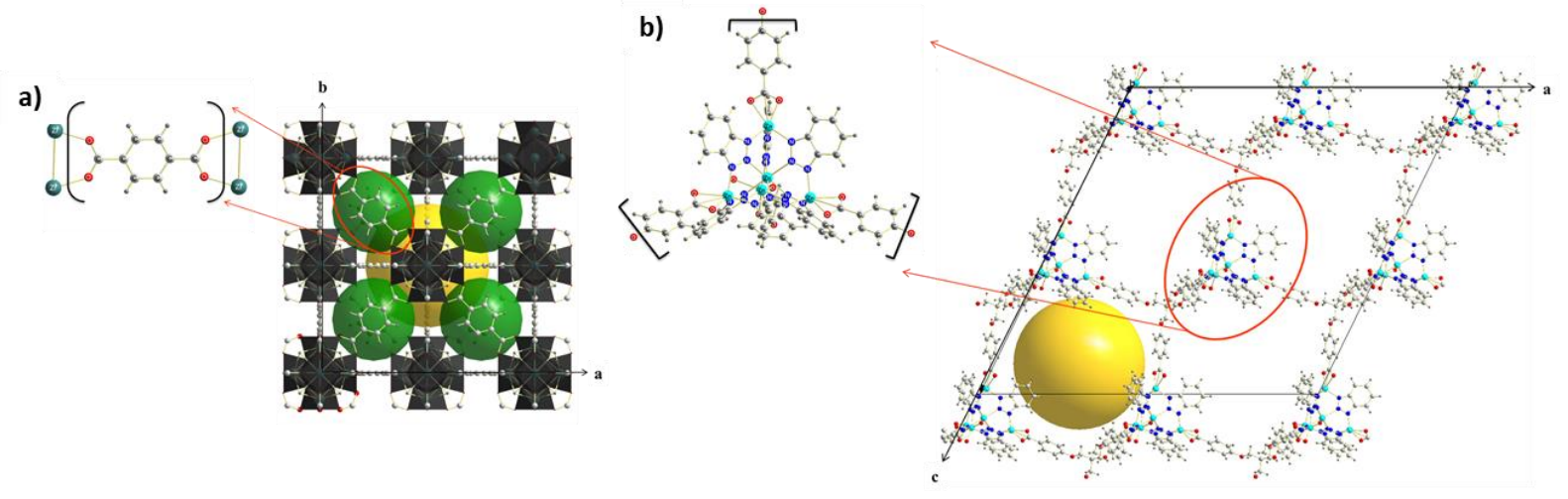

Figure 10: Three-dimensional presentation of (a) UiO-66, $\mathrm{Zr}_{6} \mathrm{O}_{4}(\mathrm{OH})_{4}\left(\mathrm{O}_{2} \mathrm{CC}_{6} \mathrm{H}_{4} \mathrm{CO}_{2}\right)_{6}$ and (b) DMOF-1, $\mathrm{Zn}_{2}(\mathrm{BDC})_{2}(\mathrm{DABCO})$. Highlighted are their respective organic ligands.

Similarly to the study of Khdhayyer et al. [129], Wang et al. [131] also faced a similar problem where the UiO-66 and UiO-66- $\mathrm{NH}_{2}$ nanoparticles tend to aggregate, causing visible interfacial defects and interphase voids. The poor compatibility inevitably reduces the overall MMM separation performances, where they only showed $P_{\mathrm{CO} 2}$ increment at the expenses of its $\alpha_{\mathrm{CO} 2 / \mathrm{N} 2}$ and $\alpha_{\mathrm{CO} 2 / \mathrm{CH} 4}$. The MMMs enhanced permeabilities are mainly attributed to the increased diffusion coefficient. They later employed an interfacial design strategy utilizing hydrogen bonds to fabricate non-defective PIM-1/MOF hybrids, where the PIM-1 $\left(P_{\mathrm{CO} 2}=6,440\right.$ Barrer; $\left.\alpha_{\mathrm{CO} 2 / \mathrm{N} 2}=14.5\right)$ was amidoxime-functionalized using hydroxylamine in THF, achieving between $21-100 \% \mathrm{CN}$ conversion, depending on the reaction time (see reaction scheme in Figure 11(a)). The optimal amidoxime-modified PIM-1 (AO-PIM-1), at 53\% and $66 \%$ amidoxime groups, showed a greater perm-selectivity performance where the $\alpha_{\mathrm{CO} 2 / \mathrm{N} 2}$ were increased to 27.8 and 30.9 , respectively $\left(P_{\mathrm{CO} 2,53 \% \text { AO-PIM- } 1}=2,880\right.$ Barrer and $P_{\mathrm{CO} 2,66 \% \text { AO-PIM-1 }}=2,305$ Barrer).

The authors demonstrated the effective interfacial interaction by employing UiO-66- $\mathrm{NH}_{2}$ between 7-30 wt.\% in the 53\% AO-PIM-1 and successfully improved its $P_{\mathrm{CO} 2}$ to 3,825 and 8,425 Barrer at the lowest and highest loading, while maintaining the $\alpha_{\mathrm{CO} / \mathrm{N} 2}$ at $28-30$ and $\alpha_{\mathrm{CO} 2 / \mathrm{CH} 4}$ at $23-24$. In TEM analysis, they also observed that the UiO-66- $\mathrm{NH}_{2}$ nanoparticles were dispersed in the polymer matrix individually, due to strong hydrogen bonding (see Figure 11(b)). This finding was further supported through a temperature-dependent infrared spectroscopy analysis where the AO-PIM-1/ $\mathrm{NH}_{2}-\mathrm{UiO}-66$ 
showed the strongest hydrogen bonding interaction (large - $\mathrm{OH}$ and - $\mathrm{NH}$ wavenumber shift at $25 \mathrm{~cm}^{-1}$ and $46 \mathrm{~cm}^{-1}$, respectively at $40^{\circ} \mathrm{C}$ and $200^{\circ} \mathrm{C}$ ). Furthermore, in the aging test, the authors reported that PAO-PIM-1/ $\mathrm{NH}_{2}$-UiO-66 only showed $\pm 30 \% P_{\mathrm{CO} 2}$ loss in 80 days while maintaining its $\alpha_{\mathrm{CO} 2 / \mathrm{N} 2}$ at $28-$ 30, whereas the non-functionalized MMMs (AO-PIM-1/UiO-66 and PIM-1/ $\mathrm{NH}_{2}-\mathrm{UiO}-66$ ) showed $>50 \% P_{\mathrm{CO} 2}$ loss in just 28 days with a slight selectivity gain.
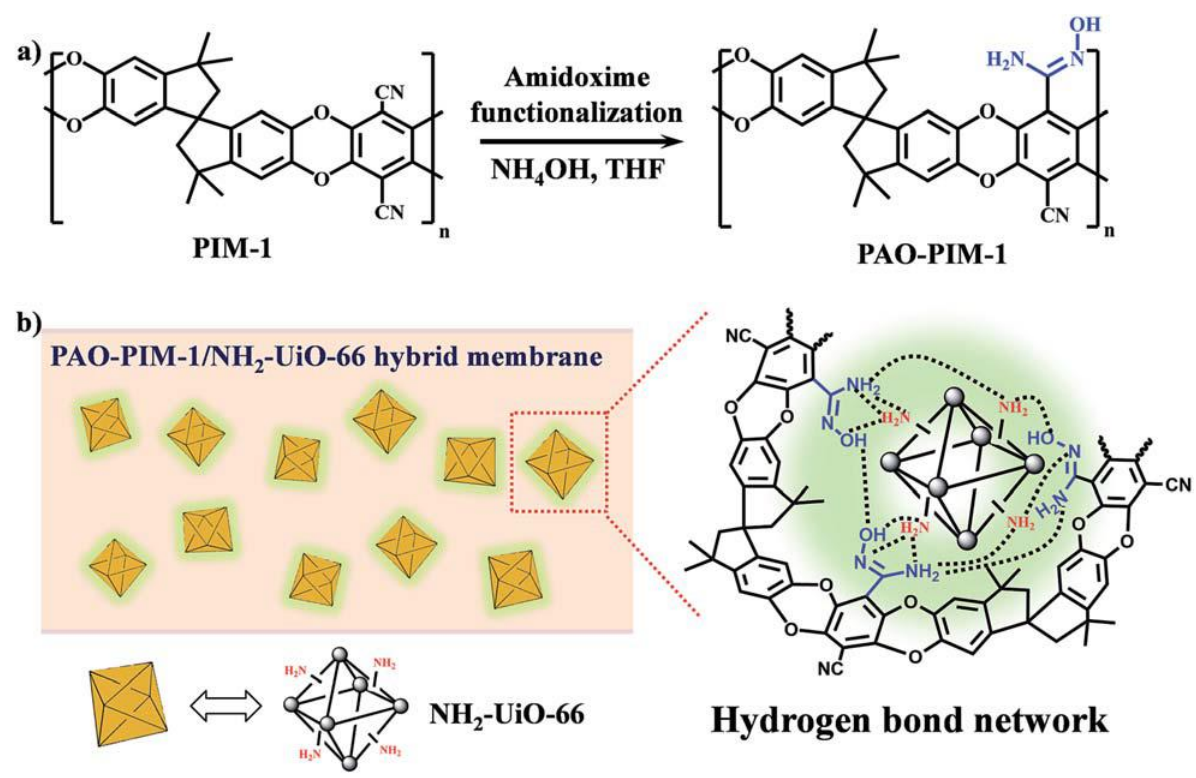

Hydrogen bond network

Figure 11: (a) Synthetic scheme of PAO-PIM-1. (b) Schematic illustration of a hydrogen bond network guided interface design of the hybrid membrane. This figure has been reproduced from ref. [131] with permission from The Royal Society of Chemistry, copyright 2017.

\subsubsection{Chromium-based MOFs}

Another promising MOF is the chromium-based MIL-101 $\left[\mathrm{Cr}_{3} \mathrm{O}(\mathrm{F} / \mathrm{OH})\left(\mathrm{H}_{2} \mathrm{O}\right)_{2}\left(\mathrm{O}_{2} \mathrm{CC}_{6} \mathrm{H}_{4} \mathrm{CO}_{2}\right)_{3}\right]$, which has a framework consisting of two permanent cages (2.9 nm and $3.4 \mathrm{~nm}$ in diameter) with pentagonal- and hexagonal-ring openings at $1.2 \mathrm{~nm}$ and $1.5 \times 1.6 \mathrm{~nm}$ diameter, respectively. The $\mathrm{Cr}$ metal site shows higher $\mathrm{O}_{2}$ and $\mathrm{CO}_{2}$ adsorption affinity as compared to $\mathrm{Fe}, \mathrm{Ni}$, $\mathrm{Co}$ and $\mathrm{Cu}$ [132]. Khdhayyer et al. [133] reported the use of several types of MIL-101 in PIM-1A $\left(M_{\mathrm{w}}=97,800 \mathrm{~g} \cdot \mathrm{mol}^{-1}\right.$; neat $P_{\mathrm{CO} 2}=5,940$ Barrer; $\left.\alpha_{\mathrm{CO} / \mathrm{CH} 4}=11.0 ; \alpha_{\mathrm{CO} 2 / \mathrm{N} 2}=18.9\right)$. The MIL-101s are fluoride terminally bound MIL-101A $\left(A_{\mathrm{BET}}=2,640 \mathrm{~m}^{2} \cdot \mathrm{g}^{-1}\right)$, hydroxyl terminally bound MIL-101B $\left(A_{\mathrm{BET}}=3,200 \mathrm{~m}^{2} \cdot \mathrm{g}^{-1}\right)$ and nanoMIL-101 $\left(A_{\mathrm{BET}}=2,850 \mathrm{~m}^{2} \cdot \mathrm{g}^{-1}\right)$. The smaller MIL-101A (average size of $180 \mathrm{~nm}$ ) exhibited optimum loading of 16.6 wt. $\%$, where the MMM showed $68 \%$ and $20 \%$ for $P_{\mathrm{CO} 2}$ and $\alpha_{\mathrm{CO} 2 / \mathrm{CH} 4}$ increments, respectively. However, the same MMMs exhibited lower $\alpha_{\mathrm{CO} 2 / \mathrm{N} 2}$ values when compared to the MMMs with lower loading of $9.1 \mathrm{wt} . \%$. This reduction is caused by the high jump in $P_{\mathrm{N} 2}$ of between $128-212 \%$ from 9.1 to 16.6 wt.\% loading. Most interestingly, the nano-MIL-101 (average size of $50 \mathrm{~nm}$ ) showed continuous $P_{\mathrm{CO} 2}$ increments up to $P_{\mathrm{CO} 2}=10,600$ Barrer without losing it $\alpha_{\mathrm{CO} 2 / \mathrm{CH} 4}=\sim 11-12$ and $\alpha_{\mathrm{CO} 2 / \mathrm{N} 2}$ $=\sim 19-21$ up to $28.6 \mathrm{wt} . \%$ particle loading. A higher molecular weight PIM-1B $\left(M_{\mathrm{w}}=112,000 ; Ð=2.3\right.$; neat $\mathrm{P}_{\mathrm{CO} 2}=4,770$ Barrer; $\alpha_{\mathrm{CO} 2 / \mathrm{CH} 4}=16.7$ ) was made into MMMs with the bigger MIL-101B (average 
size of $230 \mathrm{~nm}$ ), ethylene diamine-functionalized MIL-101 (ED-MIL-101; $A_{\mathrm{BET}}=2,220 \mathrm{~m}^{2} \cdot \mathrm{g}^{-1}$ ) and amino-functionalized MIL-101 $\left(\mathrm{NH}_{2}\right.$-MIL-101; $\left.A_{\mathrm{BET}}=1,630 \mathrm{~m}^{2} \cdot \mathrm{g}^{-1}\right)$ [133]. However, all the MOFs were unsuccessful at increasing the selectivities, even at the lowest loading of $9 \mathrm{wt} . \%$. They further investigated the aging phenomenon in their most promising MMMs, PIM-1A/MIL-101A, and PIM1A/nano-MIL-101 up to 1000 days. It would be expected that with the addition of a stable crystalline MOF, where no chemical changes or irreversible adsorption should occur, the membranes should show lower permeability loss rate over time coupled with a gain in selectivity; however, their finding is on the contrary, where their permeability losses $(\sim 80-82 \%)$ were higher than the neat membrane $(69 \%)$. This result suggests that the MIL-101 may not deter the physical aging of PIM-1.

\subsubsection{Photo-responsive MOFs}

Prasetya and Ladewig [134] recently introduced a new photo-responsive low-energy $\mathrm{CO}_{2}$ adsorbing MOF, namely Azo-DMOF-1, inspired by Dabco MOF or DMOF-1 (Zn(bdc)(dabco)0.5, see Figure 10(b)), which has previously been investigated in MMM fabrication. Despite the fact that the AzoDMOF-1 has a lower BET surface area of $581 \mathrm{~m}^{2} \cdot \mathrm{g}^{-1}$ (DMOF-1, $A_{\mathrm{BET}}= \pm 1,500 \mathrm{~m}^{2} \cdot \mathrm{g}^{-1}$, synthesized under the same conditions), it shows a similar $\mathrm{CO}_{2}$ uptake capacity of $41-43 \mathrm{~cm}^{3} \cdot \mathrm{g}^{-1}$ at standard temperature and pressure (STP) at $298 \mathrm{~K}$. They demonstrated its use in $\mathrm{MMMs}$ for $\mathrm{CO}_{2} / \mathrm{N}_{2}$ separation and presented an improvement over PIM-1 $\left(P_{\mathrm{CO} 2}=\sim 4,000\right.$ Barrer; $\left.\alpha_{\mathrm{CO} 2 / \mathrm{N} 2}=\sim 15\right)$ to $P_{\mathrm{CO} 2}=\sim 6,700$ Barrer; $\alpha_{\mathrm{CO} 2 / \mathrm{N} 2}=\sim 20$ with only 5 wt.\% Azo-DMOF-1 loading. Further addition to $10 \mathrm{wt} . \%$ increased the $P_{\mathrm{CO} 2}$ to $\sim 7,500$ Barrer while maintaining its selectivity. A permeability-selectivity trade-off phenomenon was observed when the loading was increased to $20 \mathrm{wt} \%$, where $10 \%$ selectivity loss was observed. Very recently, Shen et al. [135] utilized a new fluorinated MOF, SIFSIX-3-Zn (or Zn(pyrz) ${ }_{2}\left(\mathrm{SiF}_{6}\right)$ ), which possesses two-dimensional nets built-up from pyrazine and zinc ion nodes and pillared at the third dimension to construct a three-dimensional network with $\mathrm{SiF}_{6}{ }^{2-}$ anions. The MOF presents an effective pore size of $\sim 4.2 \AA$ in their cubic topology, theoretically perfect for the separation of $\mathrm{C}_{3} \mathrm{H}_{6}(\sim 4.0 \AA)$

from $\mathrm{C}_{3} \mathrm{H}_{8}(\sim 4.3 \AA)$. They incorporated the MOF into PIM-1 $\left(P_{\mathrm{C} 3 \mathrm{H} 6}=1,700\right.$ Barrer; $\left.\alpha_{\mathrm{C} 3 \mathrm{H} 6 / \mathrm{C} 3 \mathrm{H} 8}=3.6\right)$ and improved the permeability with the optimum SIFSIX-3-Zn loading of 10 wt.\% to 4,015 and 499 Barrer for $\mathrm{C}_{3} \mathrm{H}_{6}$ and $\mathrm{C}_{3} \mathrm{H}_{8}$, respectively. The $\alpha_{\mathrm{C} 3 \mathrm{H} 6 / \text { / з } \mathrm{H} 8}$ was improved to 7.8 , translating into $117 \%$ improvement in the separation efficiency of difficult similar-molecular size components. The best MMM also presented a stable $P_{\mathrm{C} 3 \mathrm{H} 6}$ in between 3,800-4,000 Barrer with a slight increase of selectivity to $\pm 8.0-8.2$ in 5 days, while the neat PIM-1 lost $45 \%$ of $P_{\mathrm{C} 3 \mathrm{H} 6}$ and gained $25 \%$ selectivity in the same period.

\subsubsection{Post synthetically modified MOFs}

Despite the success in obtaining functionally diverse MOFs via the standard synthesis route (i.e., direct solvothermal), the variation of functional groups within the MOF pores has remained limited. This is mostly related to the functional group instability to the high-temperature solvothermal process 
[121]. Another feasible route is to perform post synthetic modification (PSM) [136]. PSM is a term for the modification of material after attaining its final structure, through a chemical procedure [121,137]. In the case MOFs, PSM can be achieved with either further functionalization to the exterior functional groups or ligand and/or metal substitution, also occurring at the exterior surfaces, e.g., amino-UiO-66 into acetamide-UiO-66 [95,138], diamine-functionalization of MOF-74 [139], and many more. When selecting a component to be modified onto a MOF, researchers usually choose species that have a higher affinity towards a specific gas (i.e., $-\mathrm{NH}_{2}$ group to increase $\mathrm{CO}_{2}$ adsorption in the matrix) or a more prominent steric hindrance component to reduce the size of MOF openings and thus increase its permselectivity. The modification does not only change the MOF's intrinsic properties (i.e., surface area, adsorption affinity towards a specific gas, etc.) but usually improves the MOF's interaction with the polymer continuous phase. Several researchers have demonstrated the benefit of PSM of MOFs in increasing the perm-selectivity of MMMs, e.g., acetamide-UiO-66 in 6FDA-DAM [95], $\mathrm{NH}_{2}-\mathrm{MIL}(\mathrm{Al})$ 53 in 6FDA-DAM-DAB [93], UiO-66- $\mathrm{NH}_{2}$ in Matrimid $^{\circledR} 9725$ [94] and $\mathrm{HSO}_{3}$-MIL-101(Cr) in sulfonated poly(ether ether ketone), SPEEK [96], all for $\mathrm{CO}_{2} / \mathrm{CH}_{4}$ separation. It also includes the terminally modified MIL-101 [133] which has been discussed in the previous section.

Ma et al. [140] demonstrated the effectiveness of incorporating a task-specific ionic liquid (TSIL) into a MOF. The use of a selected TSIL is not solely for pore tailoring, but an inherent property of rapid and reversible interaction towards guest molecules makes it a better candidate than the normal room temperature ionic liquid (RTIL). Using $\mathrm{NH}_{2}-\mathrm{MIL}-101(\mathrm{Cr})\left(\mathrm{CO}_{2}\right.$ uptake $=15.3 \mathrm{cc} \cdot \mathrm{g}^{-1}$ and $\left.\alpha_{\mathrm{CO} 2 / \mathrm{N} 2}=21.0\right)$, they incorporated amine-containing $\mathrm{C}_{3} \mathrm{NH}_{2}$ bim] $\left[\mathrm{Tf}_{2} \mathrm{~N}\right]$ for its reversible reactivity towards $\mathrm{CO}_{2}$ onto the MOF in an anhydrous ethanol solution (see Figure 12). The modified- $\mathrm{NH}_{2}-\mathrm{MIL}-101(\mathrm{Cr}$ ), which shows higher $\mathrm{CO}_{2} / \mathrm{N}_{2}$ selectivity $\left(\mathrm{CO}_{2}\right.$ uptake $\left.=11.0 \mathrm{cc}^{\cdot} \mathrm{g}^{-1} ; \alpha_{\mathrm{CO} 2 / \mathrm{N} 2}=25.7\right)$, was then later loaded into PIM-1 through physical mixing. In terms of gas separation, the performance of PIM-1 ( $P_{\mathrm{CO} 2}=2,443$ Barrer; $\left.\alpha_{\mathrm{CO} 2 / \mathrm{N} 2}=16.9\right)$ was enhanced between $\sim 3,000-3,200$ Barrer for $P_{\mathrm{CO} 2}$, while presenting a high $\mathrm{CO}_{2} / \mathrm{N}_{2}$ selectivity of 29.1 - 37.4 at 5-15 wt.\% filler loading. The best performing TSIL-MOF MMM is however at the lowest filler loading of $5 \mathrm{wt} . \%\left(P_{\mathrm{CO} 2}=2,973 \mathrm{Barrer} ; \alpha_{\mathrm{CO} 2 / \mathrm{N} 2}=37.4\right)$. At the same loading, the use of unmodified $\mathrm{NH}_{2}$-MIL-101(Cr) was only able to increase $P_{\mathrm{CO} 2}$ up to $\sim 3,500$ Barrer but unable to show any selectivity improvement (only at $14.1-17.2$ ). This work demonstrates the beneficial use of a porous material that is capable of performing $\mathrm{CO}_{2}$ reversible catch-and-release efficiently, to selectively facilitate $\mathrm{CO}_{2}$ transport for enhanced gas separation. Unfortunately, this work does not include any membrane aging data.

Besides these PSM approaches, the intrinsic physicochemical properties (i.e., adsorption, affinity, etc.) of a MOF can be modified or improved through metal and organic bridging ligand substitution of intact MOF crystals [141-143]. Smith et al. [144] drastically enhanced the gas transport performances of PIM-1/UiO-66 by post-synthetically exchanging the Zr-based UiO-66 with titanium (Ti), termed as $\mathrm{Ti}_{\mathrm{x}}$-UiO-66 ( $\mathrm{x}=$ exchange yield percentage, studied range between 1-15\%). Even though the smaller Ti atom shrunk the pores within the framework (centric octahedral cages of native UiO-66 is ca. $11 \AA$ [29]), 
the best $\mathrm{Ti}_{5}$-UiO-66 showed $33 \%$ higher $\mathrm{CO}_{2}$ adsorption capacity compared to the native UiO-66 of only $2.53 \mathrm{mmol} \cdot \mathrm{g}^{-1}$ (STP). The finding is related to the improved size-to-charge ratio of $\mathrm{Ti}^{4+}$ for polarising $\mathrm{CO}_{2}$. The addition into PIM-1 $\left(M_{\mathrm{w}}=86,900 \mathrm{Da} ; \emptyset=10.6 ; P_{\mathrm{CO} 2}=3,620\right.$ Barrer; $\alpha_{\mathrm{CO} 2 / \mathrm{N} 2}=20.1 ; \alpha_{\mathrm{CO} 2 / \mathrm{CH} 4}$ $=15.1)$ of Tis-UiO-66 at 5 wt. $\%$ improved the $P_{\mathrm{CO} 2}$ tremendously, $275 \%$ higher than that of the pristine PIM-1, while maintaining its $\mathrm{CO}_{2} / \mathrm{N}_{2}$ selectivity but losing its $\mathrm{CO}_{2} / \mathrm{CH}_{4}$ selectivity by $21 \%$. The $P_{\mathrm{CO} 2}$ is also $153 \%$ higher than the corresponding 5 wt. $\%$ of parent UiO-66 MMM ( $P_{\mathrm{CO} 2}=5,340$ Barrer). They concluded that the competitive advantage of $\mathrm{Ti}_{\mathrm{x}}-\mathrm{UiO}-66$, despite having higher gas adsorption and stronger $\mathrm{CO}_{2}$ affinity, only presents at low loading (optimum at $5 \mathrm{wt} . \%$ ) as it does not influence the selective gas transport level in the MMMs. In their aging test, the pristine PIM-1 showed loss of $\mathrm{CO}_{2}$ and $\mathrm{N}_{2}$ permeability of $52 \%$ and $59 \%$, respectively, in only 16 days. Whereas, the Ti ${ }_{5}-\mathrm{UiO}-665 \mathrm{wt} . \%$ MMMs displayed delayed $P_{\mathrm{CO} 2}$ and $P_{\mathrm{N} 2}$ loss of only $25 \%$ and $20 \%$ on day 14 , reached $56-59 \%$ loss at day 35 and finally at $71-75 \%$ on day 63 . Nonetheless, it is notable that the $\alpha_{\mathrm{CO} 2 / \mathrm{N} 2}$ increased from 20 to 24 throughout membrane aging.

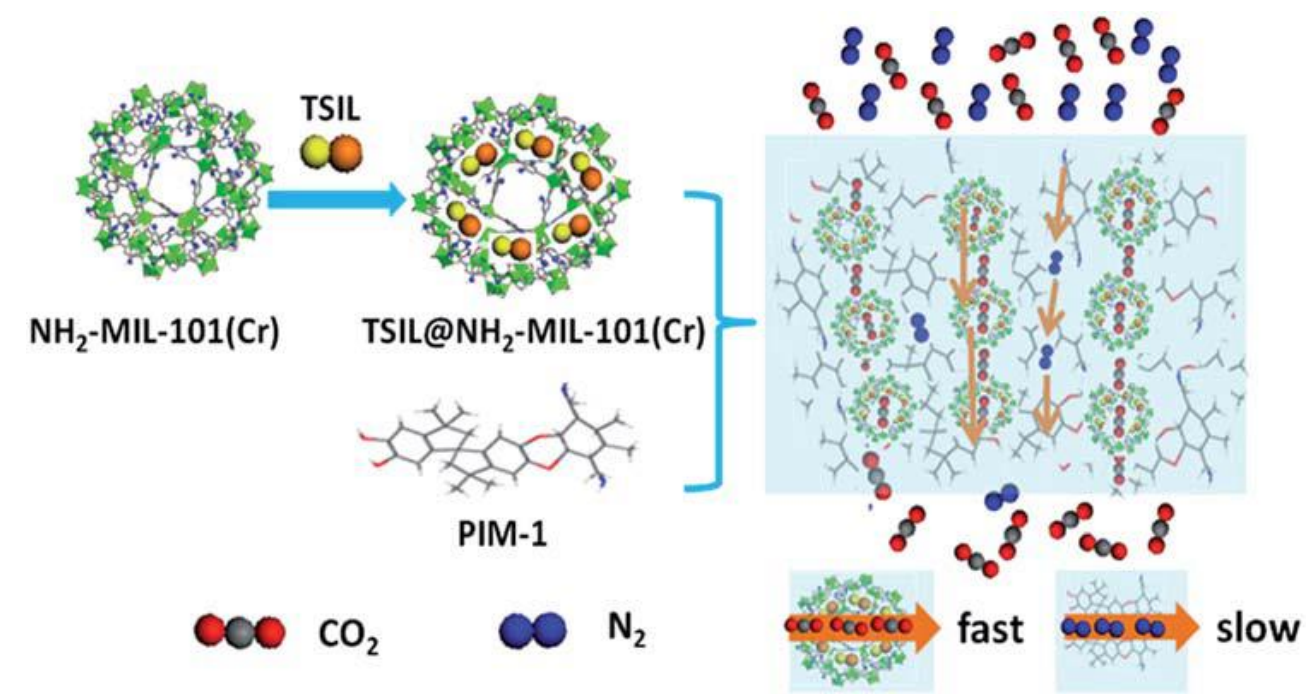

Figure 12: Schematic illustration of the preparation of TSIL@ $\mathrm{NH}_{2}-\mathrm{MIL}-101(\mathrm{Cr}) / \mathrm{PIM}-1 \mathrm{MMMs}$, and the proposed gas separation process. This figure has been reproduced from ref. [140] with permission from The Royal Society of Chemistry, copyright 2016.

\subsubsection{Two-dimensional (2D) MOFs}

A newly introduced generation of MOFs is two-dimensional, which shows higher potential in MMM fabrication as the nano-material presents a high aspect ratio for increased filler-polymer contact area [145]. One of the first introduced 2D-MOF nanosheets is Cu-BDC, copper coordinated MOF with 1,4benzene dicarboxylic acid $\left(\mathrm{H}_{2} \mathrm{BDC}\right.$ ) ligand (see Figure 13(a)). The 2D MOFs, especially the ultrathin nanosheets with atomic-scale thickness and high surface area, arose to be the 2D material of choice due to their ability to maintain a high flux and exceptional rejection rate in membrane processes [146]. Thus it is able to alleviate the permeability-selectivity trade-off relationship. The utmost benefit of a MMM 
with 2D MOF nanosheets can only be achieved with an ideal filler orientation where it affects the separating molecules' diffusion pathways, as illustrated in Figure 13(b).

Cheng et al. [147] prepared ultrathin PIM-1 $\left(M_{\mathrm{w}}=188,746 \mathrm{~g} \cdot \mathrm{mol}^{-1} ; Ð=3.2\right)$ MMMs with layered 2D copper 1,4-benzenedicarboxylate nanosheets, CuBDC-ns $\left(A_{\mathrm{BET}}=180 \mathrm{~m}^{2} \cdot \mathrm{g}^{-1} ; \mathrm{CO}_{2}\right.$ uptake of 0.28 $\mathrm{mmol} \cdot \mathrm{g}^{-1}$ ) through a spin-coating method. The MOF consists of $\mathrm{Cu}^{\mathrm{II}}$ dimers interconnected by benzenedicarboxylate anions, arranged in two orthogonal dimensions resulting in ordered pores of 5.2 $\AA$. The stacked lamellar structure of CuBDC-ns was in the thickness range of $15-40 \mathrm{~nm}$, exhibiting a high aspect ratio of $\sim 100$. Upon addition into PIM-1 $\left(K_{\mathrm{CO} 2}=1,773 \mathrm{GPU} ; \alpha_{\mathrm{CO} 2 / \mathrm{CH} 4}=4.4\right)$, in the form of ultrathin membranes with loading as low as 2 wt. $\%$, CuBDC-ns showed $70 \%$ and $88 \%$ reduction for $K_{\mathrm{CO} 2}$ and $K_{\mathrm{CH} 4}$, respectively, while increasing its selectivity by $128 \%$. This significant permeability loss while gaining selectivity is a typical proof that the diffusion resistance is generated by the narrow filler pores. Meanwhile at higher loadings (>15 wt.\% of CuBDC-ns), the MMMs started to lose their selectivity, deemed to be caused by the non-selective gas diffusion paths in the interface regions. At their best loading of $10 \mathrm{wt} . \% \mathrm{CuBDC}$-ns, the MMM showed the highest $\alpha_{\mathrm{CO} 2 / \mathrm{CH} 4}$ at 15.5 , translating into $\pm 250 \%$ improvement, with a slightly lower $K_{\mathrm{CO} 2}$ of 473 GPU.

a)

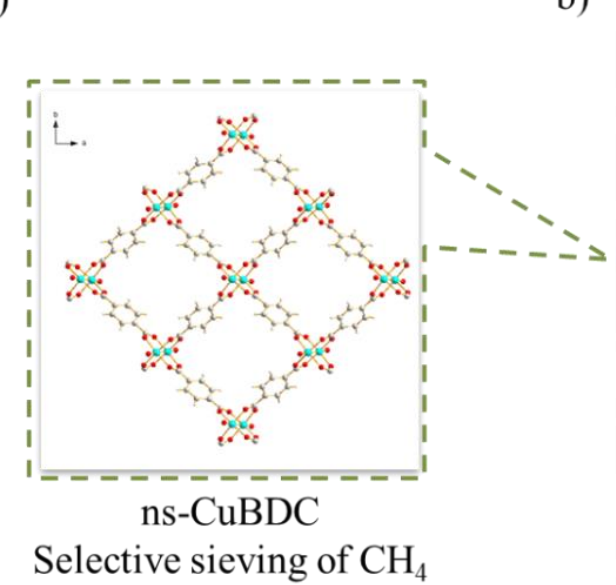

b)

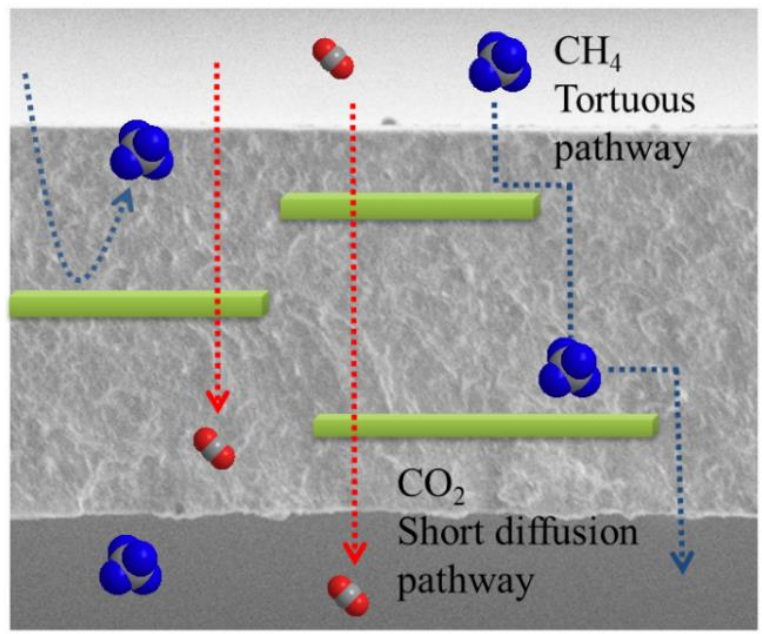

Figure 13: (a) Cu-BDC structure drawn by Diamond. cif file obtained from Asghar et al. [148], and (b) schematic illustration of a MMM containing a 2D nanosheet filler with ideal orientation.

\subsubsection{Modification of MOF-MMM fabrication procedure}

Exceptional gas separation performances of MMMs may be obtained from improved MMM fabrication procedures. Conventional MMM preparation involves the filler dispersion and the polymer solution being prepared separately, then physically and rigorously mixed to ensure uniform particle distribution with minimal agglomeration (Figure 14, method A). Tien-Binh et al. [149] reported in-situ interface crosslinking of PIM-1 $\left(M_{\mathrm{w}}=190,000 \mathrm{~g} \cdot \mathrm{mol}^{-1} ; D=2.6\right)$ with amino-functionalized UiO-66 $\left(\mathrm{Zr}_{6} \mathrm{O}_{4}(\mathrm{OH})_{4}\left(\mathrm{BDC}-\mathrm{NH}_{2}\right)_{6}\right.$; at the size of ca. $\left.1 \mu \mathrm{m}\right)$. The procedure is illustrated as method B in Figure 14. The substances were covalently linked and enhanced physical properties were determined in the 
form of $\mathrm{N}_{2}$ adsorption and thermal degradation profiles. The interface crosslinking of UiO-66- $\mathrm{NH}_{2}$ and PIM-1 polymer was further determined by ${ }^{13} \mathrm{C}$ MAS NMR, where the peak of the amine-linked carbon in UiO-66- $\mathrm{NH}_{2}$ at $150.9 \mathrm{ppm}$ shifted to $161 \mathrm{ppm}$, confirming the transformation of primary to a secondary amine. The authors reported enhanced gas separation performances of pristine PIM-1 $\left(P_{\mathrm{CO} 2}\right.$ $=6,576 ; P_{\mathrm{O} 2}=1,072$ Barrer; $\left.\alpha_{\mathrm{CO} 2 / \mathrm{N} 2}=18.7 ; \alpha_{\mathrm{CO} 2 / \mathrm{CH} 4}=12.3 ; \alpha_{\mathrm{O} 2 / \mathrm{N} 2}=3.0\right)$, in PIM-co-UiO-66 $72 \mathrm{~h}\left(P_{\mathrm{CO} 2}=\right.$ 12,$498 ; P_{\mathrm{O} 2}=945$ Barrer; $\left.\alpha_{\mathrm{CO} 2 / \mathrm{N} 2}=54.2 ; \alpha_{\mathrm{CO} 2 / \mathrm{CH} 4}=31.9 ; \alpha_{\mathrm{O} 2 / \mathrm{N} 2}=4.1\right)$, which was prepared through method B for $72 \mathrm{~h}$. The performance way surpassed the $2008 \mathrm{CO}_{2} / \mathrm{CH}_{4}$ upper bound [15]. The MMM prepared at the same $20 \mathrm{wt} . \%$ loading through method A, however, showed $37 \%$ lower $P_{\mathrm{CO} 2}$ while maintaining its $\alpha_{\mathrm{CO} / \mathrm{N} 2}=12.5$ and $\alpha_{\mathrm{CO} / \mathrm{CH} 4}$ at 17.3. More interestingly, the PIM-co-UiO-66 6 72h proved to suppress physical aging by showing only $25 \% P_{\mathrm{CO} 2}$ reduction over 400 days and maintained its excellent $\alpha_{\mathrm{CO} / \mathrm{CH} 4}$ at 31.7 . In comparison, the pristine PIM-1 lost $83 \% P_{\mathrm{CO} 2}$ while only gaining $20 \%$ in $\alpha_{\mathrm{CO} 2 / \mathrm{CH} 4}$. It confirms that this improved method produces excellently performing MMMs, outperforming other similar PIM-1/UiO-66- $\mathrm{NH}_{2}$ MMMs reported previously.
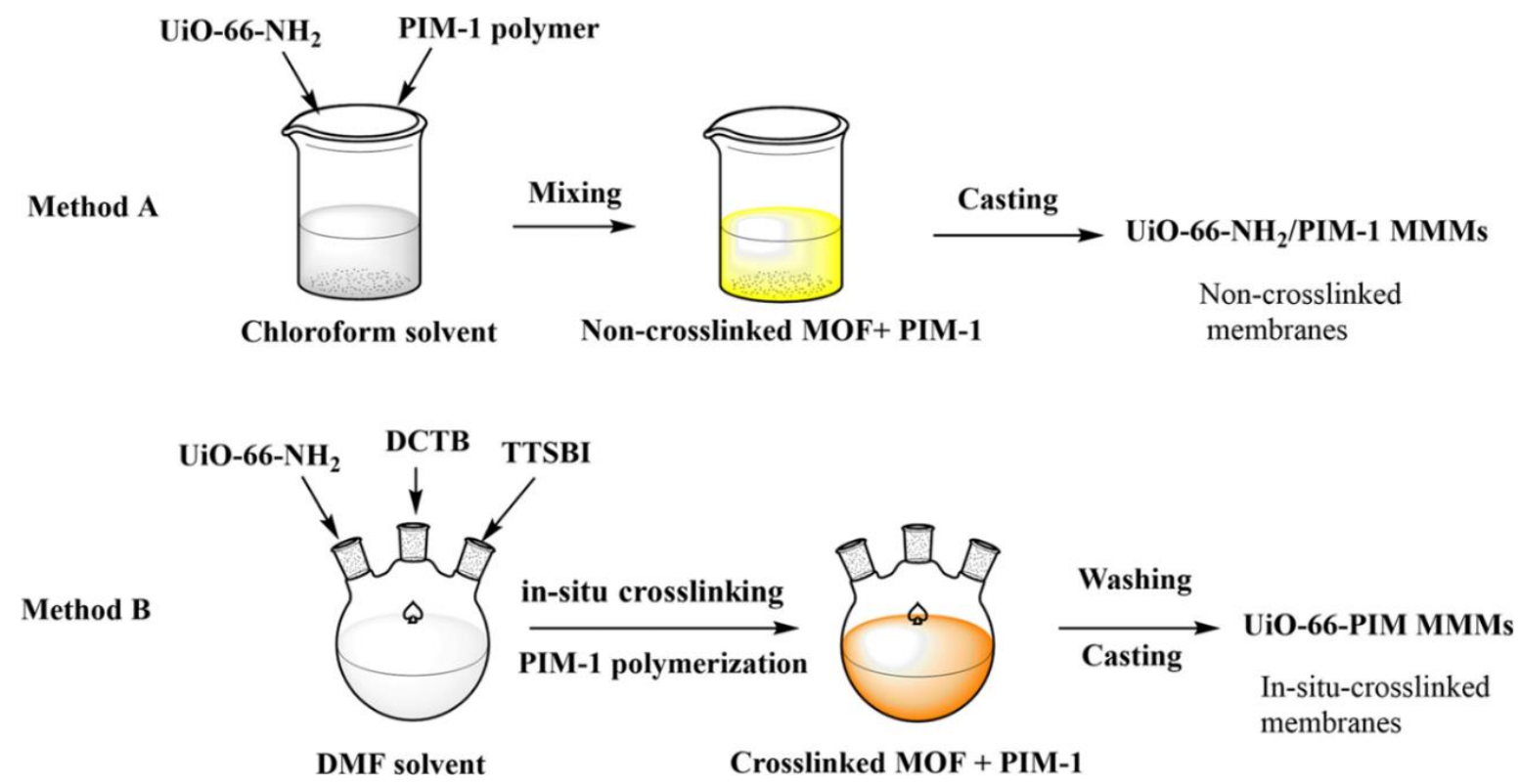

Figure 14: Cross interface linking between UiO-66- $\mathrm{NH}_{2}$ and PIM-1 obtained during the in situ polymerization (method B). This figure has been reproduced from ref. [149] with permission from Elsevier, copyright 2017.

In a similar PIM-1/UiO-66- $\mathrm{NH}_{2}$ MMM system, Yu et al. [150] in a very recent publication reported a different strategy, where they first post-functionalized UiO-66- $\mathrm{NH}_{2}$ (narrow pore opening of $\sim 6.0 \AA$ ) into cyano UiO-66 (denoted as UiO-66-CN; pore opening of $5.4 \AA$ ). Afterward, they interweaved the physically and traditionally mixed PIM-1 and UiO-66-CN in a $\mathrm{N}_{2}$ atmosphere between $30-250{ }^{\circ} \mathrm{C}$ for $24 \mathrm{~h}$. The goal was to link the PIM-1 through thermal cyclization of $-\mathrm{CN}$ groups on the MOF surfaces onto PIM-1 chains. The pristine untreated PIM-1 $\left(M_{\mathrm{w}}=144,271 \mathrm{~g} \cdot \mathrm{mol}^{-1} ; Ð=2.0\right)$ initially showed $P_{\mathrm{CO} 2}$ of 3,028 Barrer; $\alpha_{\mathrm{CO} 2 / \mathrm{N} 2}$ of 26.6. In addition to the contribution of dual adsorption sites of polar $\mathrm{Zr}-\mathrm{O}$ entities and cyano groups in UiO-66-CN, their optimum MMM of $20 \mathrm{wt} . \%$ loading presented an improved $P_{\mathrm{CO} 2}$ of 7,071 Barrer and maintained the $\alpha_{\mathrm{CO} 2 / \mathrm{N} 2}$ at 26.7. After the weaving procedure, the 
MMM showed a tremendous improvement of $P_{\mathrm{CO} 2}$ to 16,121 Barrer while maintaining its $\alpha_{\mathrm{CO} 2 / \mathrm{N} 2}$ at 27.0. Interestingly, the authors also demonstrated the MMM efficiency in the presence of competing absorptive gases using 50:50 $\mathrm{CO}_{2}: \mathrm{N}_{2}$ mixed gas (vol.\%: vol.\%), which presented a superior $P_{\mathrm{CO} 2}$ performance of 12,063 Barrer and $\alpha_{\mathrm{CO} 2 / \mathrm{N} 2}$ of 53.5. Additional testing using a flue gas composition (15\% $\mathrm{CO}_{2}$ and $85 \% \mathrm{~N}_{2}$ ) also showed excellent findings: $P_{\mathrm{CO} 2}$ of 10,389 Barrer and $\alpha_{\mathrm{CO} 2 / \mathrm{N} 2}$ of 33.7 . Furthermore, the interweaved MMM showed no significant permeability loss and selectivity gain after six months of aging, proudly still residing way above the $\mathrm{CO}_{2} / \mathrm{N}_{2} 2008$ upper bound [15].

Lately, the traditional mixing protocol was further amended and improved by many researchers. Amongst the latest advancements, several researchers have demonstrated the effectiveness of growing MOF particles on the membrane surfaces, i.e., continuous and thick crystalized ZIF-8 growth layer on highly porous polysulfone, PSF [151] and bromomethylated poly(2,6-dimethyl-1,4-phenylene oxide), BPPO [152] for effective $\mathrm{H}_{2}$ separation. The method was also reported very recently in PIM-1 $\left(M_{\mathrm{w}}=\right.$ $219,832 \mathrm{~g} \cdot \mathrm{mol}^{-1} ; Ð=2.4$ ), where the ZIF-8 (average particle size distribution of ca. $80 \mathrm{~nm}$ ) was grown concurrently to the PIM-1 rejuvenation in methanol [153]. The performance of neat PIM-1 $\left(P_{\mathrm{O} 2}=1,808\right.$ Barrer; $\alpha_{\mathrm{O} 2 / \mathrm{N} 2}=2.5$ ) was best improved with a $\sim 200 \mathrm{~nm}$ intergrown ZIF-8 crystals layer, obtained after seven cycles of growth, producing MMMs with $P_{\mathrm{O} 2}$ of 1,287 Barrer and $\alpha_{\mathrm{O} 2 / \mathrm{N} 2}$ of 3.7. At lower loading (fewer growth cycles), the MMMs also presented lower $P_{\mathrm{CO} 2}$, however the overall selectivity was not improved significantly.

Fuoco et al. [154] prepared symmetric MOF/PIM-1/MOF sandwich membranes by growing layers of ZIF-8 and $\mathrm{Cu}_{3}(\mathrm{BTC})_{2}$ (better known as HKUST-1). Firstly, the PIM-1 membrane was chemically modified by converting the nitrile group to amide (AMD-PIM-1) and by aminohexamethylamide modification (HMDA-PIM-1), to boost the interaction with MOFs' metal ions and the organic ligands, followed by layer-by-layer (LbL) crystal growth steps. The effectiveness of crystal growth is in the order of their group functionality, PIM-1 < AMD-PIM-1 < HMDA-PIM-1, while the thickness is dependent on the number of growth cycles. In term of gas permeation, the PIM-1 performance $\left(P_{\mathrm{CO} 2}=6,132 ; P_{\mathrm{O} 2}\right.$ $=1,015$ Barrer; $\left.\alpha_{\mathrm{CO} 2 / \mathrm{CH} 4}=13.7 ; \alpha_{\mathrm{CO} 2 / \mathrm{N} 2}=19.0 ; \alpha_{\mathrm{O} 2 / \mathrm{N} 2}=3.1\right)$ was increased after ZIF-8 monolayer growth (1-cycle) by $48 \%, 32 \%$ and $25 \%$ for $\alpha_{\mathrm{CO} / \mathrm{CH} 4}, \alpha_{\mathrm{CO} / \mathrm{N} 2}$ and $\alpha_{\mathrm{O} 2 / \mathrm{N} 2}$, respectively. Additional growth cycles did not further enhance the selectivity, but exhibited tremendous permeability reduction ( $>95 \%)$. Similar trends of selectivity increase occurred after only one cycle of both ZIF-8 and HKUST-1 deposited onto AMD-PIM-1 $\left(P_{\mathrm{CO} 2}=6,132 ; P_{\mathrm{O} 2}=1,015\right.$ Barrer; $\alpha_{\mathrm{CO} 2 / \mathrm{CH} 4}=11.4 ; \alpha_{\mathrm{CO} 2 / \mathrm{N} 2}=16.6 ; \alpha_{\mathrm{O} 2 / \mathrm{N} 2}=$ 4.0) and HMDA-PIM-1 $\left(P_{\mathrm{CO} 2}=620 ; P_{\mathrm{O} 2}=145\right.$ Barrer; $\left.\alpha_{\mathrm{CO} 2 / \mathrm{CH} 4}=14.8 ; \alpha_{\mathrm{CO} 2 / \mathrm{N} 2}=21.3 ; \alpha_{\mathrm{O} 2 / \mathrm{N} 2}=3.8\right)$.

\subsection{PIM-1 with nanotubes and $2 \mathrm{D}$ fillers}

\subsubsection{Carbon nanotubes (CNTs)}

CNTs are a graphitic carbon material, made of graphite sheets rolled up into a tubular shape. These hollow cylinders are considered as nearly one-dimensional structures with a high length $(l)$ to diameter 
$(\varnothing)$ ratio $(\varnothing=1-10 \mathrm{~nm}, l=$ several $\mathrm{mm})$. The CNTs are either in the form of a single layer of graphene which forms a cylindrical shape, referred to as single-walled carbon nanotubes (SWCNTs), or made of multiple layers of graphene, formed in a concentric pattern around the smallest nanotube and referred to as multi-walled carbon nanotubes (MWCNTs). CNT-based MMMs are expected to serve as a valuable means of upgrading separation performance, owing to their smooth interior channels and when aligned appropriately, it provides rapid gas transport paths. Despite the merits, one main point of concern is their poor interfacial interaction with the polymer matrix, causing difficulties in dispersing the entangled CNTs during processing, leading to agglomerates $[155,156]$.

Khan et al. [78] functionalized MWCNTs using PEG through a 'grafting to' method (Figure 15(a)) and incorporated them into PIM-1 $\left(M_{\mathrm{w}}=221,000 \mathrm{~g} \cdot \mathrm{mol}^{-1} ; Ð=4.8\right)$. The pristine performance $\left(P_{\mathrm{CO} 2}=\right.$ 5,360 Barrer; $\left.\alpha_{\mathrm{CO} / \mathrm{N} 2}=28.2 ; \alpha_{\mathrm{CO} / \mathrm{CH} 4}=15.4\right)$ was improved by incorporating only 2 wt. $\%$ of functionalized MWCNTs ( $f$-MWCNTs) up to $P_{\mathrm{CO} 2}=7,090$ Barrer, giving selectivities of 32.9 and 10.4 for $\alpha_{\mathrm{CO} 2 / \mathrm{N} 2}$ and $\alpha_{\mathrm{CO} 2 / \mathrm{CH} 4}$, respectively. The functionalization of MWCNTs using PEG not only improves its interphase interaction (Figure 15(b-c)) but also increases $\mathrm{CO}_{2}$ solubility while limiting the solubility of the nonpolar gas, which is advantageous for $\mathrm{CO}_{2} / \mathrm{N}_{2}$ selectivity. Please note that in the cross-section SEM images, $f$-MWCNT agglomeration can sometimes be observed and is explained by strong $\pi-\pi$ interaction between the MWCNTs themselves $[155,156]$.

a)
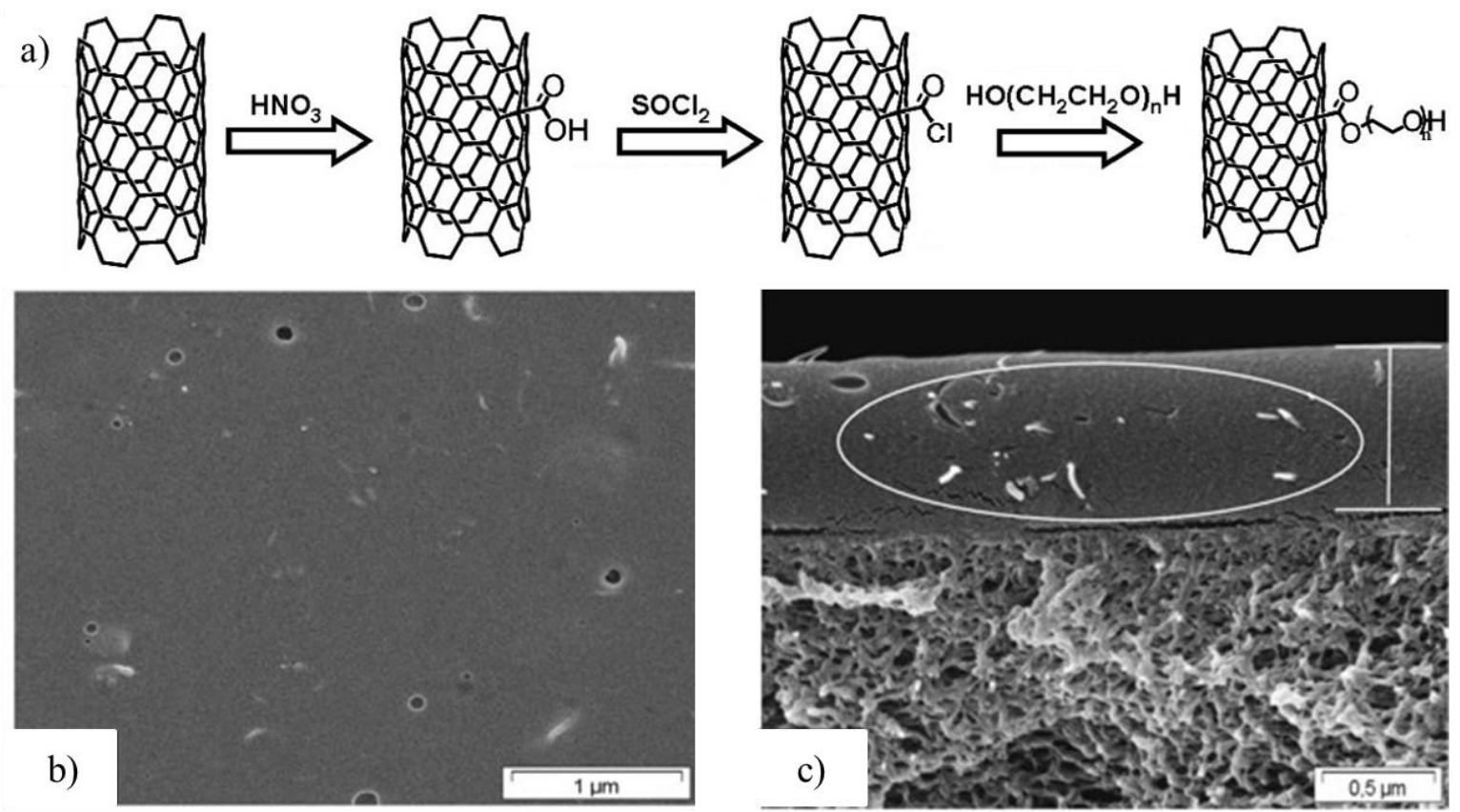

Figure 15: (a) Functionalization of pristine MWCNTs via 'grafting to' method, and (b-c) SEM surface and crosssection images of PIM- 1 with 2 wt. $\%$ of $f$-MWCNT loading. Circled area indicates the presence of $f$-MWCNT agglomeration. This figure has been reproduced from ref. [78] with permission from Springer Nature, copyright 2012.

Following that, Golzar et al. [77] investigated the gas $\left(\mathrm{CO}_{2}, \mathrm{CH}_{4}, \mathrm{O}_{2}, \mathrm{~N}_{2}\right)$ transport properties through PIM-1 MMMs, using pristine CNTs ( $p$-SWCNT and p-MWCNT) and PEG-functionalized 
counterparts ( $f$-SWCNT and $f$-MWCNT) using molecular dynamics (MD) and grand canonical Monte Carlo (GCMC) simulations. The extensive simulation data was compared to the experimental data presented by Khan et al. [78]. The authors concluded that the pristine and PEG-functionalized CNTs improve the transport properties such as diffusivity $\left(D_{\mathrm{O} 2}>D_{\mathrm{CO} 2}>D_{\mathrm{N} 2}>D_{\mathrm{CH} 4}\right)$, solubility $\left(S_{\mathrm{CO} 2}>S_{\mathrm{CH} 4}\right.$ $\left.>S_{\mathrm{O} 2}>S_{\mathrm{N} 2}\right)$, and permeability $\left(P_{\mathrm{CO} 2}>P_{\mathrm{O} 2}>P_{\mathrm{CH} 4}>P_{\mathrm{N} 2}\right)$ of the PIM-1 membranes, without sacrificing their selectivity. Also, the MMMs incorporating functionalized CNT particles indicate better performance, up to $2 \mathrm{wt} . \%$ particle loadings.

\subsubsection{Graphene}

Graphene is a two-dimensional carbon allotrope of $s p^{2}$ bonded atoms in a hexagonal honeycomb structure, or more simply a single layer of graphite [157]. This material is impermeable to all molecules in its defect-free form, while offering high surface-to-volume ratios for adsorption [158]. The graphene platelets can be used to control permeation when dispersed in a polymer and is deemed to be a costeffective and straightforward method that can bring significant improvement to the properties of the polymer [159].

Althumayri et al. [160] demonstrated that the addition of graphene into PIM-1 $\left(M_{\mathrm{w}}=170,000 \mathrm{~g} \cdot \mathrm{mol}^{-}\right.$ $\left.{ }^{1} ; Ð=4.0\right)$ improved the gas permeation performance of the pristine self-supported membrane $\left(P_{\mathrm{CO} 2}=\right.$ 5,$120 ; P_{\mathrm{O} 2}=1,130$ Barrer; $\left.\alpha_{\mathrm{CO} 2 / \mathrm{CH} 4}=15.1 ; \alpha_{\mathrm{CO} 2 / \mathrm{N} 2}=19.0 ; \alpha_{\mathrm{O} 2 / \mathrm{N} 2}=4.2\right)$ by just adding $0.003 \mathrm{wt} . \%$ of graphene. The MMM showed increased $P_{\mathrm{CO} 2}$ and $P_{\mathrm{O} 2}$ of 7,830 and 1,560 Barrer, respectively, while maintaining its separation selectivity. The authors also made a comparison between this planar graphene-filled PIM-1 to the other MMMs with different filler morphologies, e.g., spherical (fumed silica Cabosil TS 530 [50]) and cylindrical (f-MWCNT [78]). They found that the optimum loading is often at very low loadings. Moving forward, the group further investigated the effect of graphene addition on the PIM-1's molecular packing and its gas adsorption properties, by both experimental and simulation work [79]. Visualization of simulated systems revealed that PIM-1 fragments arranged themselves parallel to the graphene sheets (Figure 16(a)) with a separation layer between the two phases of ca. $3.5-4 \AA$, however in the presence of PIM-1 chain fragments, the arrangement of the whole chain was constrained and therefore tended to align randomly on the graphene sheet. The study also concluded that a medium graphene sheet size is more suitable because it increases accessible surface area rather than blocking or occupying the PIM-1 pores.

Additionally, the small sheets tend to agglomerate, forming a stack of two or three graphene sheets (Figure 16(b)). In terms of $\mathrm{CO}_{2}$ adsorption, they found that the MMM did not show a plateau point where the saturation capacity was reached, as per the simulated isotherm, but tended to have a linear relationship at high pressures between adsorbed $\mathrm{CO}_{2}$ loading and pressure (up to 20 bar, see Figure 16(c)). These findings indicate possible polymer swelling and increased dominance of gas-gas interactions, and show that the polymer chains can re-orientate, adjusting to pressure and loading changes [79,161]. 
The group revealed how the material was dispersed in the polymer in a later extensive characterization study, using Raman spectroscopy, scanning transmission electron microscopy (STEM), and electron energy loss spectroscopy (EELS) to study the composite membrane's structure [158]. The stabilization of exfoliated graphene sheets in the PIM-1 solution is enhanced via $\pi$ - $\pi$ interaction, however the re-stacking tendency is very high. Therefore, through the extensive characterization conducted, the authors demonstrated that the presence of PIM-1 enhances the direct exfoliation of graphene in chloroform, although the efficiency of the process and stability of the resulting dispersion is highly dependent on the graphene concentration. This finding justifies the very low graphene loadings in MMMs presented by Althumayri et al. [160].

a)

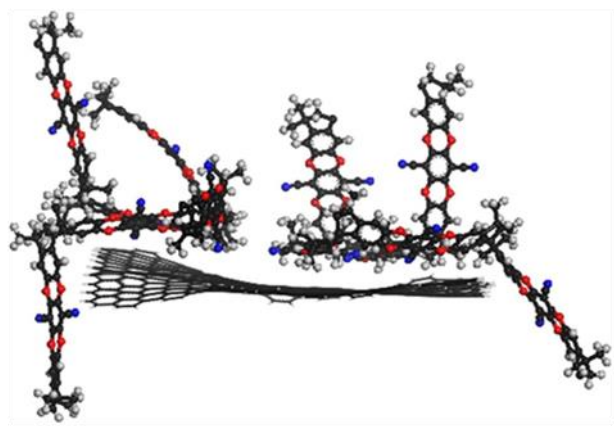

b)

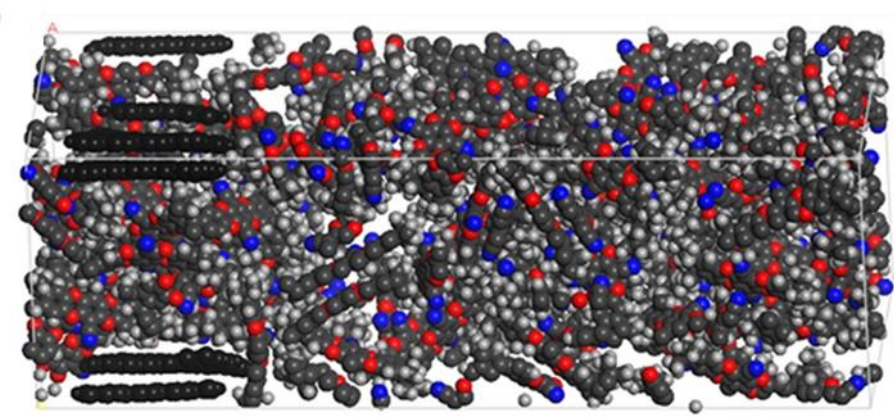

c)
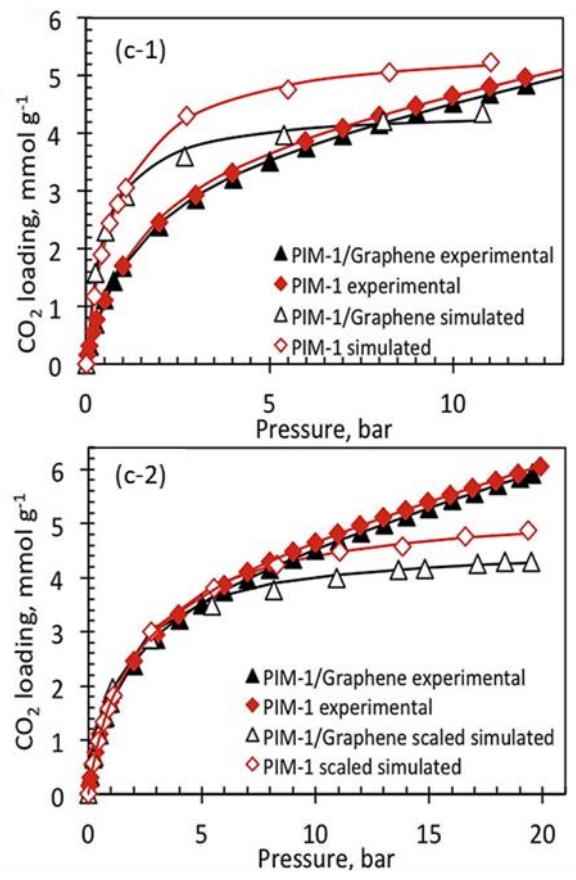

Figure 16: (a) Representative arrangement of PIM-1 chain fragments on the graphene sheet, (b) snapshots of the

final box configuration of a composite with small graphene platelets and also in an occurrence of phase separation, as observed in stacking of two or three graphene sheets. (c) The experimental and simulated $\mathrm{CO}_{2}$ isotherms at $293 \mathrm{~K}$. Simulated isotherm calculated using (a) original L-J parameters and (b and c) reduced L-J interaction strength, $\varepsilon$, by $24 \%$. This figure has been reproduced from ref. [79] with permission from Elsevier, copyright 2015.

\subsubsection{Graphene oxide (GO)}

Graphene can be oxidised to graphene oxide (GO), which bears various oxygen-containing functional groups (epoxide, alcohol, carboxylic acid) that make it more hydrophilic and that provide sites for chemical modification. At the University of Manchester, Nair et al. [162] found that "laminate" membranes composed entirely of GO flakes in an interlocked layer structure are impermeable to liquids, vapors and gases (even helium), with the exception of water, which can permeate through a GO "laminate" membrane almost as readily as if it were not there. The membranes had thicknesses in the 
range of $0.1-10 \mu \mathrm{m}$. The study further emphasises that the molecular transport in GO laminates should involve a permeation path through the network of graphene nanocapillaries. Li et al. [163] further demonstrated that the selective permeation of small gases does occur through ultrathin GO membranes (typically $<20 \mathrm{~nm}$ thickness in their study), which was attributed to transport through structural defects in GO flakes. They were able to achieve selectivities for $\mathrm{H}_{2} / \mathrm{CO}_{2}$ and $\mathrm{H}_{2} / \mathrm{N}_{2}$ up to 3,400 and 900 , respectively.

Subsequently, Chen et al. [164] presented the ideal case of GO addition into the polymer as a MMM. They incorporated GO nanosheets (thickness of 0.55-1.2 nm, diameter of 0.5-3.0 $\mu \mathrm{m})$ into PIM-1 ( $P_{\mathrm{CO} 2}$ $=3,277$ Barrer; $\left.\alpha_{\mathrm{CO} 2 / \mathrm{N} 2}=16.2\right)$ and increased the selectivity to 124 . This outstanding selectivity is attributed to the two-fold increase in $P_{\mathrm{CO} 2}$, as well as a four-fold decrease in $P_{\mathrm{N} 2}$. They concluded that this is due to the formation of nanoscale gas transport channels, small enough to favorably transport $\mathrm{CO}_{2}$

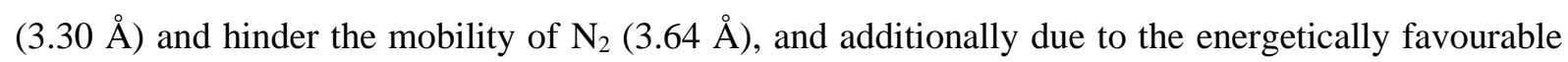
surface interaction between $\mathrm{CO}_{2}$ and the $\mathrm{GO}$ at low pressure, which increases its adsorption [165]. The hypothesis is confirmed by atomic force microscopy (AFM) analysis, which showed distinct regions attributed to hydrophilic domains of GO nanosheets and hydrophobic domains of PIM-1 (Figure 17). Heat treatment at $150{ }^{\circ} \mathrm{C}$ for $12 \mathrm{~h}$, to reduce the GO back to a more graphene-like material, not only lowers the $P_{\mathrm{CO} 2}$ by $57 \%$ but also decreases the $\alpha_{\mathrm{CO} 2 / \mathrm{N} 2}$ by $16 \%$.
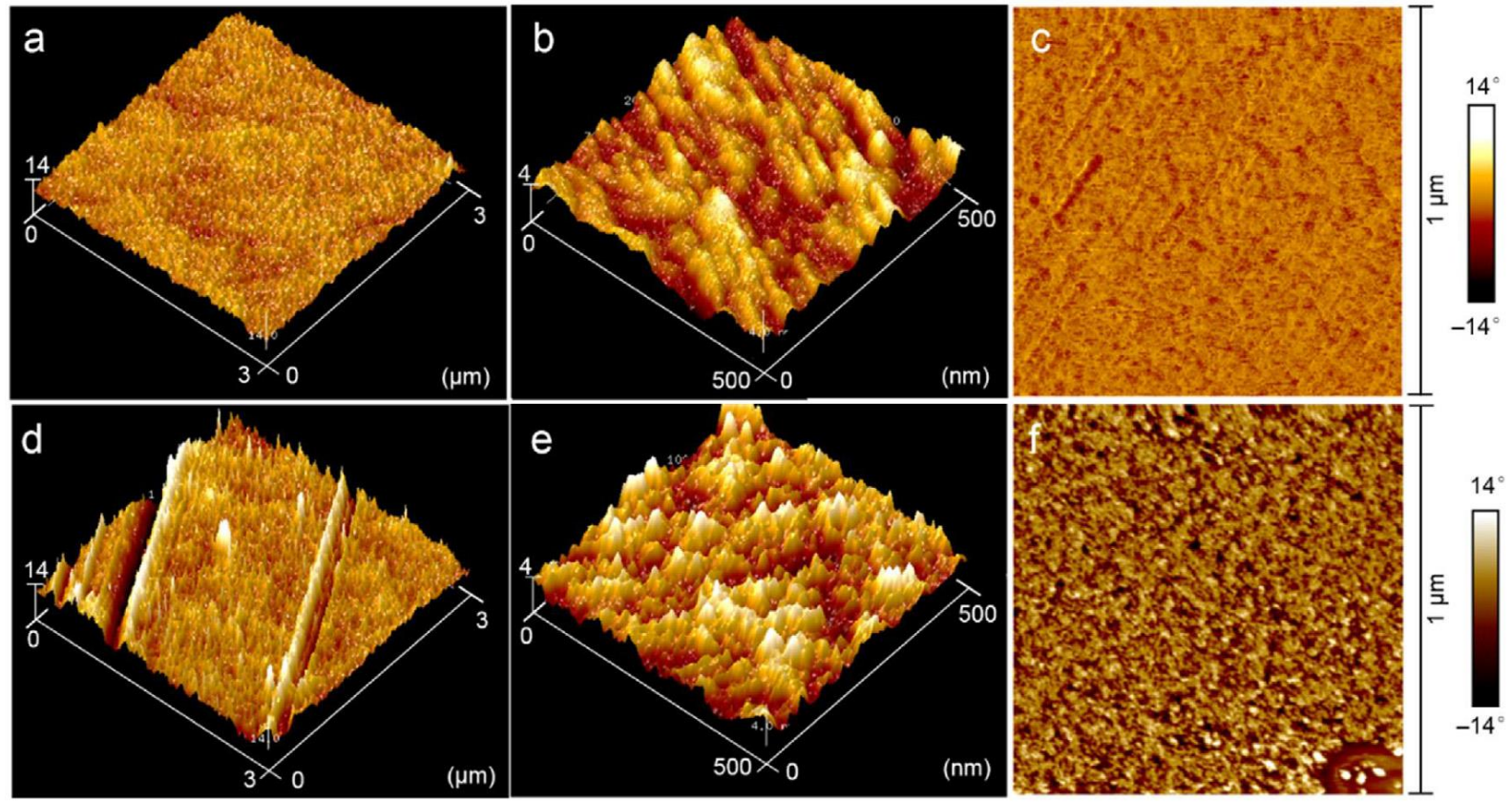

Figure 17: AFM 3D topographic images (a-b) of the PIM-1 membrane and (d-e) its GO nanosheet filled membrane, $(c, f)$ are the corresponding phase images. This figure has been reproduced from ref. [164] with permission from Elsevier, copyright 2018.

A number of studies have utilised GO as a filler in a MMM, while aiming to tackle the aging issue in PIMs. However, good interface compatibility between polymer and GO phases is an issue. Alberto et al. [42] decorated GO with alkyl chains of different lengths by reaction with alkylamines, comparing 
octadecyl (GO-ODA) with its reduced counterpart (rGO-ODA) and with a reduced octyl version (rGOOA $)$ in MMMs with PIM-1 $\left(M_{\mathrm{w}}=123,410 \mathrm{~g} \cdot \mathrm{mol}^{-1}\right.$; neat $P_{\mathrm{CO} 2}=\sim 6,400$ Barrer; $\left.\alpha_{\mathrm{CO} 2 / \mathrm{CH} 4}=20.3\right)$. While the functionalized fillers did not improve the initial $\mathrm{CO}_{2}$ permeability or $\mathrm{CO}_{2} / \mathrm{CH}_{4}$ selectivity, MMMs with the addition of as little as $0.05 \mathrm{wt} . \%$ filler showed lower aging rates over 155 days. Aliyev et al. [166] performed several covalent chemical functionalization of GO (i.e., amines, thionyl chloride, phosphorus trichloride) and further functionalized the chlorinated-GO (GO-Cl) with ferrocene and oxime derivatives for their affinity towards oxygen and carbon dioxide, respectively (see Figure 18). The fillers were utilised in mixed matrix thin film composite (TFC) membranes with PIM-1. The fillers, even though agglomerated to a certain degree in the near-surface region of the TFC, succeeded in improving the $\mathrm{O}_{2} / \mathrm{N}_{2}$ and $\mathrm{CO}_{2} / \mathrm{N}_{2}$ selectivity of PIM-1 $\left(M_{\mathrm{w}}=200,000 \mathrm{~g} \cdot \mathrm{mol}^{-1} ; P_{\mathrm{CO} 2}=11.04 ; P_{\mathrm{O} 2}=0.52\right.$ $\left.\mathrm{m}^{3}(\mathrm{STP}) \mathrm{m}^{-2} \mathrm{~h}^{-1} \mathrm{bar}^{-1} ; \alpha_{\mathrm{CO} 2 / \mathrm{N} 2}=21.3 ; \alpha_{\mathrm{O} 2 / \mathrm{N} 2}=3.26\right)$. Compared to the GO-MMMs at 9 wt. $\%$ filler loading $\left(\alpha_{\mathrm{CO} 2 / \mathrm{N} 2}=18.0 ; \alpha_{\mathrm{O} 2 / \mathrm{N} 2}=3.06\right)$, the same loading of GO-AEDPFF increased the $\alpha_{02 / \mathrm{N} 2}$ by $54 \%$, whereas GO-DCIBAO increased the $\alpha_{\mathrm{CO} 2 / \mathrm{N} 2}$ by $21 \%$.
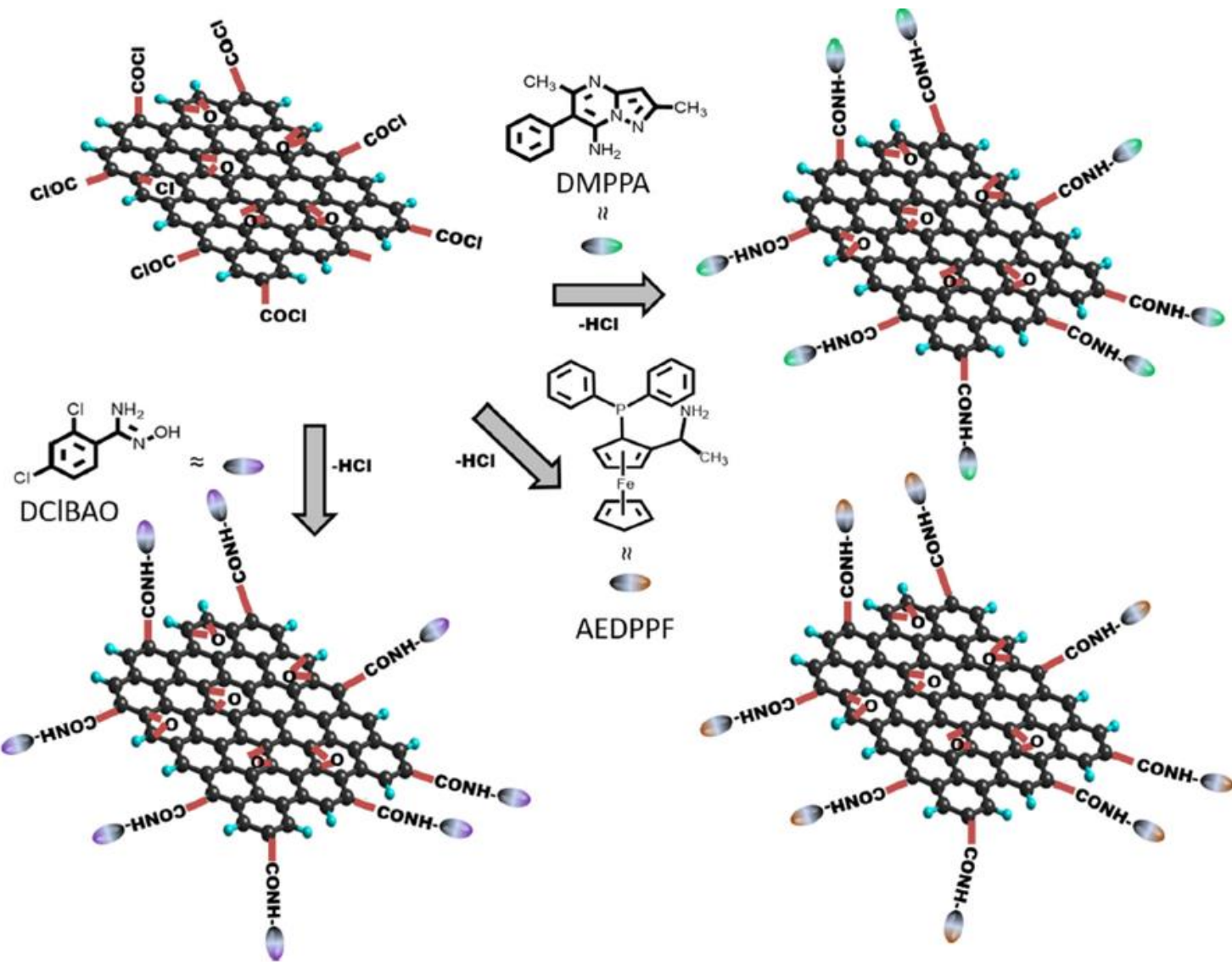

AEDPPF

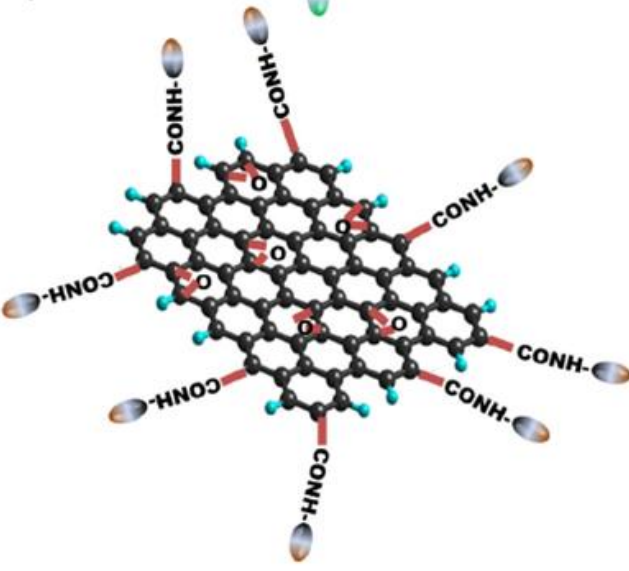

Figure 18: Illustration of GO-DMPPA, GO-AEDPPF, and GO-DClBAO synthesis from GO-Cl. This figure has been reproduced from ref. [166] with permission from Springer Nature, copyright 2018.

\subsubsection{Graphitic carbon nitride $\left(\mathrm{g}-\mathrm{C}_{3} \mathrm{~N}_{4}\right)$}

Graphitic carbon nitride (Figure 19), a 2D material constituted of tris-s-triazine rings as the basic units forming periodic triangular ultramicropores $(\sim 3.11 \AA)$, also comes with structural defects giving pores of size $3.1-3.4 \AA$ [167]. The material can be rapidly and synthesized with inexpensive raw 
materials and can be fashioned into graphene-like 2D nanosheets [168], making it more competitive as a MMM filler compared to other 2D materials. Tian et al. [169] reported significant permeability increases $\left(\mathrm{CO}_{2}\right.$ by $70 \%, \mathrm{CH}_{4}$ by $120 \%, \mathrm{H}_{2}$ by $98 \%$ and $\mathrm{N}_{2}$ by $\left.139 \%\right)$ for as-cast membranes of PIM-1 with 1 wt.\% $\mathrm{g}-\mathrm{C}_{3} \mathrm{~N}_{4}$, while methanol-treated membranes showed a lower or only comparative improvement. The 1 wt. $\%$ g- $\mathrm{C}_{3} \mathrm{~N}_{4}$ addition also increased the membrane FFV by $10 \%$ in the interface region between PIM-1 matrix and $\mathrm{g}-\mathrm{C}_{3} \mathrm{~N}_{4}$ nanosheets. In durability and aging tests, the MMM showed lower $\mathrm{CO}_{2}$ permeability reduction by $9 \%$ in the 200 day test period compared to the neat PIM-1. This is believed to be contributed by the strong restriction on conformational freedom caused by the rigid g$\mathrm{C}_{3} \mathrm{~N}_{4}$ on the PIM-1 backbone.

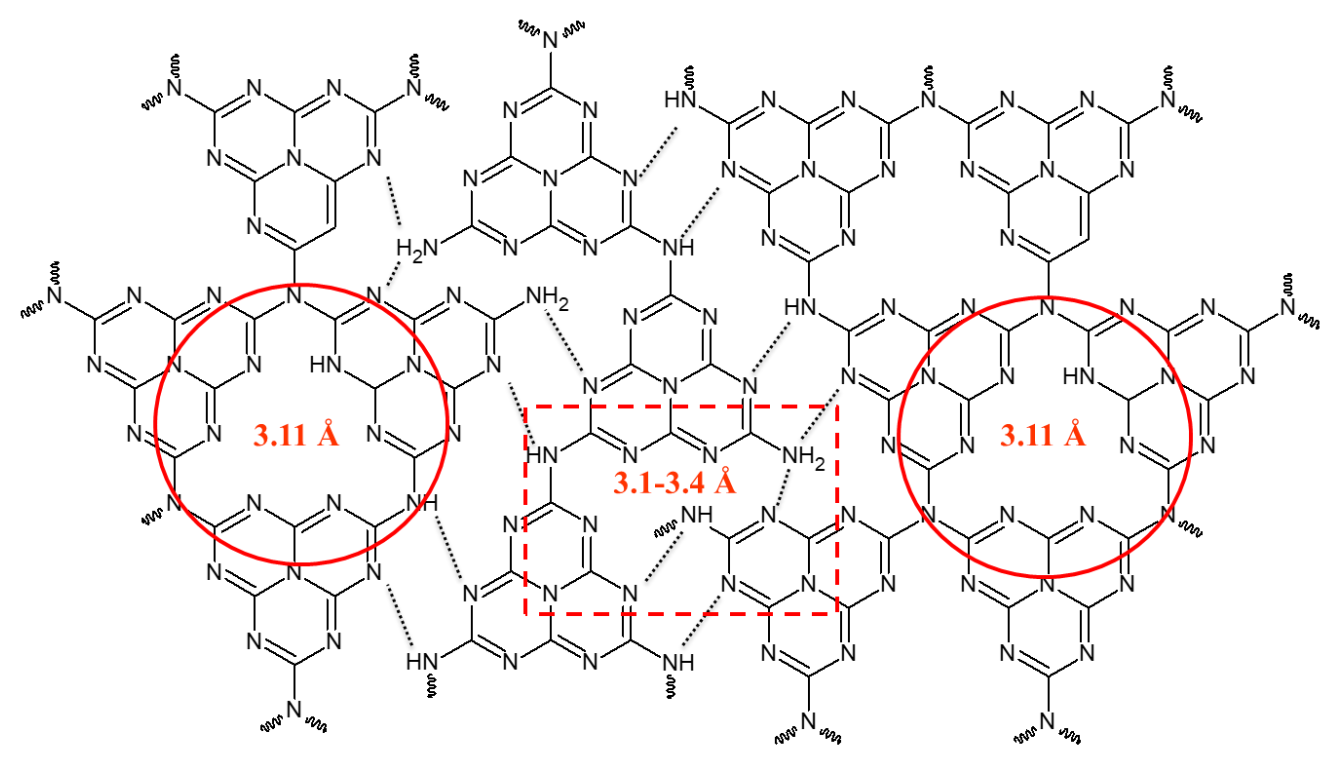

Figure 19: Illustration of graphene carbon nitride $\left(\mathrm{g}-\mathrm{C}_{3} \mathrm{~N}_{4}\right)$ with triangular ultramicropores (circled) and its structural defects (rectangle). This figure has been adapted from ref. [169] with permission from Elsevier, copyright 2016.

\subsection{PIM-1 with inorganic fillers}

The separation of gases in non-porous polymeric membranes is based on the solution-diffusion mechanism $[6,170]$. The difference in the final gas permeability results not only from diffusivity (mobility) differences of the gas species, but also from differences in physicochemical interactions of these species with the polymer [33]. The addition of inorganic molecular sieve fillers (e.g., sieving property of zeolites and CMS) is another obvious option, because of their excellent diffusivity selectivities, which are usually higher than polymeric materials [9]. The accurate size and shape discrimination resulting from the narrow pore distribution ensures superior selectivity, and the surface modification or functionalization often will improve the physicochemical interactions between the materials and the separating molecules.

A study has been reported of MMMs of PIM-1 with the hydrophobic pure silica zeolite silicate-1, functionalized with 2-phenylethyl groups, with crystal size $350 \mathrm{~nm}$ [171]. The 2-phenylethyl 
functionalization improved not only the hydrophobicity but also its compatibility with PIM-1, where no pore plugging was observed. Commonly when preparing zeolite-filled membranes, one tends to produce a three-phase membrane as a result of zeolite pore plugging (also referred to as "sieve in a cage morphology" due to poor interface adhesion between the two matrixes $[60,99])$, causing loss of permeability. In terms of gas separation, the MMM with 35.5 vol.\% silicalite- $1\left(\mathrm{CH}_{2}\right)_{2} \mathrm{Ph}$ (coded as PIMMFI3) presented an improved $\alpha_{\mathrm{O} 2 / \mathrm{N} 2}$ and $\alpha_{\mathrm{CO} 2 / \mathrm{N} 2}$ of $31 \%$ and $25 \%$, respectively $\left(P_{\mathrm{CO} 2}=2,530 ; P_{\mathrm{O} 2}=351\right.$ Barrer; $\left.\alpha_{\mathrm{O} 2 / \mathrm{N} 2}=4.2 ; \alpha_{\mathrm{CO} 2 / \mathrm{N} 2}=14.5\right)$. The pristine PIM-1 permeated 580 and 4,390 Barrer of $\mathrm{O}_{2}$ and $\mathrm{CO}_{2}$, respectively, with $\alpha_{\mathrm{O} 2 / \mathrm{N} 2}$ of 3.2 and $\alpha_{\mathrm{CO} / \mathrm{N} 2}$ of 24 .

Ahn et al. [50] incorporated the commercial pyrogenic fumed silica nanoparticles, Cabosil TS 530 with average equivalent spherical particle diameter $(d)$ of $11.1-13.3 \mathrm{~nm}\left(A_{\mathrm{BET}}=205-245 \mathrm{~m}^{2} \cdot \mathrm{g}^{-1}\right)$ into PIM-1 $\left(M_{\mathrm{w}}=100,000 \mathrm{~g} \cdot \mathrm{mol}^{-1} ; Ð=2.9\right)$. The authors studied several fumed silica loadings, of between 7-24 vol.\% and recorded a steady, continuous permeability increase with loading percentage, achieving more than $100 \% P_{\mathrm{CO} 2}$ and $P_{\mathrm{O} 2}$ increases at 19 vol. $\%$ fumed silica (pristine PIM-1, $P_{\mathrm{CO} 2}=6,000 ; P_{\mathrm{O} 2}=$ 1,$\left.340 ; \alpha_{\mathrm{CO} 2 / \mathrm{N} 2}=15.0 ; \alpha_{\mathrm{O} 2 / \mathrm{N} 2}=3.3\right)$. Unfortunately, the MMMs lost their $\alpha_{\mathrm{CO} 2 / \mathrm{N} 2}$ selectivity by at least $50 \%$ at the said loading. In another study, Khan et al. [172] utilized potassium dodecahydrododecaborate $\left(\mathrm{K}_{2} \mathrm{~B}_{12} \mathrm{H}_{12}\right)$, a type of boron icosahedron $\left(\mathrm{B}_{n} \mathrm{H}_{n}{ }^{2-}\right)$ which is highly temperature stable up to $700{ }^{\circ} \mathrm{C}$, incorporated in PIM-1 (pristine PIM-1, $P_{\mathrm{CO} 2}=9,896 ; \alpha_{\mathrm{CO} 2 / \mathrm{N} 2}=20.5 ; \alpha_{\mathrm{CO} / \mathrm{CH} 4}=12.5$ ) between 2.5-20 wt.\%. PIM-1/K $\mathrm{K}_{2} \mathrm{~B}_{12} \mathrm{H}_{12} 10$ wt.\% MMM showed the best performing membrane with $P_{\mathrm{CO} 2}=12,954$, translating into $31 \%$ improvement in permeability with slight selectivity $\left(\alpha_{\mathrm{CO} / \mathrm{N} 2}\right.$ and $\left.\alpha_{\mathrm{CO} / \mathrm{CH} 4}\right)$ reductions. From their SEM cross-section images, the PIM-1/ $\mathrm{K}_{2} \mathrm{~B}_{12} \mathrm{H}_{12} \mathrm{MMMs}$ only showed good filler dispersion up to $10 \mathrm{wt} . \%$, and at higher loadings the defective morphologies negatively affected the perm-selectivity.

\subsection{PIM-1 with other fillers}

As discussed previously, the use of isotropic bulk crystals (MOFs, zeolites, etc.) often leads to a 'weak and problematic' interface between the filler and the polymer matrix. One way to improve this performance-limiting phenomenon is to use organic-based fillers with abundant functional groups for optimum filler-polymer compatibility [173-175]. In contrast to the inorganic-organic hybrid MOFs, the lightweight organic-based fillers such as organic cage molecules, porous organic frameworks (POFs), covalent organic frameworks (COFs) and porous aromatic frameworks (PAFs) offer better potential in achieving the ideal MMM morphology.

Additionally, fillers with high aspect ratios, such as 2D COFs and GO [145], as previously discussed, are also preferred in order to achieve high filler-polymer contact areas.

\subsubsection{Polyhedral oligomeric silsesquioxanes (POSS)}

A polyhedral oligomeric silsesquioxane (POSS) is a very interesting silica-based material and is often termed a 'molicle' as the smallest possible silica particle to exist. Conceptually, it is described as 
a three-dimensional 'cage-shaped' molecule composed of a silicon-oxygen (silica-like) core, surrounded by a shell of organic groups $[176,177]$. This unique combination benefits from both the rigidity of an inorganic particle and the solubility of organic molecules [176]. A POSS is a silica core cage with the formula $\mathrm{R}_{n}\left(\mathrm{SiO}_{1.5}\right)_{n}(n \geq 6)$, where $n$ is the number of silica atoms, and it has chemically stable organic substituents R (e.g., methyl, vinyl, aryl, alkylene, aryl arylene, H) at the edges, making it a structure with an abundance of organic functional groups. The inherent substituents directly make POSS highly compatible with a polymer, suitable for MMM fabrication. The material also gains attention due to its low cost, variation in structural and property tuning, and the capability of producing large areas of flexible thin films [178]. This material has demonstrated its advantages for several membrane separation applications, including natural gas separation.

Yong et al. [179] investigated the use of disilanol isobutyl (SO1440) POSS ( $d$-spacing of $12.5 \AA$, equivalent to an inter-planar spacing of $1.18 \mathrm{~nm}$; see Figure 20(a)) with PIM-1 $\left(M_{\mathrm{w}}=52,400 \mathrm{~g} \cdot \mathrm{mol}^{-1} ; \doteq\right.$ = 1.4). They reported $\mathrm{CO}_{2}, \mathrm{O}_{2}, \mathrm{~N}_{2}, \mathrm{CH}_{4}$ permeability increments of between $62-86 \%$ with only 0.5 wt.\% POSS loading, at the expense of selectivity. However, MMMs with 2 wt.\% POSS presented the optimum PIM-1/POSS combination, where the $\mathrm{CO}_{2} / \mathrm{CH}_{4}$ and $\mathrm{O}_{2} / \mathrm{N}_{2}$ selectivity was improved by $11 \%$ and $5 \%$, with a lower gas permeability improvement of between $28-41 \%$. Greater selectivity improvements were achieved with $>5 \mathrm{wt}$.\% POSS loading, but regrettably the gas permeability was reduced significantly as well (68-77\%), indicating the classic case of polymer chain rigidification upon filler addition at higher than the optimum loading [174,179], and also probably due to filler partial agglomeration and stacking which impedes the gas diffusion [169,174]. The PIM-1/POSS (98:2) also showed no $\mathrm{CO}_{2}$-induced plasticization for measurements at 15 atm up to 30 atm with $50: 50 \mathrm{CO}_{2}: \mathrm{CH}_{4}$ binary mixture at $25^{\circ} \mathrm{C}$, while exhibiting less aging effect by $12 \%$ compared to the neat PIM-1 in the testing duration of 120 days. At the end of their aging study, the MMM lost $37 \% P_{\mathrm{CO} 2}$ while gaining $19 \%$ and $53 \%$ of $\alpha_{\mathrm{CO} 2 / \mathrm{N} 2}$

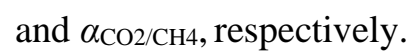

Similarly, Konnertz et al. [174] utilized only 1 wt.\% of a higher density phenethyl POSS, with silica core diameter of $5 \AA$ and outer shell diameter of 10-12 $\AA$ (see Figure 20(b)). The addition distinctly improved the $P_{\mathrm{CO} 2}$ of PIM-1 $\left(M_{\mathrm{w}}=82,800 \mathrm{~g} \cdot \mathrm{mol}^{-1}\right.$; neat $P_{\mathrm{CO} 2}=1112$ Barrer $)$ by $343 \%$, tested at a feed pressure of $\sim 2$ bar and $35{ }^{\circ} \mathrm{C}$. Even though the PIM-1/Phe-POSS $1 \mathrm{wt} . \% \mathrm{MMM}$ failed to show $\alpha_{\mathrm{CO} / \mathrm{CH} 4}$ improvement (neat $\alpha_{\mathrm{CO} 2 / \mathrm{CH} 4}=\sim 10$ ), the membrane showed excellent suppression of $\mathrm{CO}_{2}$-induced plasticization of PIM-1 ( 10 bar) and exhibited continuous $\mathrm{CO}_{2}$ permeability reduction (dual-mode sorption behaviour $[130,180])$ up to 20 bar.

However, often the lack of an interphase interaction between POSS and PIM-1 has also been a challenge and deters the researchers from achieving the ideal improvement of a MMM [60]. One way to improve the miscibility is by further functionalization of the POSS, which inherently possesses several oxygen-containing functional groups, with more hydrophilic and bulkier substituents. Kinoshita et al. [181] demonstrated an improved homogenous distribution of octa-phenyl POSS (OPS), constituted of a silica core diameter of $4.7 \AA$ with the outer shell diameter of $10.8 \AA$ (see Figure 20(c)). OPS was 
further functionalized into octa-nitrophenyl POSS (ONPS) through a nitration reaction and octa-amino phenyl POSS (OAPS), obtained from further hydrogenation of ONPS, in PIM-1 ( $M_{\mathrm{w}}=110,000 \mathrm{Da} ; \nexists$ $=2.1$ ).

a)

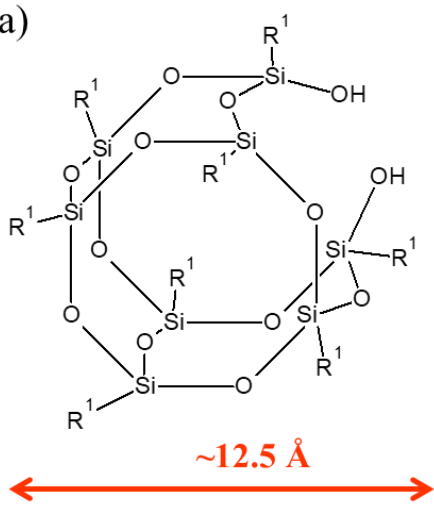

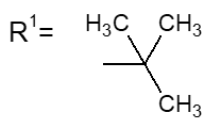

b)

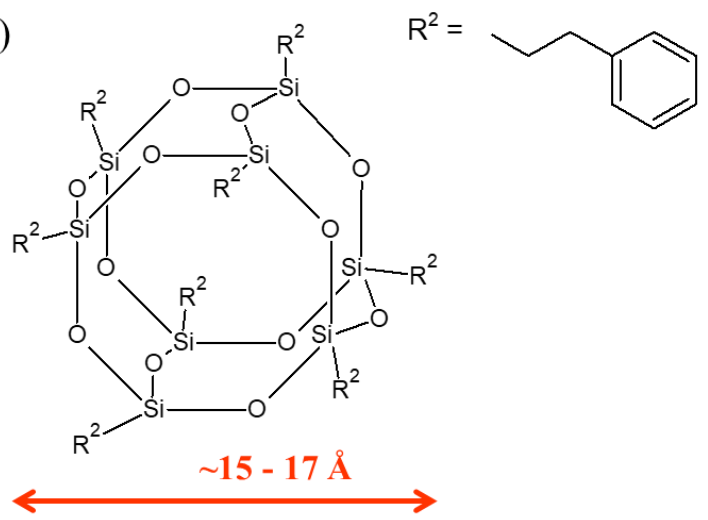

c)

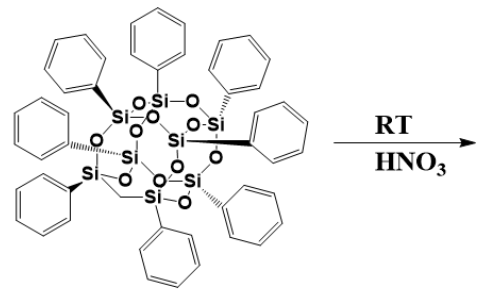

OPS

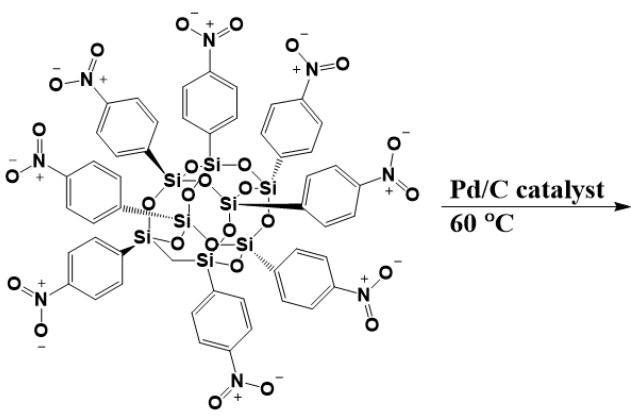

ONPS

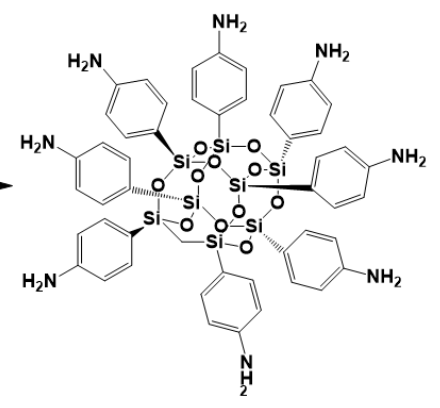

OAPS

Figure 20: The illustration of (a) disilanol isobutyl (SO1440) POSS where $\mathrm{R}^{1}=i$-butyl, (b) phenethyl-POSS (Phe-POSS) where $\mathrm{R}^{2}=$ phenethyl and (c) octa-phenyl POSS (OPS) and its modification into octa nitrophenyl POSS (ONPS) and further hydrogenation into octa amino-phenyl POSS (OAPS).

In their cross-section SEM images (see Figure 21), the OPS-MMMs showed considerable OPS agglomeration, whereas the ONPS-MMMs displayed an improved particle distribution and enhanced interface interaction (Figure 21(b-c)). The best filler-polymer compatibility was achieved with OAPS particles, consisting of an abundance of amino-terminated groups. The images show a very distinctive stretched crater-like morphology typical for the MMMs, and the eye of each crater is formed by the added particle. The concentric cavities in the MMMs indicate a strong interaction between the polymer and the particles [95,182], resulting in the elongated matrix around the particles due to the interfacial stress concentrations as a result of particle-matrix delamination [183]. This good physical condition also well correlated to their gas separation properties, where the neat PIM-1 performances $\left(P_{\mathrm{H} 2}=2,504 ; P_{\mathrm{CO} 2}\right.$ $=4,087 ; P_{\mathrm{O} 2}=966$ Barrer; $\left.\alpha_{\mathrm{O} 2 / \mathrm{N} 2}=3.8 ; \alpha_{\mathrm{CO} 2 / \mathrm{N} 2}=16.0 ; \alpha_{\mathrm{CO} 2 / \mathrm{CH} 4}=12.2 ; \alpha_{\mathrm{H} 2 / \mathrm{N} 2}=9.8\right)$ were greatly improved. At the highest loading of $20 \mathrm{wt} \%$, ONPS-MMMs showed 11\%, 31\% and 34\% improvement, respectively, for $\alpha_{\mathrm{O} 2 / \mathrm{N} 2}, \alpha_{\mathrm{CO} 2 / \mathrm{N} 2}$, and $\alpha_{\mathrm{CO} / \mathrm{CH} 4}$. Moreover, the OAPS-MMMs (up to $10 \mathrm{wt} \%$ loading) showed outstanding selectivity enhancements $85-120 \%$ for $\mathrm{O}_{2} / \mathrm{N}_{2}, \mathrm{CO}_{2} / \mathrm{N}_{2}$, and $\mathrm{CO}_{2} / \mathrm{CH}_{4}$ gas pairs, and 
even higher improvements for $\mathrm{H}_{2} / \mathrm{N}_{2}(470 \%)$ and $\mathrm{H}_{2} / \mathrm{CH}_{4}(575 \%)$. At the highest loading of $20 \mathrm{wt} \%$, the selectivity improvements are even higher, unfortunately the $P_{\mathrm{CO} 2}$ loss is at $98 \%$. However, for the non-functionalized OPS, besides increasing the gas permeability, the addition failed to improve any selectivity. Even at the lowest loading of $5 \mathrm{wt} . \%$, the aging test of both thick- and thin-film MMMs (200 $\mathrm{nm}-70 \mu \mathrm{m})$ showed around 50\% slower aging rate compared to the neat PIM-1 ( 55\% $\mathrm{P}_{\mathrm{CO} 2}$ and $~ 70 \%$ $P_{\mathrm{N} 2}$ reduction in 90 days). This was attributed to the uniform and nano-metric filler distribution in the polymer matrix, which increases its rigidity and consequently lowers the rate of polymer free volume collapse. Both $\mathrm{CO}_{2} / \mathrm{N}_{2}$ and $\mathrm{CO}_{2} / \mathrm{CH}_{4}$ selectivities in MMM were improved by $30-32 \%$.

Yang et al. [184] anchored the POSS with PEG, also aiming to increase the filler's $\mathrm{CO}_{2}$-philic property. Assessment with static water contact angle (CA) proved that the hydrophilicity of the MMMs increased with increasing PEG content in PIM-1. The authors later incorporated 1 to $10 \mathrm{wt} . \%$ of PEGPOSS into PIM-1 $\left(M_{\mathrm{w}}=118,000 \mathrm{~g} \cdot \mathrm{mol}^{-1} ; D=2.5\right)$, where the neat membrane performances are as follows: $P_{\mathrm{CO} 2}=3,795$ Barrer, $\alpha_{\mathrm{CO} / \mathrm{CH} 4}=12$, and $\alpha_{\mathrm{CO} 2 / \mathrm{N} 2}=19$. As expected from POSS addition when the filler matrix is in a random tortuous pattern and displaying a 'barrier effect'; the $P_{\mathrm{CO} 2}$ was decreased by $\pm 11 \%$ with $1-2$ wt.\% PEG-POSS, while increasing the $\alpha_{\mathrm{CO} 2 / \mathrm{CH} 4}$ and $\alpha_{\mathrm{CO} 2 / \mathrm{N} 2}$ between $8-33 \%$ and $5-16 \%$, respectively. At higher loadings (5 and $10 \mathrm{wt} . \%$ ), the PEG-POSS/PIM-1 membranes lost their $P_{\mathrm{CO} 2}$ tremendously, up to 51-66\%, which can be speculated to be because PEG-POSS has a rigidification effect on the bulk polymer. Nevertheless, the selectivities were increased by $75-150 \%$ and $37-63 \%$ for $\alpha_{\mathrm{CO} / \mathrm{CH} 4}$ and $\alpha_{\mathrm{CO} 2 / \mathrm{N} 2}$, respectively, allowing them to surpass the $\mathrm{CO}_{2} / \mathrm{CH}_{4} 2008$ Robeson upper bound. The 10 wt.\% PEG-POSS/PIM-1 were subjected to accelerated aging tests by treating in vacuum for 12 $\mathrm{h}$ at $60{ }^{\circ} \mathrm{C}$ in each cycle to remove the adsorbed gas and stored in a sealed condition, measured at 2 and 12 bar ( 9 cycles in 30 days). The MMMs showed at least $20-25 \% P_{\mathrm{CO} 2}$ reduction, whereas the neat PIM1 displayed a reduction of up to 50\%. The study demonstrated that the physical aging results of PIM-1 were reduced by embedding the POSS base nanoparticles, possibly due to the polymer matrix rigidification. 

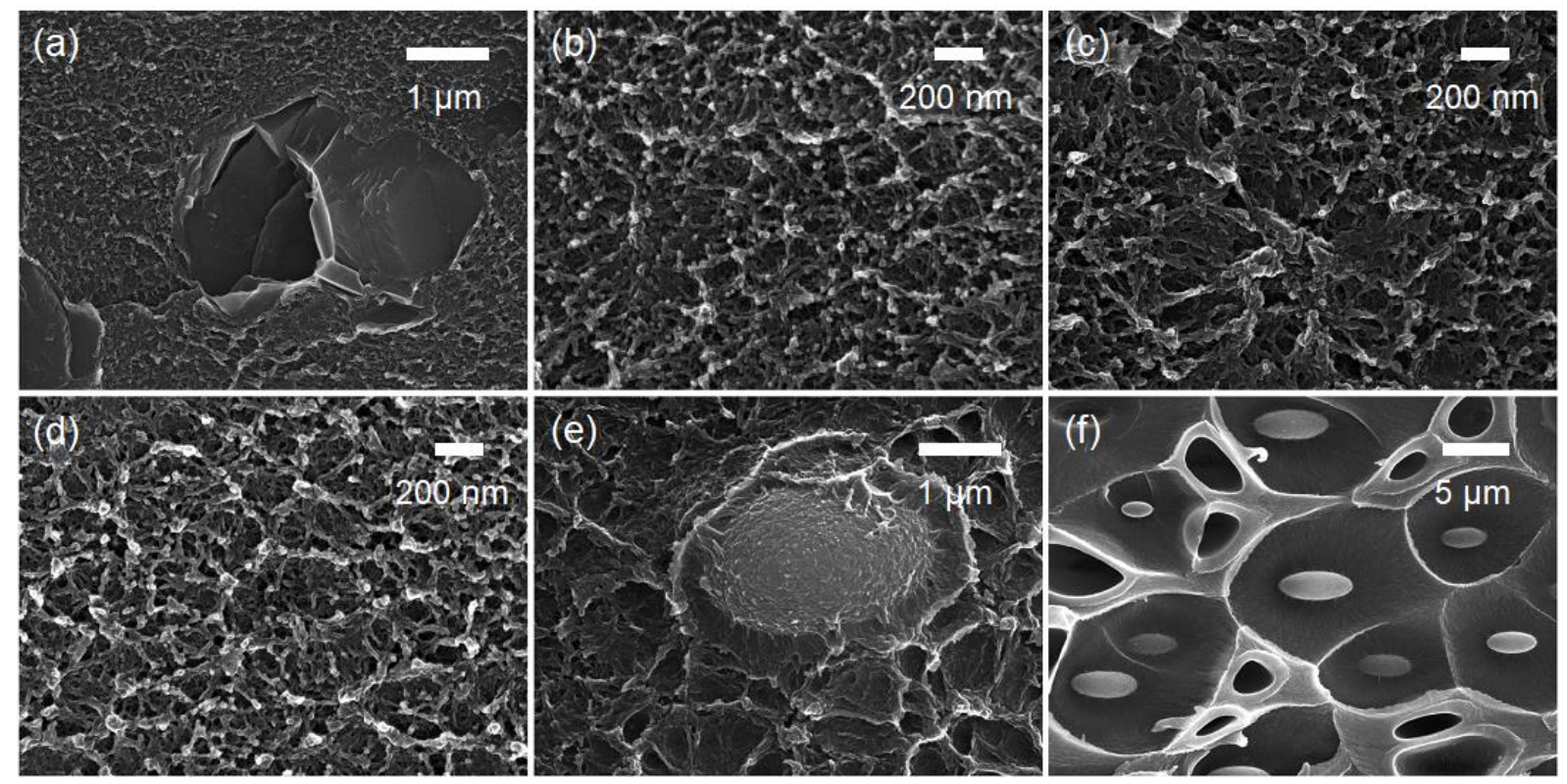

Figure 21: Cross-section SEM images of PIM-1/POSS containing (a) OPS, (b) ONPS, (c) ONPS, (d) OAPS, (e)

OAPS, (f) OAPS, between 5 - 20 wt.\% loadings. This figure has been reproduced from ref. [181] with permission from Elsevier, copyright 2017.

\subsubsection{Organic cage molecules}

Bushell et al. [185] exploited the intrinsic nature of a porous organic cage molecule which can crystallise in-situ while a membrane forms by slow evaporation from a single, homogenous, molecular solution of the cages and polymer. The porous imine cage $\mathrm{CC} 3$ has triangular windows with an effective diameter of $6 \AA$ and is prepared through a condensation reaction (Figure 22(a)). In-situ crystallization of CC3 gave relatively large crystals, 5-10 $\mu \mathrm{m}$, in a PIM-1 membrane (Figure 22(b)). A comparison was made with CC3 nanocrystals, about $90 \mathrm{~nm}$ in size, which was prepared as a racemate of low solubility and dispersed in the membrane casting mixture. A further comparison was made with redCC3, for which reduction of CC3's 12 imine linkages with sodium borohydride transformed the material into a less rigid dodecaamine molecule that does not give a solid with permanent porosity. 
a)

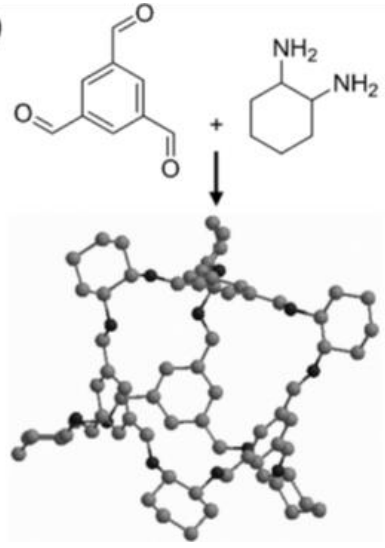

b)

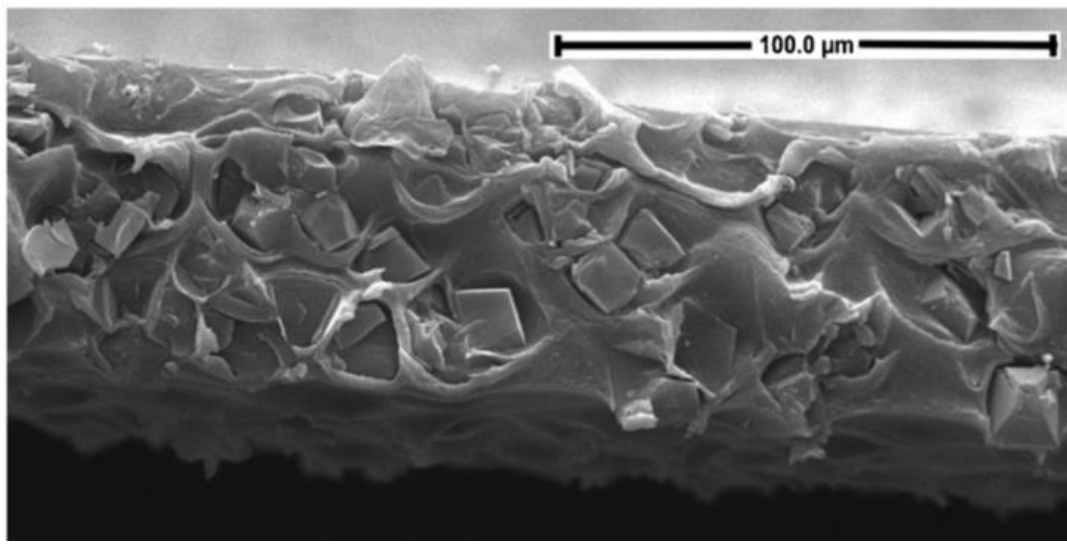

Figure 22: Illustration of (a) porous imine cage CC3 synthesized from a condensation reaction and (b) SEM image of a cross-section of a PIM-1/CC3 $20 \mathrm{wt}$ \% composite membrane. This figure has been reproduced from ref. [185] with permission from John Wiley \& Sons, copyright 2013.

For in-situ crystallised CC3 in PIM-1 $\left(P_{\mathrm{CO} 2}=2,790 ; P_{\mathrm{O} 2}=510\right.$ Barrer; $\left.\alpha_{\mathrm{CO} 2 / \mathrm{N} 2}=23.3 ; \alpha_{\mathrm{O} 2 / \mathrm{N} 2}=4.3\right)$, the $P_{\mathrm{CO} 2}$ were increased proportionally to the $10-30 \mathrm{wt}$ \% loadings, reaching up to 5,430 Barrer, while maintaining its $\alpha_{\mathrm{CO} 2 / \mathrm{N} 2}$ between 20-22. However, a different trend was observed in $\mathrm{O}_{2} / \mathrm{N}_{2}$, where the selectivity decreases (down to 3.0) due to the steady permeability increase of both of the non-polar gases with loading. Similarly to the MMMs with in-situ crystallised CC3, nanoCC3 (20-30 wt.\%) also increases the gas permeability (up to 9,730 Barrer for $\mathrm{CO}_{2}$ and 980 Barrer for $\mathrm{O}_{2}$ ), at the expenses of gas selectivity. In contrast, redCC3 at loadings between 10-20 wt.\% managed to slightly increase or maintain the $\alpha_{\mathrm{CO} / \mathrm{N} 2}$ at $23-24$ and $\alpha_{\mathrm{O} 2 / \mathrm{N} 2}$ at 3.7-3.8, with reduced but still substantial gas permeability values $\left(P_{\mathrm{CO} 2}=780-1,480 ; P_{\mathrm{O} 2}=120-240\right.$ Barrer $)$. In their aging test for ethanol-rejuvenated MMMs over a period of 400 days, the authors concluded that the aging phenomenon still occurred and reflected the PIM-1 dominant behaviour as the primary phase, showing significant permeability loss (60-68\%) in the first 300 days. In the latter $\sim 100$ days, the permeability reductions were lower, in the range of 8 $21 \%$, reaching to a near-plateau permeation trend.

\subsubsection{Triptycene-based porous organic polymer (POP)}

Despite the reported successes of MMMs for gas separation enhancement, in many cases complex behaviour of the polymer-filler interface is encountered. A new class of porous organic polymers (POPs) was recently introduced. It is said to have superior compatibility with the polymer to form MMMs, owing to its extended aromatic chains that offer great affinity to the polymer matrix through the formation of $\pi-\pi$ aromatic group stacking. Wang et al. [173] presented the use of high porosity amine-containing rigid 3D triptycene based POP (TP-FC) with an average surface area of $1,235 \mathrm{~m}^{2} \cdot \mathrm{g}^{-1}$ and $\mathrm{CO}_{2}$ adsorption capacity of $3.78 \mathrm{mmol} \cdot \mathrm{g}^{-1}$ into PIM-1. Also included are its two different amine post-modification TP-FC, referred to as TP-FC- $\mathrm{CH}_{2} \mathrm{NH}_{2}$ (surface area of $1,083 \mathrm{~m}^{2} \cdot \mathrm{g}^{-1}, \mathrm{CO}_{2}$ adsorption of $4.87 \mathrm{mmol} \cdot \mathrm{g}^{-1}$ ) and TP-FC-CH $2 \mathrm{PEI}$ (surface area of $59 \mathrm{~m}^{2} \cdot \mathrm{g}^{-1}, \mathrm{CO}_{2}$ adsorption of $2.91 \mathrm{mmol} \cdot \mathrm{g}^{-1}$ ). All the particles are in a size range of $100-200 \mathrm{~nm}$ and the synthesis route is indicated in Figure 23(a). 
Their addition into PIM-1 $\left(P_{\mathrm{CO} 2}=3,060\right.$ Barrer; $\left.\alpha_{\mathrm{CO} 2 / \mathrm{N} 2}=18.0 ; \alpha_{\mathrm{CO} 2 / \mathrm{CH} 4}=16.3\right)$ at particle loadings of 5 -20 wt.\% increases its $\mathrm{CO}_{2}$ permeability to between $\sim 3,160-6,230$ Barrer with TP-FC, $~ 5,920-9,670$ Barrer with TP-FC-CH${ }_{2} \mathrm{NH}_{2}$ and $~ 3,560-6,240$ Barrer with TP-FC-CH${ }_{2}$ PEI. In their Density Functional Theory (DFT) analysis to understand PIM-1 compatibility to the TP-FCs, the authors reported that the dihedral angle and the distance between two closed planes of TP-FC and PIM-1 were $23.1 \AA$ and $3.4 \AA$, indicating a definite presence of interfacial voids, leading to the significant increase of gas permeability. Conversely, in PIM-1/TP-FC- $\mathrm{CH}_{2} \mathrm{NH}_{2}$ MMM, it was revealed that the distances for parallel planes are only $3.8 \AA$ and $3.2 \AA$, indicating no presence of interfacial voids.

a)

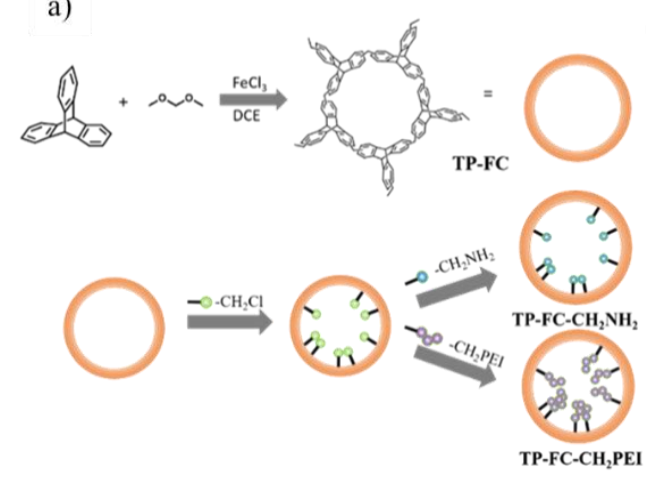

b)

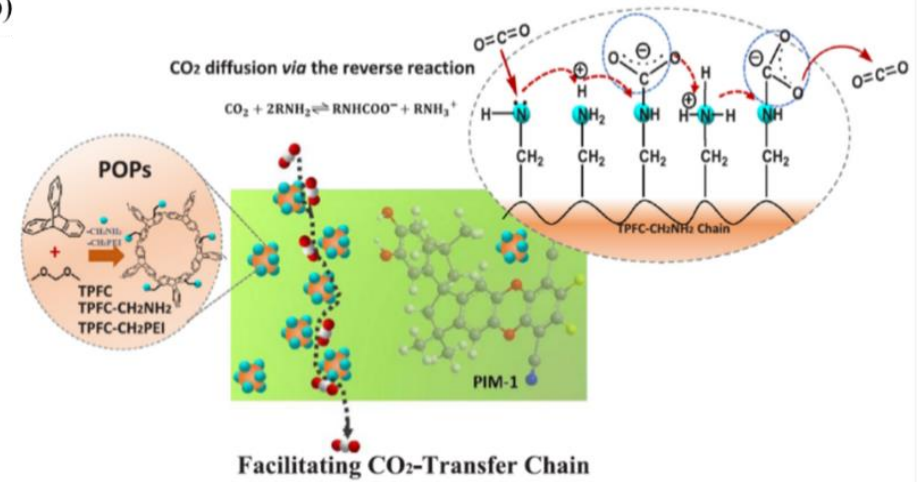

Figure 23: (a) Synthesis route of TP-FC, TP-FC- $\mathrm{CH}_{2} \mathrm{NH}_{2}$, and TP-FC-CH $2 \mathrm{PEI}$, (b) schematic illustration of $\mathrm{CO}_{2}$ facilitated transfer chain mechanism for enhancing $\mathrm{CO}_{2}$ permeability in PIM-1/TP-FC- $\mathrm{CH}_{2} \mathrm{NH}_{2}$ MMM. This figure has been reproduced from ref. [173] with permission from Elsevier, copyright 2018.

The TP-FC MMMs lost selectivity while gaining permeability proportionally to the amount of added filler, showing permeability-selectivity trade-off behaviour. Interestingly, TP-FC- $\mathrm{CH}_{2} \mathrm{NH}_{2} \mathrm{MMMs}$ showed the most significant increment, up to 45.9 and 36.4 for $\mathrm{CO}_{2} / \mathrm{N}_{2}$ and $\mathrm{CO}_{2} / \mathrm{CH}_{4}$, respectively, and lower increments were recorded for TP-FC-CH 2 PEI MMMs, up to 34.8 for $\mathrm{CO}_{2} / \mathrm{N}_{2}$ and 24.0 for $\mathrm{CO}_{2} / \mathrm{CH}_{4}$. The authors suggested a facilitated $\mathrm{CO}_{2}$-transfer chain mechanism in the MMMs (see Figure 23(b)), based on the extremely fast mobility of $\mathrm{H}^{+}$ions to perform proton-transfer. This mechanism could explain the increased gas permeation and selectivity in their functionalized-TP-FC MMMs. Their aging test was conducted on the highest performing TP-FC- $\mathrm{CH}_{2} \mathrm{NH}_{2} \mathrm{MMM}$ for 210 days and presented the lowest permeability loss of $22 \%$ for the MMM, while the pristine PIM-1 lost $\sim 55 \% \mathrm{CO}_{2}$ permeability in the period.

\subsubsection{Covalent organic frameworks (COFs)}

Very recently, the use of covalent organic frameworks (COFs), a sub-class of porous crystalline organic frameworks, has become a research hotspot. COFs are two- or three-dimensional purely organic solids linked by strong covalent bonds, composed of only light elements such as $\mathrm{H}, \mathrm{B}, \mathrm{C}, \mathrm{N}$, and $\mathrm{O}$, in an ordered network. The COF structured networks give the material extremely high specific surface area (i.e., 2D COF-1 $=711 \mathrm{~m}^{2} \cdot \mathrm{g}^{-1}$ [186], 2D COF-5 = 1,590 $\mathrm{m}^{2} \cdot \mathrm{g}^{-1}$ [187], 3D COF-105 $=6,450 \mathrm{~m}^{2} \cdot \mathrm{g}^{-1}$ [146] 
and 3D COF-108 $=6,280 \mathrm{~m}^{2} \cdot \mathrm{g}^{-1}[146]$ ) and high inherent nanoporosity (pore size $0.5-4.7 \mathrm{~nm}$ ). In a membrane, the thin separating layer provides exceptional rejection while maintaining high flux, simultaneously mitigating the trade-off relationship between permeability and selectivity [146]. Their designable porous structures (pore diameter and functional groups) are achievable through the reaction of suitable monomers under specific synthesis methodologies, often under harsh conditions (high temperature and pressure, with high boiling point solvent and catalyst in an inert gas protection [146]). The covalent combination causes the COFs to be thermally and chemically stable. Furthermore, the materials can form homogenous and stable suspensions in several organic solvents (DMF, $\mathrm{CHCl}_{3}, \mathrm{NMP}$, etc.), of assistance to avoid the formation of filler agglomeration and non-ideal MMM interface morphologies which negatively affect the membrane performance.

The use of COFs has been shown to give positive impacts in $\mathrm{CO}_{2} / \mathrm{CH}_{4}$ and $\mathrm{CO}_{2} / \mathrm{N}_{2}$ separation, as demonstrated in both conventional (i.e., ACOF-1 in Matrimid ${ }^{\circledR}$ [188], TpBD in PBI [189]) and high microporosity polymers (i.e., TCPP in Pebax ${ }^{\circledR}$ [190]). Meanwhile in PIM-1, Wu et al. [191] reported the incorporation of Schiff base network, SNW-1 (BET surface area $=780 \mathrm{~m}^{2 \cdot} \mathrm{g}^{-1} ; \mathrm{CO}_{2} / \mathrm{CH}_{4}$ adsorption selectivity $=\sim 4.9)$ through physical blending in PIM-1 $\left(M_{\mathrm{w}}=120,000 \mathrm{~g} \cdot \mathrm{mol}^{-1}\right)$. The separation performance of PIM-1 (neat $P_{\mathrm{CO} 2}=3,672$ Barrer; $\alpha_{\mathrm{CO} 2 / \mathrm{CH} 4}=10.6 ; \alpha_{\mathrm{CO} 2 / \mathrm{CH} 4}=16.5$ ) was improved by $16 \%$ and $27 \%$, respectively, for $P_{\mathrm{CO} 2}$ and $\alpha_{\mathrm{CO} 2 / \mathrm{CH} 4}$ tested with pure gas at $2 \mathrm{bar}, 30{ }^{\circ} \mathrm{C}$, with the addition of 10

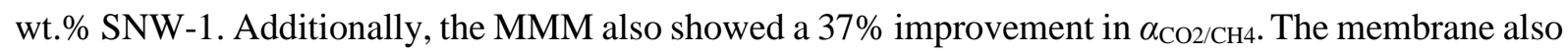
showed an increased fractional free volume (FFV) by $65 \%$, due to an extra $0.5 \mathrm{~nm}$ gas transport pathway, translated accordingly to the largely enhanced permeability.

\subsubsection{Porous aromatic framework (PAFs)}

A highly striking finding was reported by Lau et al. [192], where the authors described the use of a specific microporous porous aromatic framework (PAF), a sub-class of POFs, interwoven into several super-glassy polymers including PIM-1. They utilized the tetrakis(4-bromophenyl)-methane, selfcondensed by a Yamamoto coupling reaction to construct carbon-carbon-bond-linked aromatic-based microporous array building units (PAF-1; $A_{\mathrm{BET}}$ of $5,200 \mathrm{~m}^{2} \cdot \mathrm{g}^{-1}$, the average pore size of $12 \AA$ ). The abundance of PAF-1 brominated side groups is favoured and anticipated to intercalate with the polyacetylene side-chains and the bulky functional moieties of PIM-1, simultaneously freezing the polymer free-volume during aging. Upon addition into PIM-1 $\left(P_{\mathrm{CO} 2}=3,770\right.$ Barrer; $\left.\alpha_{\mathrm{CO} 2 / \mathrm{N} 2}=14.9\right)$, the $P_{\mathrm{CO} 2}$ was increased up to $320 \%\left(P_{\mathrm{CO} 2}=12,535\right.$ Barrer $)$ and lost its selectivity by $21 \%$, explained in relation to the increase of pore fraction by $32 \%$ in their PIM-1/PAF-1 MMMs, obtained from PALS analysis.

A crucial part of their finding is their aging data, where the PIM-1/PAF-1 MMM showed only 7\% $\mathrm{CO}_{2}$ permeability loss in 240 days. A slight reduction in $\mathrm{N}_{2}$ permeability also contributed to an insignificant hike in $\alpha_{\mathrm{CO} / \mathrm{N} 2}$. The authors also presented solid-state ${ }^{13} \mathrm{C}$ NMR and PALS results to assist our understanding of how PIM-1 behaves when it physically ages. From the carbon spin-lattice 
relaxation times $\left(T_{1}\right)$ in Figure 24(a), we understand that aged PIM-1/PAF-1 showed increases in the main chain and specific bulky group local packing densities, but indicated additional free volume in the vicinity of bulky $-\mathrm{CN}$ groups. PALS analysis further strengthens the effectiveness of PAF-1 in hindering the aging process where the pore diameter of the MMM was reduced insignificantly compared to considerable changes in as-cast and aged PIM-1 (see Figure 24(b)). It is noteworthy that this was also demonstrated to 'end' the aging behaviour in other super-glassy polymers, i.e., PTMSP, that showed a similar $\mathrm{CO}_{2}$ permeability loss of $7 \%$ in 240 days, and PMP, which presented a lower permeability loss of only $5 \%$ in the same period.
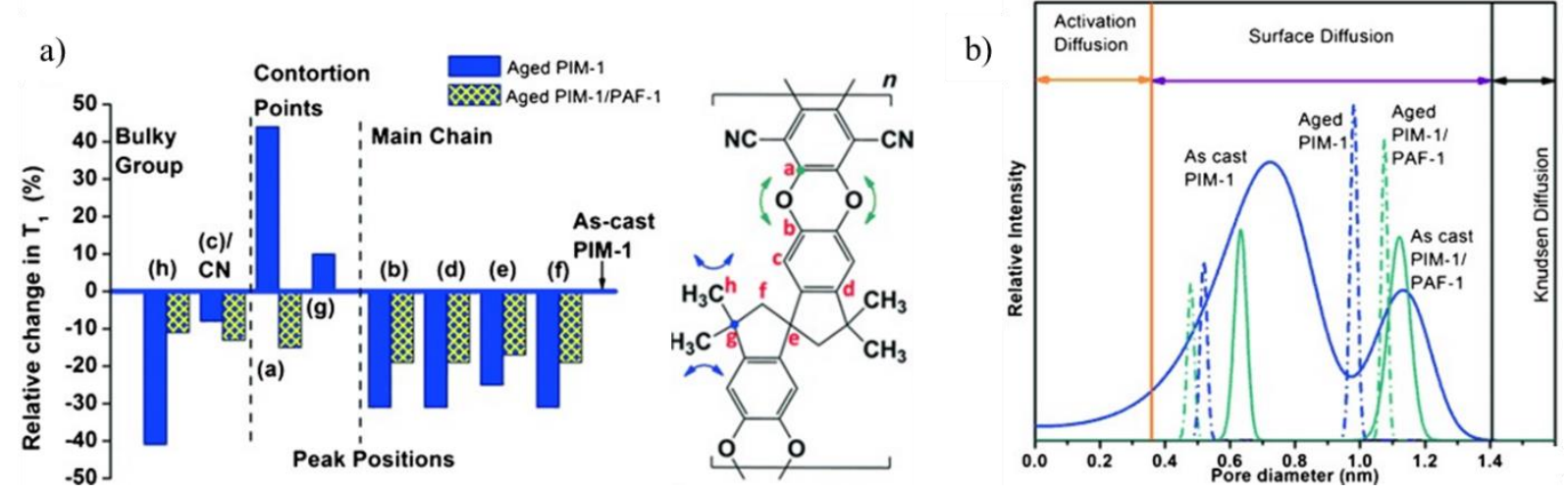

Figure 24: The results from (a) solid-state ${ }^{13} \mathrm{C}$ NMR and (b) PALS for as-cast and aged PIM-1/PAF-1 based membranes. This figure has been reproduced from ref. [192] with permission from John Wiley \& Sons, copyright 2014.

\subsubsection{Hypercrosslinked polymers (HCPs) and porous carbons}

When considering a filler for a MMM, researchers not only have to choose the filler type (size, morphology, property) intelligently for the intended separation purposes, but also consider a smarter preparation protocol or modification to produce a superior-performing MMM. A brilliant example is the use of a specially tailored porous carbon as a filler, intended to optimize its size-sieving ability. To boost the performance, Zhao et al. [193] made nitrogen-doped porous carbon (NDPC), synthesized using taskspecific ionic liquids containing nitrile functionalized imidazolium-based cations [194]. They successfully incorporated NDPC into PIM-1 membranes with 2 and 5 wt.\% filler loadings and annealed at $300{ }^{\circ} \mathrm{C}$. The $\mathrm{CO}_{2}$ permeability performances of PIM-1 $\left(P_{\mathrm{CO} 2}=3,402\right.$ Barrer; $\left.\alpha_{\mathrm{CO} 2 / \mathrm{N} 2}=16.1\right)$ were boosted by at least 8 -fold and 10-fold for 2 and 5 wt.\% NDPC/PIM-1, respectively. The basic Nfunctional sites in NPDC contribute to the overall $\mathrm{CO}_{2}$ permeation increase due to its greater affinity towards the gas, besides NPDC being a 'disruptive material' in the continuous polymer phase and creating a gas permeation path. The disruption intensifies the membrane free-volume and increases the gas diffusion rate, as observed in the loss of separation factor by $12 \%$ and $23 \%$, according to the loading content increment.

While most of the MMM studies to date have investigated 'thick' films (typically ca. 40-150 $\mu \mathrm{m}$ thickness) which usually show low flux due to their thickness, Bhavsar et al. [195] demonstrated the 
effectiveness of thin-film nanocomposite (TFN) membrane formation using a mixed matrix as the top selective layer. For the top layer, they incorporated carbonized hyper-crosslinked polystyrene polymers (c-HCPs), produced with a diameter of $c a .55 \mathrm{~nm}$ under a gentle $\mathrm{N}_{2}$ flow at $800{ }^{\circ} \mathrm{C}$, into PIM-1 $\left(M_{\mathrm{w}}=\right.$ $120,000 \mathrm{~g} \cdot \mathrm{mol}^{-1} ; Ð=3.1$ ). The $\mathrm{c}-\mathrm{HCPs}$ presented a high $\mathrm{CO}_{2}$ uptake of $4.95 \mathrm{mmol} \cdot \mathrm{g}^{-1}$, more than double that of the non-carbonized HCP counterpart $\left(1.98 \mathrm{mmol} \cdot \mathrm{g}^{-1}\right)$. The separation performance of pristine PIM-1 $\left(P_{\mathrm{CO} 2}=3,331\right.$ Barrer; $\left.\alpha_{\mathrm{CO} 2 / \mathrm{N} 2}=14.2\right)$ was proportionally increased with the loading, reaching up to $P_{\mathrm{CO} 2}=5,341$ Barrer at $10 \mathrm{wt} . \%$, at the expense of $15 \%$ of its selectivity. At higher c-HCP loadings (20-60 wt.\%), the MMMs showed the classic case of the formation of non-separating interface voids, losing $30-55 \%$ of the selectivity. This new approach of using a carbonized organic polymer as a nano filler at high loadings does not achieve the ideal improvement desired in a MMM. Nevertheless, they presented significant permeation values even after 90 days of aging (i.e., PIM-1/c-HCP $20 \mathrm{wt} . \%, P_{\mathrm{CO} 2}$ $=1,266$ Barrer; $\alpha_{\mathrm{CO} 2 / \mathrm{N} 2}=14.5 ;$ PIM-1/c-HCP 40 wt. $\%, P_{\mathrm{CO} 2}=2,800$ Barrer; $\alpha_{\mathrm{CO} 2 / \mathrm{N} 2}=13.5 ;$ PIM-1/cHCP 60 wt. $\%, \mathrm{P}_{\mathrm{CO} 2}=9,379$ Barrer; $\alpha_{\mathrm{CO} 2 / \mathrm{N} 2}=11.3$ ), which can be considered as good performing aged PIM-1 membranes.

\subsubsection{Network PIMs}

Arguably, the ideal filler for use in a MMM would be a network version of the same polymer as is used as the continuous phase. Tamaddondar et al. [196] presented a grafting route to decorate a lowcrosslink-density (LCD) network-PIM-1 for use as a dispersed phase in PIM-1. Two PIM-1 polymerizations ( $24 \mathrm{~h}$ and $72 \mathrm{~h}$ ) were conducted in the presence of LCD-network-PIM-1, which contains active fluoro- groups that readily react with TTSBI (5,5',6,6'-tetrahydroxy-3,3,3',3'-tetramethyl-1,10spirobisindane) monomer and thus facilitate the formation of PIM-1 chains attached to the network. The 24 h grafting route showed a higher $P_{\mathrm{CO} 2}$ of 12,510 Barrer $\left(\alpha_{\mathrm{CO} 2 / \mathrm{CH} 4}=11.9\right)$, well surpassing the 2008 upper bound [15], and markedly improved the pristine PIM-1 performance $\left(P_{\mathrm{CO} 2}=5,920\right.$ Barrer, $\alpha_{\mathrm{CO} 2 / \mathrm{CH} 4}$ $=13.1$ ). The membrane also showed only $29 \% P_{\mathrm{CO} 2}$ loss in the 160-day aging test, significantly reduced compared to almost $70 \%$ and $48 \%$ in pristine PIM- 1 and the traditionally fabricated MMM counterparts.

The same group further studied PIM-1 synthesis with a less reactive and cheaper monomer, tetrachloroterephthalonitrile (TCTPN), at modified polymerization temperatures of between $100-160$ ${ }^{\circ} \mathrm{C}$ [197], based on the previously reported 'high temperature' PIM synthesis methods [198,199]. They reported various structural differences in the obtained PIM-1s (cyclic, branched, tadpole, extended and network topologies) with different gas permeation properties, and demonstrated that network structures that behave as nanofillers may be formed during synthesis, leading to behaviour like that of a MMM. The overall study can be summarized as depicted in Figure 25.

The group also [200] used a highly crosslinked nanosheet form of network-PIM-1 as the filler in a more linear PIM-1. The authors demonstrated that the network-PIM-1 nanosheets $\left(A_{\mathrm{BET}}=940 \mathrm{~m}^{2} \cdot \mathrm{g}^{-1}\right)$, produced by using tetra-functional (octafluoro) monomer instead of the typical bi-functional (tetrafluoro) monomer, when incorporated into PIM-1 $\left(M_{\mathrm{w}}=158,000 \mathrm{~g} \cdot \mathrm{mol}^{-1} ; \doteq=3.0, A_{\mathrm{BET}}=780 \mathrm{~m}^{2} \cdot \mathrm{g}^{-}\right.$ 
$\left.{ }^{1}\right)$ positively changed the membrane performance. Pristine PIM-1 performance was recorded at $P_{\mathrm{CO} 2}=$ 5,917 Barrer and $\alpha_{\mathrm{CO} / \mathrm{CH} 4}=13.1$, residing on the $2008 \mathrm{CO}_{2} / \mathrm{CH}_{4}$ upper bound [15]. Best performance is recorded at a very low loading of $0.5 \mathrm{wt} . \%$, where the $\mathrm{MMM}$ showed $65 \%$ and $10 \%$ increase in $P_{\mathrm{CO} 2}$ and $\alpha_{\mathrm{CO} 2 / \mathrm{CH} 4}$, respectively. At higher loadings up to $10 \mathrm{wt} . \%$, the MMMs started to lose their permeability but gained selectivity, indicating a classic case of partial pore blockage or rigidification $[59,60]$. Similarly to the pristine membrane, the MMM lost ca. $80 \% P_{\mathrm{CO} 2}$ throughout seven months aging time, accompanied by an increase in selectivity, indicating that the tightly network PIM-1 addition as filler does not suppress the physical aging.

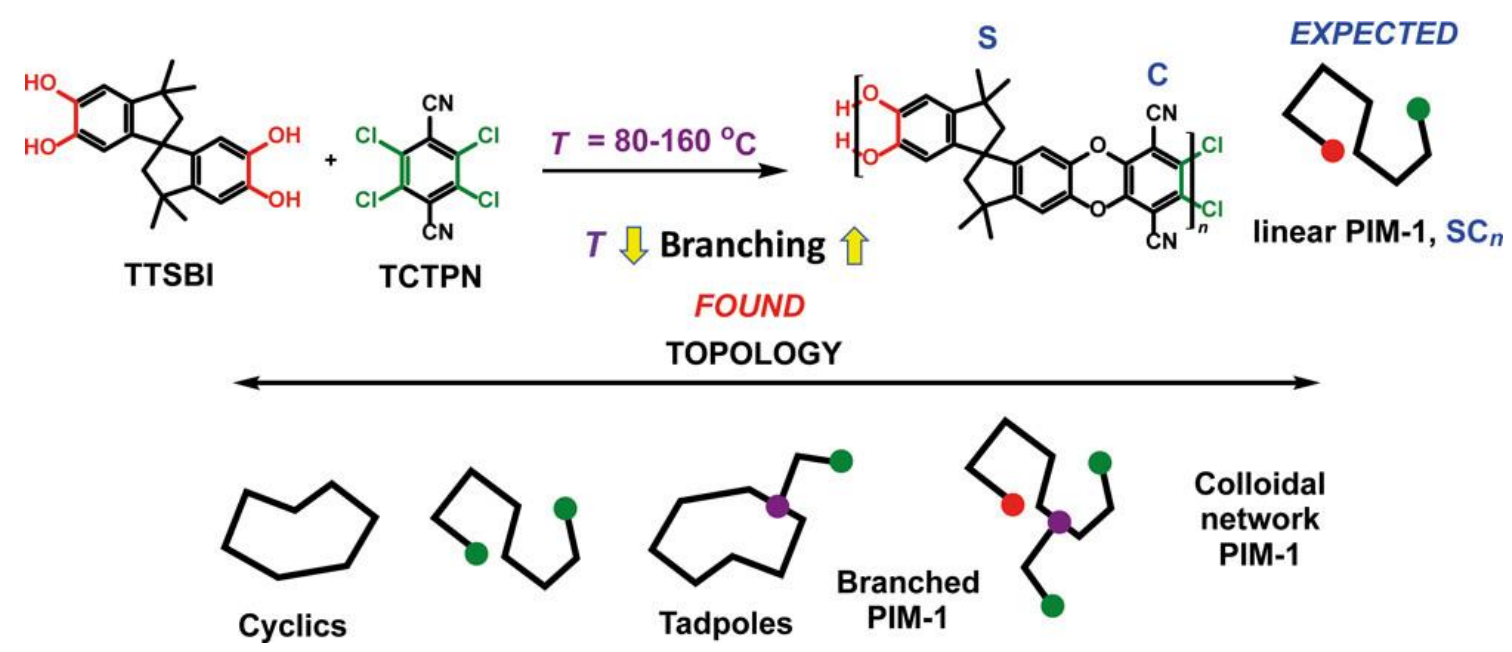

Figure 25: Modified PIM-1 synthesis approach using tetrachloro-functionalized monomer, at low- and hightemperature synthesis, obtaining PIM-1 with various topologies. This figure has been adapted from ref. [197] with permission from American Chemical Society, copyright 2020.

\section{MMM viewpoints}

\subsection{Separation performance}

The benefit of blending a nanomaterial with a polymer to form a MMM depends on the type of material employed and its intrinsic gas separation characteristics. The key aspect to achieving a positive effect is to ensure that an ideal MMM morphology is obtained, in all cases without the presence of interfacial defects in the interphase regions. The defect morphologies and their influences in a MMM were described thoroughly by Moore and Koros [60]. Figure 26 and Figure 27 summarise the separation improvement achieved in all the MMM systems discussed in this review, divided into Quadrant I (Case 0; ideal morphology and improvement of MMM), Quadrant II (Case 1; rigidification of polymer around the filler and Case 5; partial blockage of pores in filler), Quadrant III (a disastrous situation where there is a loss of both permeability and selectivity) and Quadrant IV (Case 3; voids at the interface of a sizecomparable to the penetrant species). Some MMMs lie at the boundary between Quadrants I and IV (Case 2: voids at the interface) or at the boundary between Quadrants II and III (Case 4: full blockage of pores in filler). MMM permeabilities vary in the order: Cases $2 \& 3>$ Case $0>$ neat polymer $>$ Case 
$1>$ Cases $4 \& 5$, whereas the selectivities are in the order: Cases $0 \& 1>$ Case $5>$ neat polymer and Cases $2 \& 5>$ Case 3 .

The aim is to have a MMM performing in Quadrant 1, where both permeability and selectivity are increased. Several as-synthesized MOFs (i.e., ZIF-67, MIL-101A, Azo-DMOF-1) and modified MOFs (i.e., $\mathrm{T}_{15}$-UiO-66, TSIL @ $\mathrm{NH}_{2}$-MIL-101), at their optimum loadings show the ideal and significant improvement, while the majority of discussed MOFs fail to improve the selectivity. Regardless of their tremendous permeability increment (contributed by the large MOF pore sizes), many MMMs lost their selectivity, translating into a loss of separation efficiency. When making MMMs with highly permeable polymers like PIM-1, it is generally more appropriate to increase its selectivity without losing significant permeability, rather than solely improving its permeability. Several fillers such as $\mathrm{TPFC}-\mathrm{CH}_{2} \mathrm{NH}_{2}$, TPFC, $\mathrm{CH}_{2} \mathrm{PEI}, \mathrm{SNW}-1$ and nano-CC3 show ideal improvement too, attributable to size sieving properties and their improved filler-polymer interface interaction, similarly to the performance of several MMMs prepared through modified or non-conventional MMM preparation using MOFs (PIMco-UiO-66 $12 \mathrm{~h}$, PIM-co-UiO-66 6 2h, UiO-66-CN@ @PIM-1). However, it can be concluded that 2D fillers such as graphene, GO and $\mathrm{Cu}$-BDC fail to achieve this and, additionally, they tend to lose both permeability and selectivity. This is because of their almost impermeable characteristic property and the poor interaction with polymer, causing the MMMs to either lose substantial permeability with insignificant selectivity increase or resulting in enhancement of permeability, while losing its selectivity tremendously. 

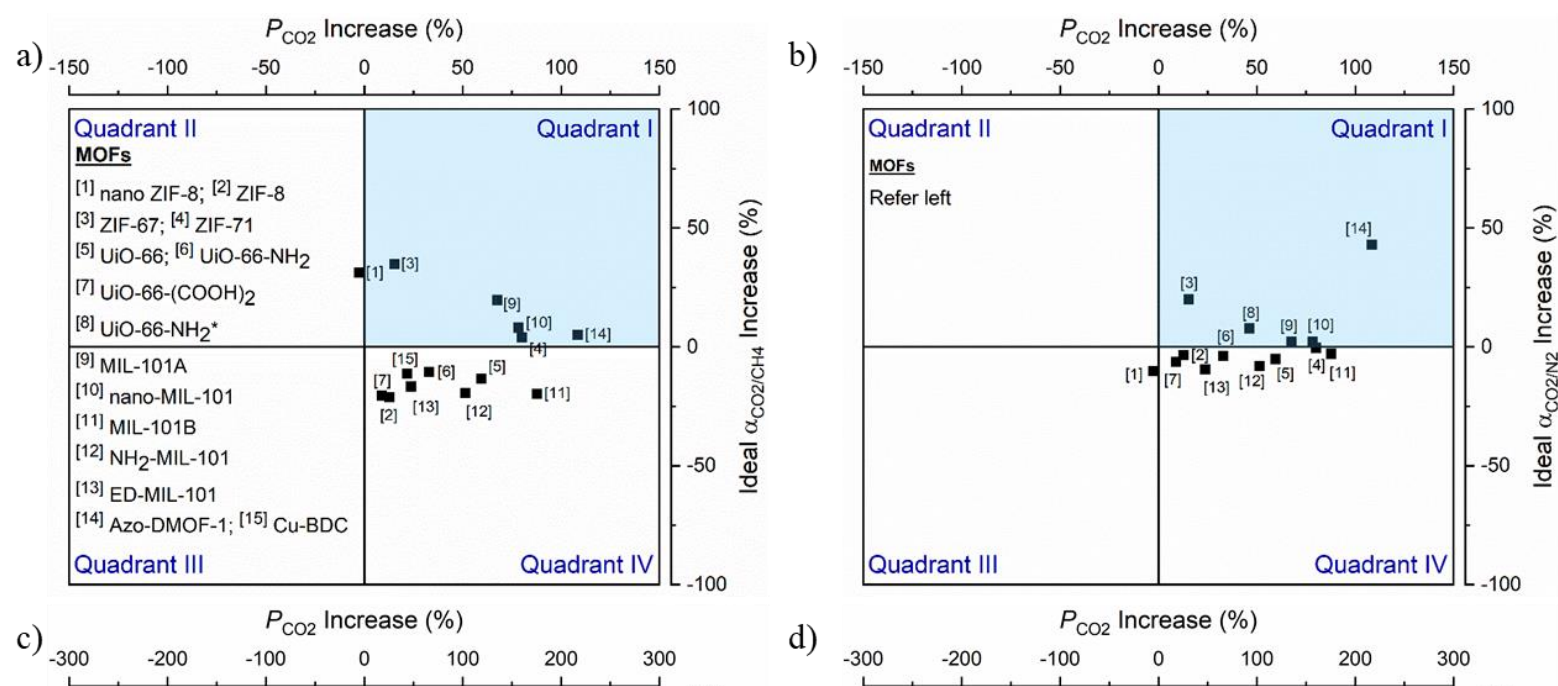

d)

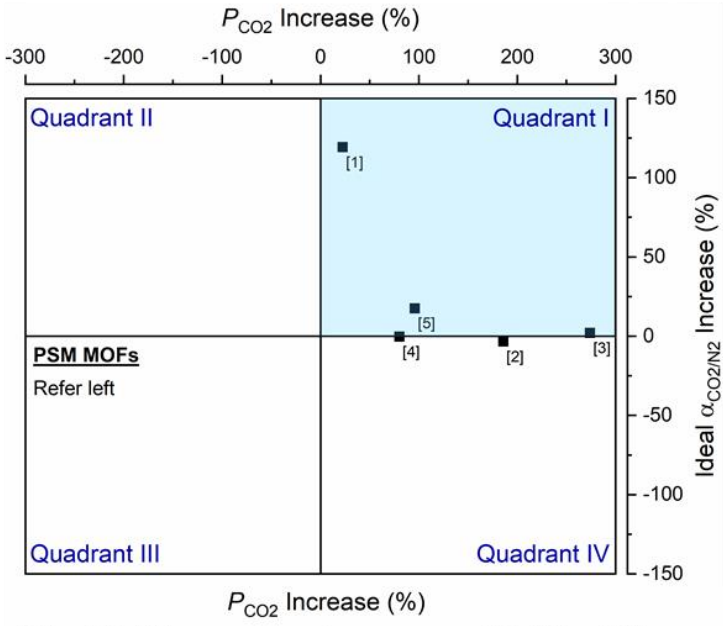

e)
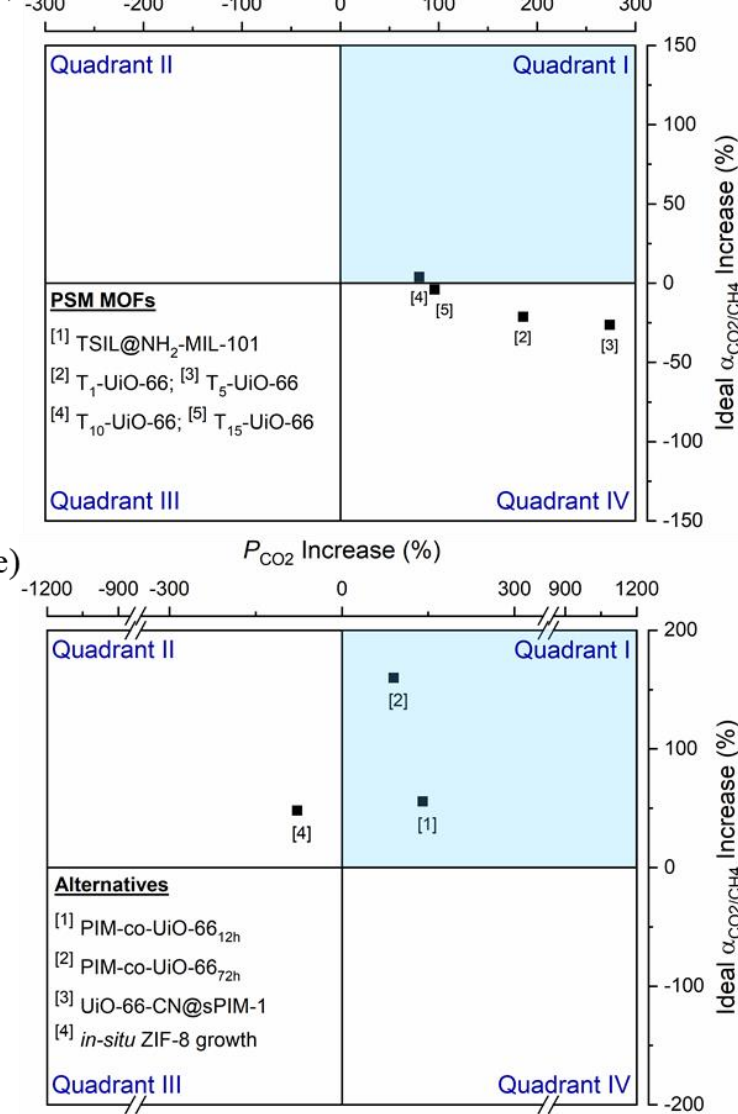

f)

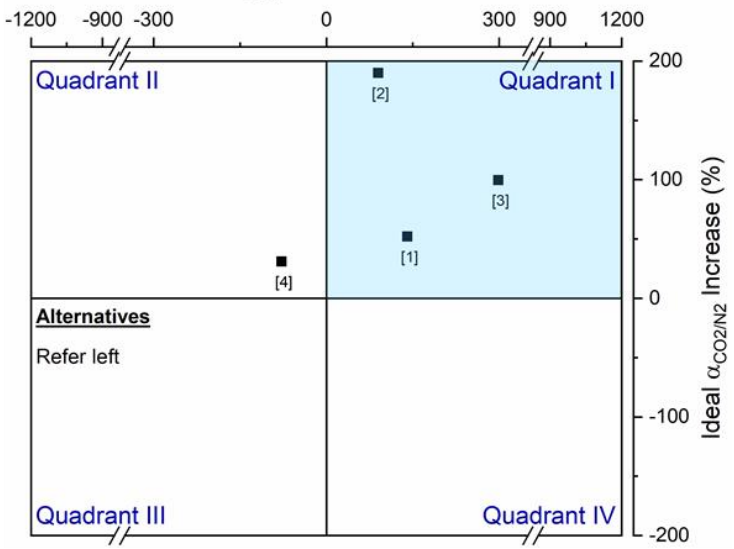

Figure 26: Summary of $\mathrm{CO}_{2} / \mathrm{CH}_{4}$ and $\mathrm{CO}_{2} / \mathrm{N}_{2}$ separation performances of PIM-1 MMMs with (a-b) $2 \mathrm{D}$ and $3 \mathrm{D}$ MOFs, (c-d) post synthetically modified MOF, and (e-f) MOF-MMMs through non-conventional fabrication procedure. Quadrant I represents the most desirable situation of improvements in both permeability and selectivity; Quadrant II, a gain in selectivity at the expense of permeability; Quadrant III, a bad situation where both permeability and selectivity are lost, and Quadrant IV, a gain in permeability at the expense of selectivity. 
a)

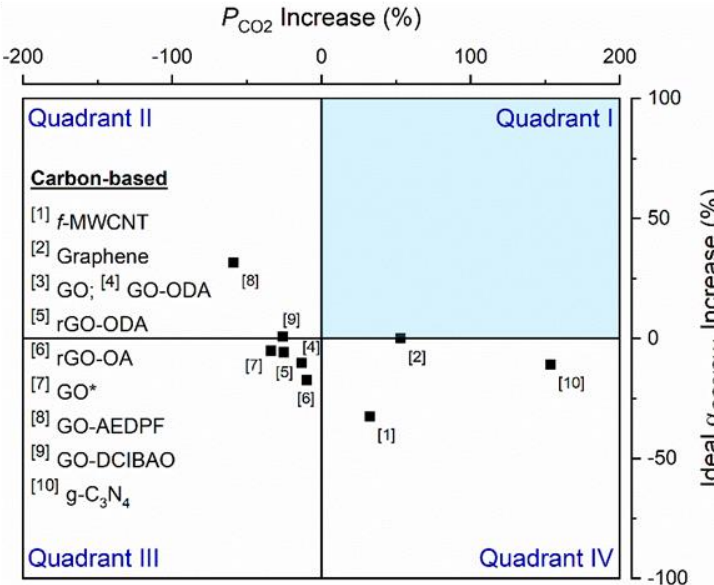

c)

$P_{\mathrm{CO} 2}$ Increase (\%)

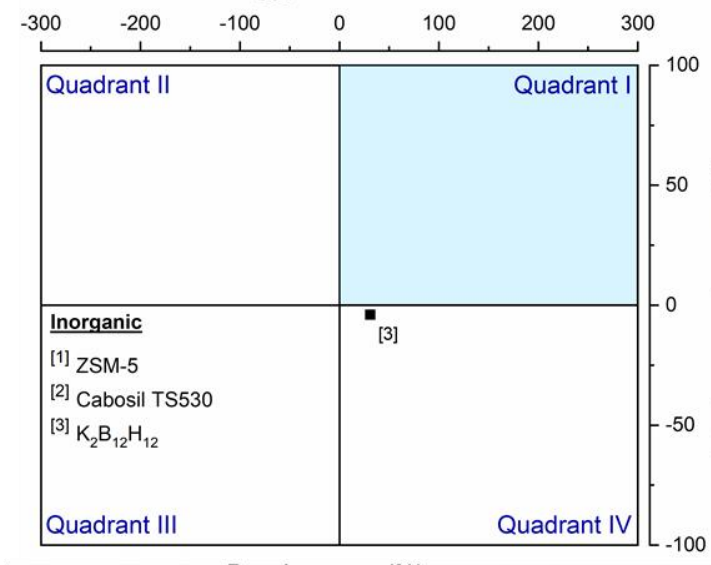

e)

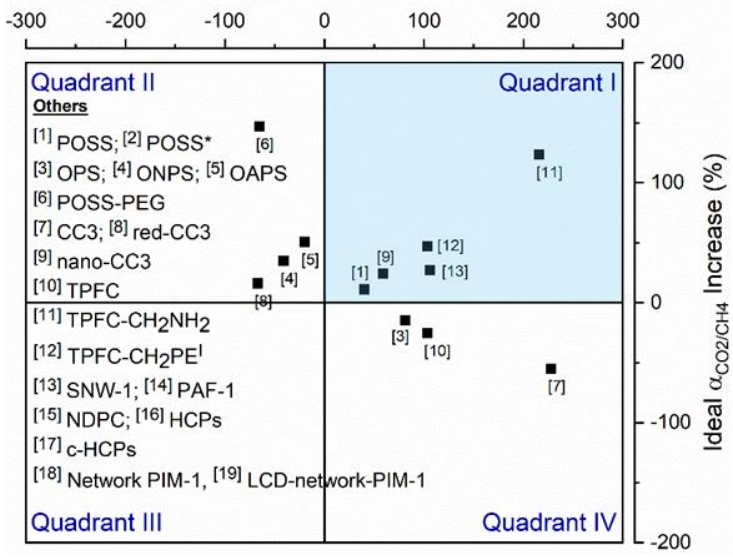

b)

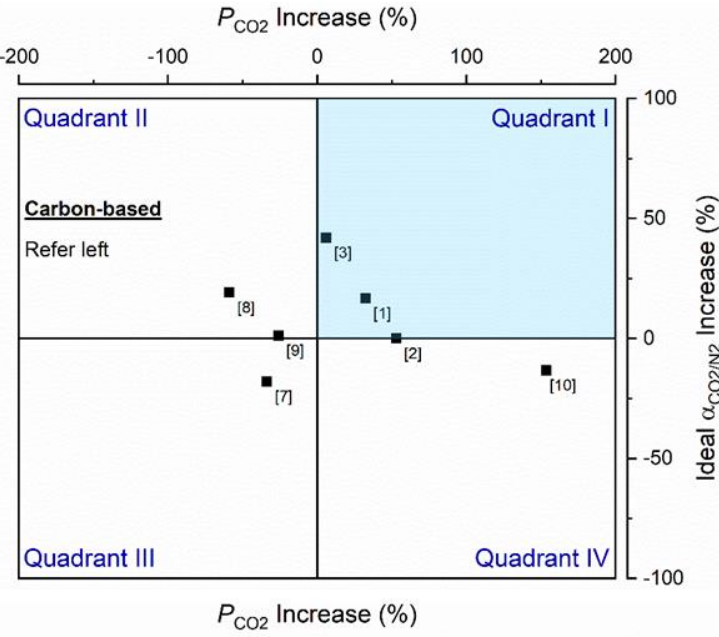

d)

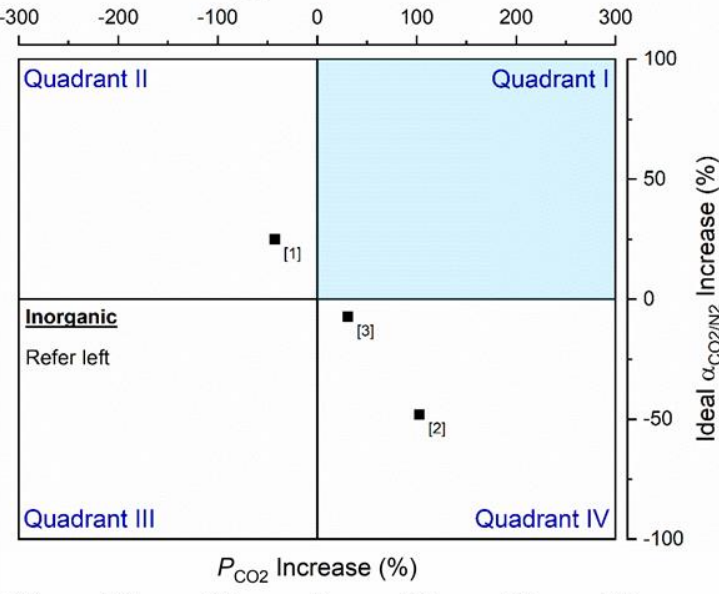

f)

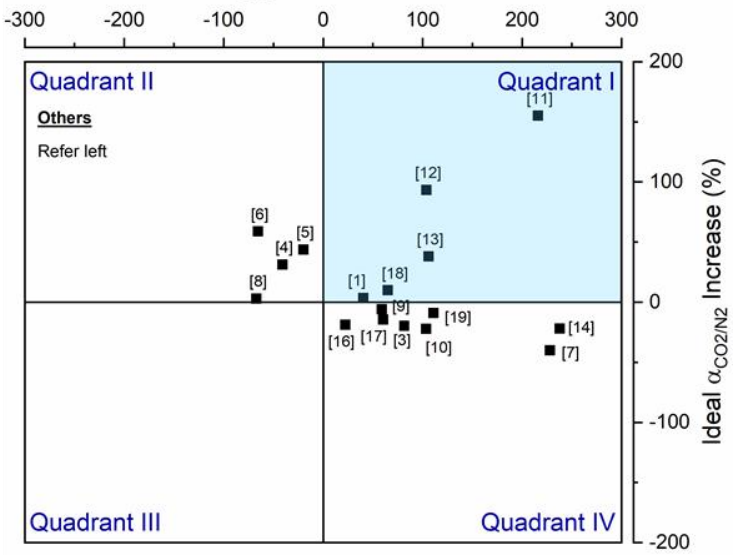

Figure 27: Summary of $\mathrm{CO}_{2} / \mathrm{CH}_{4}$ and $\mathrm{CO}_{2} / \mathrm{N}_{2}$ separation performances of PIM-1 MMMs with (a-b) carbonbased fillers, (c-d) inorganic fillers, and (e-f) other filler types such as POSS, porous cages, POP, COFs, PAFs,

HCPs and network PIM-1. Quadrant I represents the most desirable situation of improvements in both permeability and selectivity; Quadrant II, a gain in selectivity at the expense of permeability; Quadrant III, a bad situation where both permeability and selectivity are lost, and Quadrant IV, a gain in permeability at the expense of selectivity.

\subsection{Aging behavior}

With regards to ending the aging phenomenon by devising PIM-1 MMMs, the approach does not entirely stop, but nonetheless is able to suppress aging to a certain degree. Figure 28 shows the 
performance of PIM-1 MMMs discussed in this review, with aging data separated by the test period $(<100,101-365$, and $>365$ days) and segregated into four quadrants as previously discussed.

As can be observed, most of the MMMs presented the typical aging where the final performance is in Quadrant II, where the membrane's $\mathrm{CO}_{2}$ permeability was reduced. These membranes often showed $\sim 50 \%$ or more permeability reduction, regardless of their aging period. Despite the loss of permeability, several MMMs, such as POSS-PEG (in $\mathrm{CO}_{2} / \mathrm{CH}_{4}$ separation, see Figure 28(a)), HCP (in $\mathrm{CO}_{2} / \mathrm{N}_{2}$ separation, see Figure 28(b)), MIL-101A and nano-MIL-101 (see Figure 28(e-f)) show important selectivity improvement of around $100 \%$. The membranes could be beneficial for separation processes for which the highest purity of a product is required. However, several others, such as POSS-PEG MMM (in $\mathrm{CO}_{2} / \mathrm{N}_{2}$ separation, see Figure 28(b)), POSS and nanoCC3 MMMs (in $\mathrm{CO}_{2} / \mathrm{N}_{2}$ separation, see Figure 28(d)) and PIM-co-UiO-66 $72 \mathrm{~h}$ MMM (in $\mathrm{CO}_{2} / \mathrm{CH}_{4}$ separation, see Figure 28(e)) seem to migrate into Quadrant III by losing both permeability and selectivity upon aging (highlighted using dashed-line arrows). There are several factors that dictate the aging trend in PIM-1, which includes its various macromolecular topologies and is yet to be fully understood [197]. This complexity is increased once a filler is incorporated, making the topic more challenging for the researchers. Nevertheless, the ideal case of all is to achieve a MMM that ages towards Quadrant I, as demonstrated by PIM-1/UiO-66- $\mathrm{NH}_{2} \mathrm{MMM}$ in $\mathrm{CO}_{2} / \mathrm{N}_{2}$ (see Figure 28(b), highlighted by solid-line arrow.

\section{Perspective and conclusions}

Perspective: The main advantage of PIMs in gas separation is their very high gas permeability, so the approaches taken to manage their shortcoming (i.e., physical aging) should not significantly affect this characteristic. The approach of further improving PIM permeability using non-selective materials with poor interface-interaction is also deemed to be inappropriate, as it often jeopardizes the PIM's selectivity values. Maintaining or improving the selectivity is one of the most important aspects in membrane development as it is important for the final separation efficiency. One approach that shows considerable potential is MMMs with a filler that is a network version (usually possessing a higher perm-selectivity) of the same polymer as is used for the continuous phase. This approach seems ideal as it potentially eliminates the issue of poor interfaces encountered with other filler types.

Conclusions: The use of nanomaterials as fillers has been demonstrated to give PIM-1 the boost needed to improve the gas separation performance and to stabilize the FFV and reduce the aging negative effects, to a certain extent. Even though the discussed MMM systems do not eliminate physical aging entirely, encouraging results include (1) MMMs that gained $>100 \%$ selectivity upon aging while maintaining high $\mathrm{CO}_{2}$ permeability (>1000 Barrer), such as MMMs with POSS-PEG [184], HCP [195], MIL-101A [133] and nano-MIL-101 [133]; (2) MMMs that showed minimal permeability loss over time while maintaining high selectivity, such as PIM-1/PAF-1 [192] that showed only 7\% $P_{\mathrm{CO} 2}$ loss even after 240 days of aging; (3) MMMs that still performed exceptionally even after a long period of aging, such as the 'interweaved' PIM-1/UiO-66-CN [150] that still performs above the $\mathrm{CO}_{2} / \mathrm{N}_{2} 2008$ upper 
bound after six months of aging ( $P_{\mathrm{CO} 2}$ of 10,389 Barrer and $\alpha_{\mathrm{CO} 2 / \mathrm{N} 2}$ of 33.7$)$, despite losing $13 \%$ of $P_{\mathrm{CO} 2}$ in the duration, or the in-situ synthesized PIM-co-UiO-66 $6_{72 \mathrm{~h}}[149]$ that showed $P_{\mathrm{CO} 2}=9,373$ Barrer with high $\alpha_{\mathrm{CO} 2 / \mathrm{CH} 4}$ at 31.7 , even after showing $25 \% P_{\mathrm{CO} 2}$ reduction over 400 days. These MMMs undoubtedly exceed the separation performance of the industrially relevant polymeric membranes (tetra-bromopolycarbonate, TBPC; cellulose acetate, CA; polysulfone, PSF; Matrimid®; polyimide, PI; poly(2,6dimethyl-1,4-phenylene oxide, PPO), presented in a review by Sanders et al. [170].

Referring to the studies discussed in this review, physical aging, although reduced, still does occur after the formation of MMMs. The phenomenon is also typical of the other polymer membranes in the current commercial market. However, the acceptable aging magnitude of a polymer membrane system is highly dependent on the end-users and the type of separation process. Several characteristics of importance are the required product purity or acceptable product loss, target process productivity, and capital expenditure (CAPEX) allowance. Several other methods (chemical crosslinking, UV and heat treatment) may reduce the aging more effectively than the MMM approach, but they often lead to a major loss in gas permeability, whereas in MMMs, especially with porous nanomaterials, this disadvantage is minimized due to the permeating nature of the materials. It can be concluded that MMMs represent a viable approach, provided that the filler selection is suitable for the purpose and the polymerfiller interface interaction is understood and managed appropriately. 
a)

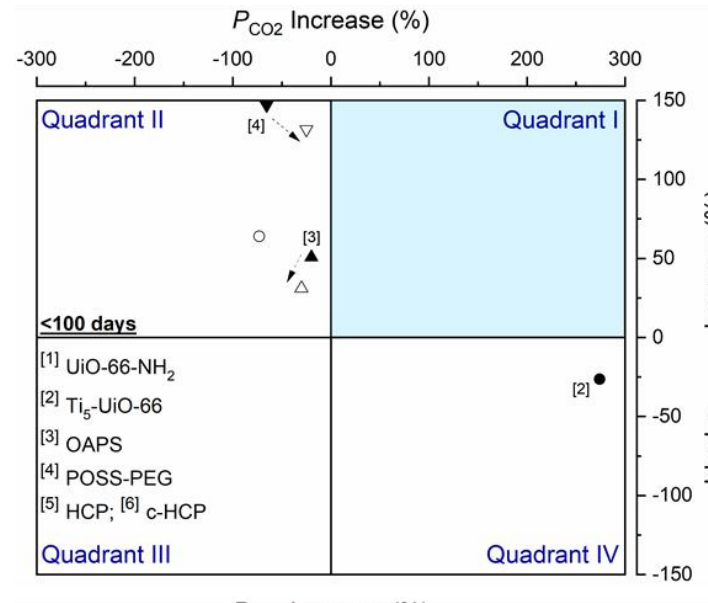

c)

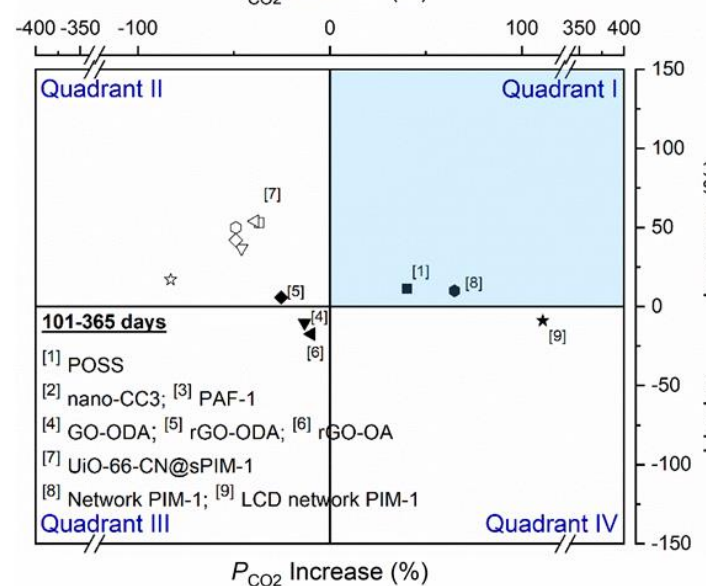

c)

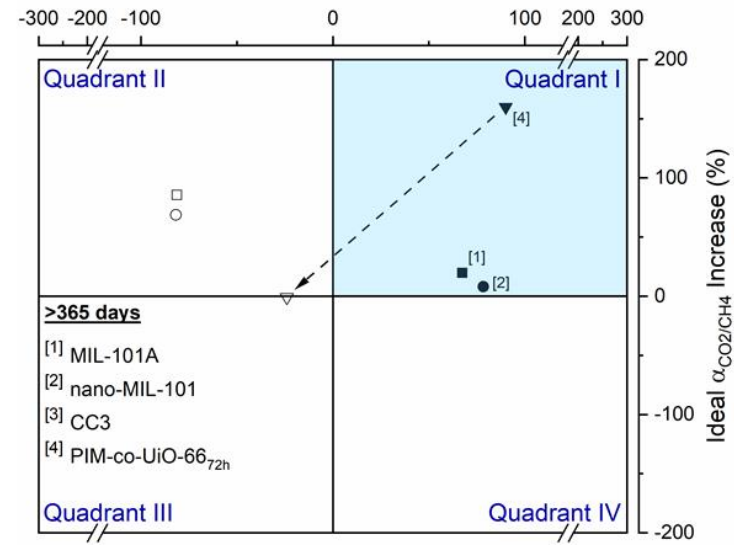

b)

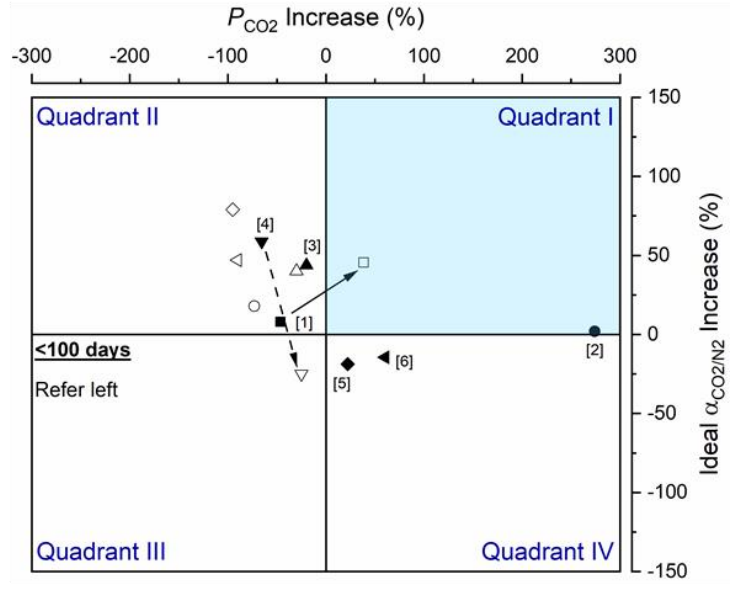

d)

$P_{\mathrm{CO} 2}$ Increase (\%)

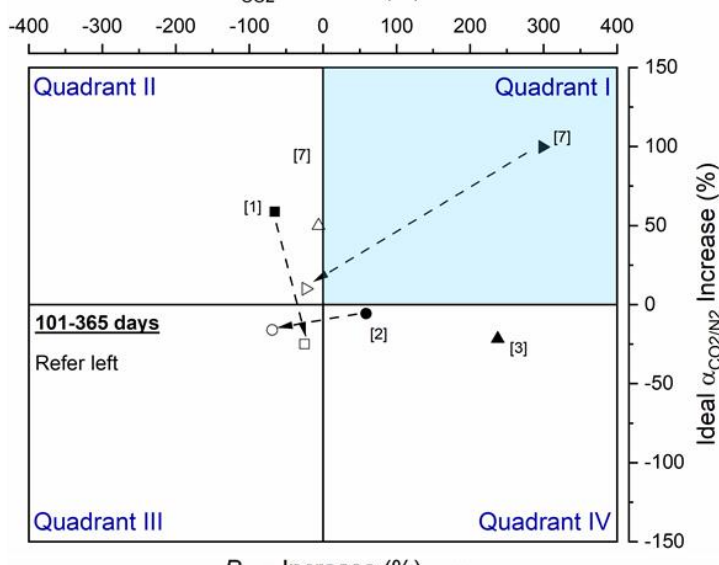

d)

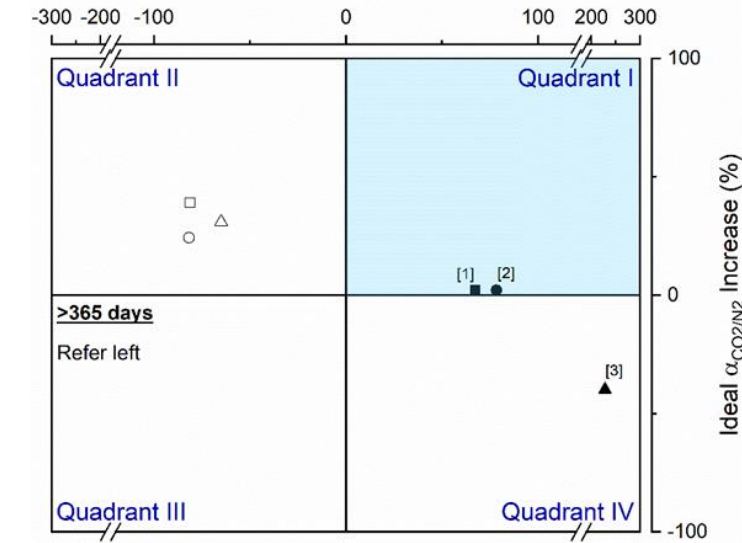

Figure 28: The aging performance of PIM-1 MMMs, where filled symbols are fresh MMMs and unfilled symbols, are aged MMMs, divided according to their aging period (a-b) <100 days, (c-d) 101-365 days, and (e-f) $>365$ days. The values are segregated into four quadrants, as previously discussed. Arrowed aging trends are the non-typical aging behaviour where the solid line arrow represents the ideal aging, while the dashed-line arrows represents non-ideal aging. The typical aging trends (permeability loss and selectivity gain), where the aged MMMs are in Quadrant II, are not arrowed. 


\section{Acknowledgment}

The authors have no external funding to acknowledge.

\section{Conflict of interest}

The authors declare no conflict of interest.

\section{Reference}

[1] E. Adatoz, A.K. Avci, S. Keskin, Opportunities and challenges of MOF-based membranes in gas separations, Sep. Purif. Technol. 152 (2015) 207-237. doi:10.1016/j.seppur.2015.08.020.

[2] Y. Alcheikhhamdon, M. Hoorfar, Natural Gas Purification from Acid Gases using Membranes: A Review of the History, Features, Techno-Commercial Challenges, and Process Intensification of Commercial $\begin{array}{lllllll}\text { Membranes, } & \text { Chem. } & \text { Eng. } & \text { Process. Process } & \text { Intensif. } 120 & \text { (2017). }\end{array}$ doi:https://doi.org/10.1016/j.cep.2017.07.009.

[3] R.W. Baker, Future Directions of Membrane Gas Separation Technology, Ind. Eng. Chem. Res. 41 (2002) 1393-1411. doi:10.1021/ie0108088.

[4] R.W. Baker, K. Lokhandwala, Natural gas processing with membranes: An overview, Ind. Eng. Chem. Res. 47 (2008) 2109-2121. doi:10.1021/ie071083w.

[5] S. Sridhar, B. Smitha, T.M. Aminabhavi, Separation of carbon dioxide from natural gas mixtures through polymeric membranes - A review, Sep. Purif. Rev. 36 (2007) 113-174. doi:10.1080/15422110601165967.

[6] V. Martin-Gil, M.Z. Ahmad, R. Castro-Muñoz, V. Fila, Economic Framework of Membrane Technologies for Natural Gas Applications, Sep. Purif. Rev. 48 (2019) 298-324. doi:10.1080/15422119.2018.1532911.

[7] C.A. Scholes, G.W. Stevens, S.E. Kentish, Membrane gas separation applications in natural gas processing, Fuel. 96 (2012) 15-28. doi:10.1016/j.fuel.2011.12.074.

[8] W.J. Koros, R. Mahajan, Pushing the limits on possibilities for large scale gas separation: which strategies?, J. Memb. Sci. 175 (2000) 181-196. doi:https://doi.org/10.1016/S0376-7388(00)00418-X.

[9] T.S. Chung, L.Y. Jiang, Y. Li, S. Kulprathipanja, Mixed matrix membranes (MMMs) comprising organic polymers with dispersed inorganic fillers for gas separation, Prog. Polym. Sci. 32 (2007) 483-507. doi:10.1016/j.progpolymsci.2007.01.008.

[10] M. Vinoba, M. Bhagiyalakshmi, Y. Alqaheem, A.A. Alomair, A. Pérez, M.S. Rana, Recent progress of fillers in mixed matrix membranes for $\mathrm{CO}_{2}$ separation: A review, Sep. Purif. Technol. 188 (2017) 431450. doi:10.1016/j.seppur.2017.07.051.

[11] X.-L. Ma, J.Y.-S. Lin, Chapter 23 - Preparation Chemistry of Inorganic Membranes, in: Mod. Inorg. Synth. Chem. (Second Ed., Elsevier, Amsterdam, 2017: pp. 669-686. doi:https://doi.org/10.1016/B978-0-44463591-4.00023-9.

[12] P.M. Budd, B.S. Ghanem, S. Makhseed, N.B. Mckeown, K.J. Msayib, E. Tattershall, Polymers of intrinsic microporosity (PIMs): robust, solution-processable, organic nanoporous materials, Chem. Commun. (2004) 230-231.

[13] P.M. Budd, N.B. McKeown, D. Fritsch, Polymers of Intrinsic Microporosity (PIMs): High free volume polymers for membrane applications, Macromol. Symp. 245-246 (2006) 403-405. doi:10.1002/masy.200651356.

[14] L.M. Robeson, Correlation of separation factor versus permeability for polymeric membranes, J. Memb. 
Sci. 62 (1991) 165-185. doi:10.1016/0376-7388(91)80060-J.

[15] L.M. Robeson, The upper bound revisited, J. Memb. Sci. 320 (2008) 390-400. doi:10.1016/j.memsci.2008.04.030.

[16] Z.X. Low, P.M. Budd, N.B. McKeown, D.A. Patterson, Gas Permeation Properties, Physical Aging, and Its Mitigation in High Free Volume Glassy Polymers, Chem. Rev. 118 (2018) 5871-5911. doi:10.1021/acs.chemrev.7b00629.

[17] B. Comesaña-Gándara, J. Chen, C.G. Bezzu, M. Carta, I. Rose, M.-C. Ferrari, E. Esposito, A. Fuoco, J.C. Jansen, N.B. McKeown, Redefining the Robeson upper bounds for $\mathrm{CO}_{2} / \mathrm{CH}_{4}$ and $\mathrm{CO}_{2} / \mathrm{N}_{2}$ separations using a series of ultrapermeable benzotriptycene-based polymers of intrinsic microporosity, Energy Environ. Sci. 12 (2019) 2733-2740. doi:10.1039/C9EE01384A.

[18] R. Swaidan, B. Ghanem, I. Pinnau, Fine-Tuned Intrinsically Ultramicroporous Polymers Redefine the Permeability/Selectivity Upper Bounds of Membrane-Based Air and Hydrogen Separations, ACS Macro Lett. 4 (2015) 947-951. doi:10.1021/acsmacrolett.5b00512.

[19] R. Minguez, L. Barrenetxea, E. Solaberrieta, E. Lizundia, A simple approach to understand the physical aging in polymers, Eur. J. Phys. 40 (2018) 15502. doi:10.1088/1361-6404/aaf244.

[20] C.L. Brinson, T.S. Gates, Effects of physical aging on long term creep of polymers and polymer matrix composites, Int. J. Solids Struct. 32 (1995) 827-846. doi:10.1016/0020-7683(94)00163-Q.

[21] J.H. Kim, W.J. Koros, D.R. Paul, Effects of $\mathrm{CO}_{2}$ exposure and physical aging on the gas permeability of thin 6FDA-based polyimide membranes. Part 1. Without crosslinking, J. Memb. Sci. 282 (2006) 21-31. doi:10.1016/j.memsci.2006.05.004.

[22] M. Yavari, T. Le, H. Lin, Physical aging of glassy perfluoropolymers in thin film composite membranes. Part I. Gas transport properties, J. Memb. Sci. 525 (2017) 387-398. doi:10.1016/j.memsci.2016.07.002.

[23] J.H. Kim, W.J. Koros, D.R. Paul, Effects of $\mathrm{CO}_{2}$ exposure and physical aging on the gas permeability of thin 6FDA-based polyimide membranes. Part 2. with crosslinking, J. Memb. Sci. 282 (2006) 32-43. doi:10.1016/j.memsci.2006.05.003.

[24] I. Borisov, D. Bakhtin, J.M. Luque-Alled, A. Rybakova, V. Makarova, A.B. Foster, W.J. Harrison, V. Volkov, V. Polevaya, P. Gorgojo, E. Prestat, P.M. Budd, A. Volkov, Synergistic enhancement of gas selectivity in thin film composite membranes of PIM-1, J. Mater. Chem. A. 7 (2019) 6417-6430. doi:10.1039/c8ta10691f.

[25] P.H. Pfromm, W.J. Koros, Accelerated physical ageing of thin glassy polymer films: evidence from gas transport measurements, Polymer (Guildf). 36 (1995) 2379-2387.

[26] J.R. White, Polymer ageing: physics, chemistry or engineering? Time to reflect, Comptes Rendus Chim. 9 (2006) 1396-1408. doi:10.1016/j.crci.2006.07.008.

[27] R.P. White, J.E.G. Lipson, Polymer Free Volume and Its Connection to the Glass Transition, Macromolecules. 49 (2016) 3987-4007. doi:10.1021/acs.macromol.6b00215.

[28] M.Z. Ahmad, H. Pelletier, V. Martin-Gil, R. Castro-Muñoz, V. Fila, Chemical crosslinking of 6FDA-ODA and 6FDA-ODA:DABA for improved $\mathrm{CO}_{2} / \mathrm{CH}_{4}$ separation, Membranes (Basel). 8 (2018) 1-16. doi:10.3390/membranes8030067.

[29] M.Z. Ahmad, M. Navarro, M. Lhotka, B. Zornoza, C. Téllez, V. Fila, J. Coronas, Enhancement of $\mathrm{CO}_{2} / \mathrm{CH}_{4}$ separation performances of $6 \mathrm{FDA}$-based co-polyimides mixed matrix membranes embedded 
with UiO-66 nanoparticles, Sep. Purif. Technol. $192 \quad$ (2018) 465-474. doi:https://doi.org/10.1016/j.seppur.2017.10.039.

[30] J. Park, D.R. Paul, Correlation and Prediction of gas permeability in glassy polymer membrane materials via a modified free volume based group contribution method, J. Memb. Sci. 125 (1997) 23-39. doi:10.1016/S0376-7388(96)00061-0.

[31] D.W. Van Krevelen, K. Te Nijenhuis, Chapter 7 - Cohesive Properties and Solubility, in: D.W. Van Krevelen, K. Te Nijenhuis (Eds.), Prop. Polym., Fourth Edi, Elsevier, Amsterdam, 2009: pp. 189-227. doi:https://doi.org/10.1016/B978-0-08-054819-7.00007-8.

[32] N.R. Horn, A critical review of free volume and occupied volume calculation methods, J. Memb. Sci. 518 (2016) 289-294. doi:10.1016/j.memsci.2016.07.014.

[33] B. Freeman, Y. Yampolskii, I. Pinnau, Materials Science of Membranes for Gas and Vapor Separation, John Wiley \& Sons, Ltd, Chichester, UK, 2006.

[34] G. Dlubek, D. Kilburn, M.A. Alam, Temperature and pressure dependence of $\alpha$-relaxation and free volume in poly(vinyl acetate), Macromol. Chem. Phys. 206 (2005) 818-826. doi:10.1002/macp.200400495.

[35] Y.P. Yampolskii, Methods for investigation of the free volume in polymers, Russ. Chem. Rev. 76 (2007) 59-78. doi:10.1070/rc2007v076n01abeh003629.

[36] Y. Yampolskii, N. Belov, Investigation of Polymers by Inverse Gas Chromatography, Macromolecules. 48 (2015) 6751-6767. doi:10.1021/acs.macromol.5b00895.

[37] R. Haul, S.J. Gregg, K.S.W. Sing, Adsorption, Surface Area and Porosity, New York, 1982. doi:10.1002/bbpc.19820861019.

[38] B.S. Ghanem, R. Swaidan, X. Ma, E. Litwiller, I. Pinnau, Energy-efficient hydrogen separation by ABtype ladder-polymer molecular sieves, Adv. Mater. 26 (2014) 6696-6700. doi:10.1002/adma.201401328.

[39] J. Fraissard, T. Ito, 129Xe n.m.r. study of adsorbed xenon: A new method for studying zeolites and metalzeolites, Zeolites. 8 (1988) 350-361. doi:10.1016/S0144-2449(88)80171-4.

[40] C.H. Lau, K. Konstas, A.W. Thornton, A.C.Y. Liu, S. Mudie, D.F. Kennedy, S.C. Howard, A.J. Hill, M.R. Hill, Gas-separation membranes loaded with porous aromatic frameworks that improve with age, Angew. Chemie - Int. Ed. 54 (2015) 2669-2673. doi:10.1002/anie.201410684.

[41] P.M. Budd, N.B. McKeown, Highly permeable polymers for gas separation membranes, Polym. Chem. 1 (2010) 63-68. doi:10.1039/b9py00319c.

[42] M. Alberto, R. Bhavsar, J.M. Luque-Alled, A. Vijayaraghavan, P.M. Budd, P. Gorgojo, Impeded physical aging in PIM-1 membranes containing graphene-like fillers, J. Memb. Sci. 563 (2018) 513-520. doi:10.1016/j.memsci.2018.06.026.

[43] C.A. Scholes, S. Kanehashi, Polymer of intrinsic microporosity (PIM-1) membranes treated with supercritical $\mathrm{CO}_{2}$, Membranes (Basel). 9 (2019) 1-12. doi:10.3390/membranes9030041.

[44] R. Hou, S.J.D. Smith, C.D. Wood, R.J. Mulder, C.H. Lau, H. Wang, M.R. Hill, Solvation Effects on the Permeation and Aging Performance of PIM-1-Based MMMs for Gas Separation, ACS Appl. Mater. Interfaces. 11 (2019) 6502-6511. doi:10.1021/acsami.8b19207.

[45] M. Heuchel, D. Fritsch, P.M. Budd, N.B. McKeown, D. Hofmann, Atomistic packing model and free volume distribution of a polymer with intrinsic microporosity (PIM-1), J. Memb. Sci. 318 (2008) 84-99. doi:10.1016/j.memsci.2008.02.038. 
[46] A.G. McDermott, P.M. Budd, N.B. McKeown, C.M. Colina, J. Runt, Physical aging of polymers of intrinsic microporosity: A SAXS/WAXS study, J. Mater. Chem. A. 2 (2014) 11742-11752. doi:10.1039/c4ta02165g.

[47] P. Bernardo, F. Bazzarelli, F. Tasselli, G. Clarizia, C.R. Mason, L. Maynard-Atem, P.M. Budd, M. Lanč, K. Pilnáček, O. Vopička, K. Friess, D. Fritsch, Y.P. Yampolskii, V. Shantarovich, J.C. Jansen, Effect of physical aging on the gas transport and sorption in PIM-1 membranes, Polymer (Guildf). 113 (2017) 283294. doi:10.1016/j.polymer.2016.10.040.

[48] F.Y. Li, Y. Xiao, T.S. Chung, S. Kawi, High-performance thermally self-cross-linked polymer of intrinsic microporosity (PIM-1) membranes for energy development, Macromolecules. 45 (2012) 1427-1437. doi:10.1021/ma202667y.

[49] S. He, X. Jiang, S. Li, F. Ran, J. Long, L. Shao, Intermediate thermal manipulation of polymers of intrinsic microporous (PIMs) membranes for gas separations, AIChE J. 66 (2020) e16543. doi:10.1002/aic.16543.

[50] J. Ahn, W.J. Chung, I. Pinnau, J. Song, N. Du, G.P. Robertson, M.D. Guiver, Gas transport behavior of mixed-matrix membranes composed of silica nanoparticles in a polymer of intrinsic microporosity (PIM1), J. Memb. Sci. 346 (2010) 280-287. doi:10.1016/j.memsci.2009.09.047.

[51] M.M. Khan, V. Filiz, G. Bengtson, S. Shishatskiy, M.M. Rahman, J. Lillepaerg, V. Abetz, Enhanced gas permeability by fabricating mixed matrix membranes of functionalized multiwalled carbon nanotubes and polymers of intrinsic microporosity (PIM), J. Memb. Sci. 436 (2013) 109-120. doi:10.1016/j.memsci.2013.02.032.

[52] H. Zhao, Q. Xie, X. Ding, J. Chen, M. Hua, X. Tan, Y. Zhang, High performance post-modified polymers of intrinsic microporosity (PIM-1) membranes based on multivalent metal ions for gas separation, J. Memb. Sci. 514 (2016) 305-312. doi:10.1016/j.memsci.2016.05.013.

[53] A.K. Sekizkardes, V.A. Kusuma, G. Dahe, E.A. Roth, L.J. Hill, A. Marti, M. Macala, S.R. Venna, D. Hopkinson, Separation of carbon dioxide from flue gas by mixed matrix membranes using dual phase microporous polymeric constituents, Chem. Commun. 52 (2016) 11768-11771. doi:10.1039/c6cc04811k.

[54] S.H. Pang, M.L. Jue, J. Leisen, C.W. Jones, R.P. Lively, PIM-1 as a Solution-Processable "molecular Basket" for $\mathrm{CO}_{2}$ Capture from Dilute Sources, ACS Macro Lett. 4 (2015) 1415-1419. doi:10.1021/acsmacrolett.5b00775.

[55] M. Rezakazemi, A. Ebadi Amooghin, M.M. Montazer-Rahmati, A.F. Ismail, T. Matsuura, State-of-the-art membrane based $\mathrm{CO}_{2}$ separation using mixed matrix membranes (MMMs): An overview on current status and future directions, Prog. Polym. Sci. 39 (2014) 817-861. doi:10.1016/j.progpolymsci.2014.01.003.

[56] S.R. Venna, M.A. Carreon, Metal organic framework membranes for carbon dioxide separation, Chem. Eng. Sci. 124 (2015) 3-19. doi:10.1016/j.ces.2014.10.007.

[57] R. Castro-Muñoz, M.Z. Ahmad, V. Fíla, Tuning of Nano-Based Materials for Embedding Into LowPermeability Polyimides for a Featured Gas Separation, Front. Chem. 7 (2020) 897. https://www.frontiersin.org/article/10.3389/fchem.2019.00897.

[58] C. Ma, J.J. Urban, Separation Membranes: A mini Review, Proc. Nat. Res. Soc. (2018) 2002. doi:10.11605/j.pnrs.201802002.

[59] B. Zornoza, C. Tellez, J. Coronas, J. Gascon, F. Kapteijn, Metal organic framework based mixed matrix membranes: An increasingly important field of research with a large application potential, Microporous 
Mesoporous Mater. 166 (2013) 67-78. doi:10.1016/j.micromeso.2012.03.012.

[60] T.T. Moore, W.J. Koros, Non-ideal effects in organic-inorganic materials for gas separation membranes, J. Mol. Struct. 739 (2005) 87-98. doi:10.1016/j.molstruc.2004.05.043.

[61] M.Z. Ahmad, V. Martin-Gil, T. Supinkova, P. Lambert, R. Castro-Muñoz, P. Hrabanek, M. Kocirik, V. Fila, Novel MMM using $\mathrm{CO}_{2}$ selective SSZ-16 and high-performance $6 \mathrm{FDA}$-polyimide for $\mathrm{CO}_{2} / \mathrm{CH}_{4}$ separation, Sep. Purif. Technol. 254 (2021) 117582. doi:https://doi.org/10.1016/j.seppur.2020.117582.

[62] R. Castro-Muñoz, V. Fíla, M.Z. Ahmad, Enhancing the $\mathrm{CO}_{2}$ Separation Performance of Matrimid 5218 Membranes for CO2/CH4 Binary Mixtures, Chem. Eng. Technol. 42 (2019). doi:10.1002/ceat.201800111.

[63] P.S. Goh, A.F. Ismail, S.M. Sanip, B.C. Ng, M. Aziz, Recent advances of inorganic fillers in mixed matrix membrane for gas separation, Sep. Purif. Technol. 81 (2011) 243-264. doi:10.1016/j.seppur.2011.07.042.

[64] S. Castarlenas, C. Tellez, J. Coronas, Gas separation with mixed matrix membranes obtained from MOF UiO-66-graphite oxide hybrids, J. Memb. Sci. 526 (2017) 205-211. doi:10.1016/j.memsci.2016.12.041.

[65] J. Ahmad, M.B. Hågg, Polyvinyl acetate/titanium dioxide nanocomposite membranes for gas separation, J. Memb. Sci. 445 (2013) 200-210. doi:10.1016/j.memsci.2013.04.052.

[66] T. Yang, T.-S. Chung, High performance ZIF-8/PBI nano-composite membranes for high temperature hydrogen separation consisting of carbon monoxide and water vapor, Int. J. Hydrogen Energy. 38 (2013) 229-239. doi:10.1016/j.ijhydene.2012.10.045.

[67] H. Yin, C.Y. Lau, M. Rozowski, C. Howard, Y. Xu, T. Lai, M.E. Dose, R.P. Lively, M.L. Lind, Freestanding ZIF-71/PDMS nanocomposite membranes for the recovery of ethanol and 1-butanol from water through pervaporation, J. Memb. Sci. 529 (2017) 286-292. doi:10.1016/j.memsci.2017.02.006.

[68] C. Zhang, Y. Dai, J.R. Johnson, O. Karvan, W.J. Koros, High performance ZIF-8/6FDA-DAM mixed matrix membrane for propylene/propane separations, J. Memb. Sci. 389 (2012) 34-42. doi:10.1016/j.memsci.2011.10.003.

[69] R. Mueller, V. Hariharan, C. Zhang, R. Lively, S. Vasenkov, Relationship between mixed and pure gas self-diffusion for ethane and ethene in ZIF-8/6FDA-DAM mixed-matrix membrane by pulsed field gradient NMR, J. Memb. Sci. 499 (2016) 12-19. doi:10.1016/j.memsci.2015.10.036.

[70] T. Bae, J.S. Lee, W. Qiu, W.J. Koros, C.W. Jones, MOF Membranes A High-Performance Gas-Separation Membrane Containing Submicrometer-Sized Metal - Organic Framework Crystals **, (2010) 9863-9866. doi:10.1002/anie.201006141.

[71] A.F. Bushell, M.P. Attfield, C.R. Mason, P.M. Budd, Y. Yampolskii, L. Starannikova, A. Rebrov, F. Bazzarelli, P. Bernardo, J. Carolus Jansen, M. Lanč, K. Friess, V. Shantarovich, V. Gustov, V. Isaeva, Gas permeation parameters of mixed matrix membranes based on the polymer of intrinsic microporosity PIM1 and the zeolitic imidazolate framework ZIF-8, J. Memb. Sci. 427 (2013) 48-62. doi:10.1016/j.memsci.2012.09.035.

[72] T. Li, Y. Pan, K.-V. Peinemann, Z. Lai, Carbon dioxide selective mixed matrix composite membrane containing ZIF-7 nano-fillers, J. Memb. Sci. 425-426 (2013) 235-242. doi:10.1016/j.memsci.2012.09.006.

[73] V. Nafisi, M.B. Hägg, Development of dual layer of ZIF-8/PEBAX-2533 mixed matrix membrane for $\mathrm{CO}_{2}$ capture, J. Memb. Sci. 459 (2014) 244-255. doi:10.1016/j.memsci.2014.02.002.

[74] L. Cao, F. Lv, Y. Liu, W. Wang, Y. Huo, X. Fu, R. Sun, Z. Lu, A high performance $\mathrm{O}_{2}$ selective membrane 
based on CAU-1-NH2@polydopamine and the PMMA polymer for Li-air batteries., Chem. Commun. (Camb). 51 (2015) 1-4. doi:10.1039/c4cc09281c.

[75] G.M. Shi, T. Yang, T.S. Chung, Polybenzimidazole (PBI)/zeolitic imidazolate frameworks (ZIF-8) mixed matrix membranes for pervaporation dehydration of alcohols, J. Memb. Sci. 415-416 (2012) 577-586. doi:10.1016/j.memsci.2012.05.052.

[76] Q. Song, S. Cao, R.H. Pritchard, H. Qiblawey, E.M. Terentjev, A.K. Cheetham, E. Sivaniah, Nanofillertuned microporous polymer molecular sieves for energy and environmental processes, J. Mater. Chem. A. (2016) 270-279. doi:10.1039/c5ta09060a.

[77] K. Golzar, H. Modarress, S. Amjad-Iranagh, Effect of pristine and functionalized single- and multi-walled carbon nanotubes on $\mathrm{CO}_{2}$ separation of mixed matrix membranes based on polymers of intrinsic microporosity (PIM-1): a molecular dynamics simulation study, J. Mol. Model. 23 (2017) 266. doi:10.1007/s00894-017-3436-3.

[78] M.M. Khan, V. Filiz, G. Bengtson, S. Shishatskiy, M. Rahman, V. Abetz, Functionalized carbon nanotubes mixed matrix membranes of polymers of intrinsic microporosity for gas separation, Nanoscale Res. Lett. 7 (2012) 504. doi:10.1186/1556-276X-7-504.

[79] A. Gonciaruk, K. Althumayri, W.J. Harrison, P.M. Budd, F.R. Siperstein, PIM-1/graphene composite: A combined experimental and molecular simulation study, Microporous Mesoporous Mater. 209 (2015) 126-134. doi:https://doi.org/10.1016/j.micromeso.2014.07.007.

[80] H. Cong, M. Radosz, B.F. Towler, Y. Shen, Polymer-inorganic nanocomposite membranes for gas separation, Sep. Purif. Technol. 55 (2007) 281-291. doi:10.1016/j.seppur.2006.12.017.

[81] M.A. Aroon, A.F. Ismail, T. Matsuura, M.M. Montazer-Rahmati, Performance studies of mixed matrix membranes for gas separation: A review, Sep. Purif. Technol. 75 (2010) 229-242. doi:10.1016/j.seppur.2010.08.023.

[82] R.D. Noble, Perspectives on mixed matrix membranes, J. Memb. Sci. 378 (2011) 393-397. doi:10.1016/j.memsci.2011.05.031.

[83] S. Basu, A. Cano-Odena, I.F.J. Vankelecom, MOF-containing mixed-matrix membranes for $\mathrm{CO}_{2} / \mathrm{CH}_{4}$ and $\mathrm{CO}_{2} / \mathrm{N}_{2}$ binary gas mixture separations, Sep. Purif. Technol. 81 (2011) 31-40. doi:10.1016/j.seppur.2011.06.037.

[84] M. Khayet, The effects of air gap length on the internal and external morphology of hollow fiber membranes, Chem. Eng. Sci. 58 (2003) 3091-3104. doi:10.1016/S0009-2509(03)00186-6.

[85] H. Hasbullah, S. Kumbharkar, A.F. Ismail, K. Li, Preparation of polyaniline asymmetric hollow fiber membranes and investigation towards gas separation performance, J. Memb. Sci. 366 (2011) 116-124. doi:10.1016/j.memsci.2010.09.050.

[86] A. Perea-Cachero, J. Sánchez-Laínez, Á. Berenguer-Murcia, D. Cazorla-Amorós, C. Téllez, J. Coronas, A new zeolitic hydroxymethylimidazolate material and its use in mixed matrix membranes based on 6FDADAM for gas separation, J. Memb. Sci. 544 (2017) 88-97. doi:10.1016/j.memsci.2017.09.009.

[87] M.Z. Ahmad, V. Martin-Gil, V. Perfilov, P. Sysel, V. Fila, Investigation of a new co-polyimide, 6FDAbisP and its ZIF-8 mixed matrix membranes for $\mathrm{CO}_{2} / \mathrm{CH}_{4}$ separation, Sep. Purif. Technol. 207 (2018) 523534. doi:https://doi.org/10.1016/j.seppur.2018.06.067.

[88] J. Sánchez-Laínez, A. Pardillos-Ruiz, M. Carta, R. Malpass-Evans, N.B. McKeown, C. Téllez, J. Coronas, 
Polymer engineering by blending PIM-1 and 6FDA-DAM for ZIF-8 containing mixed matrix membranes applied to $\mathrm{CO}_{2}$ separations, Sep. Purif. Technol. 224 (2019) 456-462. doi:10.1016/j.seppur.2019.05.035.

[89] C. Casado-Coterillo, J. Soto, M.M. Jimaré, S. Valencia, A. Corma, C. Téllez, J. Coronas, Preparation and characterization of ITQ-29/polysulfone mixed-matrix membranes for gas separation: Effect of zeolite composition and crystal size, Chem. Eng. Sci. 73 (2012) 116-122. doi:10.1016/j.ces.2012.01.024.

[90] G. Khanbabaei, E. Vasheghani-Farahani, A. Rahmatpour, Pure and mixed gas $\mathrm{CH}_{4}$ and $\mathrm{n}-\mathrm{C}_{4} \mathrm{H}_{10}$ permeation in PDMS-fumed silica nanocomposite membranes, Chem. Eng. J. 191 (2012) 369-377. doi:10.1016/j.cej.2012.03.033.

[91] S. Japip, H. Wang, Y. Xiao, T.S. Chung, Highly permeable zeolitic imidazolate framework (ZIF)-71 nanoparticles enhanced polyimide membranes for gas separation, J. Memb. Sci. 467 (2014) 162-174. doi:10.1016/j.memsci.2014.05.025.

[92] T. Yang, Y. Xiao, T.-S. Chung, Poly-/metal-benzimidazole nano-composite membranes for hydrogen purification, Energy Environ. Sci. 4 (2011) 4171. doi:10.1039/c1ee01324f.

[93] N. Tien-Binh, H. Vinh-Thang, X.Y. Chen, D. Rodrigue, S. Kaliaguine, Polymer functionalization to enhance interface quality of mixed matrix membranes for high $\mathrm{CO}_{2} / \mathrm{CH}_{4}$ gas separation, J. Mater. Chem. A. 3 (2015) 15202-15213. doi:10.1039/C5TA01597A.

[94] M.W. Anjum, F. Vermoortele, A.L. Khan, B. Bueken, D.E. De Vos, I.F.J. Vankelecom, Modulated UiO66-Based Mixed-Matrix Membranes for $\mathrm{CO}_{2}$ Separation, ACS Appl. Mater. Interfaces. 7 (2015) 2519325201. doi:10.1021/acsami.5b08964.

[95] M.Z. Ahmad, M. Navarro, M. Lhotka, B. Zornoza, C. Téllez, W.M. De Vos, N.E. Benes, N.M. Konnertz, T. Visser, R. Semino, G. Maurin, V. Fila, J. Coronas, Enhanced gas separation performance of 6FDADAM based mixed matrix membranes by incorporating MOF UiO-66 and its derivatives, J. Memb. Sci. 558 (2018) 64-77. doi:10.1016/j.memsci.2018.04.040.

[96] Q. Xin, T. Liu, Z. Li, S. Wang, Y. Li, Z. Li, J. Ouyang, Z. Jiang, H. Wu, Mixed matrix membranes composed of sulfonated poly(ether ether ketone) and a sulfonated metal-organic framework for gas separation, J. Memb. Sci. 488 (2015) 67-78. doi:10.1016/j.memsci.2015.03.060.

[97] J.R. Johnson, W.J. Koros, Utilization of nanoplatelets in organic-inorganic hybrid separation materials: Separation advantages and formation challenges, J. Taiwan Inst. Chem. Eng. 40 (2009) 268-275. doi:10.1016/j.jtice.2009.03.003.

[98] H.B. Tanh Jeazet, C. Staudt, C. Janiak, Metal-organic frameworks in mixed-matrix membranes for gas separation, Dalt. Trans. 41 (2012) 14003. doi:10.1039/c2dt31550e.

[99] S.A. Hashemifard, A.F. Ismail, T. Matsuura, Prediction of gas permeability in mixed matrix membranes using theoretical models, J. Memb. Sci. 347 (2010) 53-61. doi:10.1016/j.memsci.2009.10.005.

[100] V. Martin-Gil, A. Lopez, P. Hrabanek, R. Mallada, I.F.J. Vankelecom, V. Fila, Study of different titanosilicate (TS-1 and ETS-10) as fillers for Mixed Matrix Membranes for $\mathrm{CO}_{2} / \mathrm{CH}_{4}$ gas separation applications, J. Memb. Sci. 523 (2017) 24-35. doi:10.1016/j.memsci.2016.09.041.

[101] B. Seoane, J.M. Zamaro, C. Téllez, J. Coronas, Insight into the crystal synthesis, activation and application of ZIF-20, RSC Adv. 1 (2011) 917. doi:10.1039/c1ra00164g.

[102] M. Etxeberria-Benavides, O. David, T. Johnson, M.M. Łozińska, A. Orsi, P.A. Wright, S. Mastel, R. Hillenbrand, F. Kapteijn, J. Gascon, High performance mixed matrix membranes (MMMs) composed of 
ZIF-94 filler and 6FDA-DAM polymer, J. Memb. Sci. 550 (2018) 198-207. doi:10.1016/j.memsci.2017.12.033.

[103] J.C. Maxwell, A Treatise on Electricity and Magnetism, Vol. 1, Dover Publications, New York, 1954.

[104] T.B. Lewis, L.E. Nielsen, Dynamic mechanical properties of particulate-filled composites, J. Appl. Polym. Sci. 14 (1970) 1449-1471. doi:10.1002/app.1970.070140604.

[105] L.E. Nielsen, Thermal conductivity of particulate-filled polymers, J. Appl. Polym. Sci. 17 (1973) 3819 3820. doi:10.1002/app.1973.070171224.

[106] K.G. Papadokostaki;, M. Minelli;, F. Doghieri;, J.H. Petropoulos, A fundamental study of the extent of meaningful application of Maxwell's and Wiener's equations to the permeability of binary composite materials. Part II: A useful explicit analytical approach, Chem. Eng. Sci. 131 (2015) 353-359. doi:10.1016/j.ces.2015.03.031.

[107] J.H. Petropoulos, K.G. Papadokostaki, F. Doghieri, M. Minelli, A fundamental study of the extent of meaningful application of Maxwell's and Wiener's equations to the permeability of binary composite materials. Part III: Extension of the binary cubes model to 3-phase media, Chem. Eng. Sci. 131 (2015) 360-366. doi:10.1016/j.ces.2015.03.069.

[108] T. Rodenas, I. Luz, G. Prieto, B. Seoane, H. Miro, A. Corma, F. Kapteijn, F.X. Llabrés i Xamena, J. Gascon, Metal-organic framework nanosheets in polymer composite materials for gas separation, Nat. Mater. 14 (2014) 48-55. doi:10.1038/nmat4113.

[109] D. Schneider, F. Kapteijn, R. Valiullin, Transport Properties of Mixed-Matrix Membranes: A Kinetic Monte Carlo Study, Phys. Rev. Appl. 12 (2019) 1. doi:10.1103/PhysRevApplied.12.044034.

[110] H. Vinh-Thang, S. Kaliaguine, Predictive models for mixed-matrix membrane performance: A review, Chem. Rev. 113 (2013) 4980-5028. doi:10.1021/cr3003888.

[111] R. Semino, J.C. Moreton, N.A. Ramsahye, S.M. Cohen, G. Maurin, Understanding the origins of metalorganic framework/polymer compatibility, Chem. Sci. 09 (2018) 315-324. doi:10.1039/C7SC04152G.

[112] R. Semino, N.A. Ramsahye, A. Ghoufi, G. Maurin, Role of MOF surface defects on the microscopic structure of MOF/polymer interfaces: A computational study of the ZIF-8/PIMs systems, Microporous Mesoporous Mater. 254 (2017) 184-191. doi:10.1016/j.micromeso.2017.02.031.

[113] M. Benzaqui, R. Semino, N. Menguy, F. Carn, T. Kundu, J.M. Guigner, N.B. McKeown, K.J. Msayib, M. Carta, R. Malpass-Evans, C. Le Guillouzer, G. Clet, N.A. Ramsahye, C. Serre, G. Maurin, N. Steunou, Toward an Understanding of the Microstructure and Interfacial Properties of PIMs/ZIF-8 Mixed Matrix Membranes, ACS Appl. Mater. Interfaces. 8 (2016) 27311-27321. doi:10.1021/acsami.6b08954.

[114] Z. Sumer, S. Keskin, Computational Screening of MOF-Based Mixed Matrix Membranes for $\mathrm{CO}_{2} / \mathrm{N}_{2}$ Separations, J. Nanomater. 2016 (2016). doi:10.1155/2016/6482628.

[115] S. Keskin, D.S. Sholl, Selecting metal organic frameworks as enabling materials in mixed matrix membranes for high efficiency natural gas purification, Energy Environ. Sci. 3 (2010) 343-351. doi:10.1039/c003390c.

[116] O.M. Yaghi, M. O’Keeffe, N.W. Ockwig, H.K. Chae, M. Eddaoudi, J. Kim, Reticular synthesis and the design of new materials, Nature. 423 (2003) 705-714. doi:10.1038/nature01650.

[117] X. Yan, S. Komarneni, Z. Zhang, Z. Yan, Extremely enhanced $\mathrm{CO}_{2}$ uptake by HKUST-1 metal-organic framework via a simple chemical treatment, Microporous Mesoporous Mater. 183 (2014) 69-73. 
doi:10.1016/j.micromeso.2013.09.009.

[118] A.R. Millward, O.M. Yaghi, Metal-organic frameworks with exceptionally high capacity for storage of carbon dioxide at room temperature, J. Am. Chem. Soc. 127 (2005) 17998-17999. doi:10.1021/ja0570032.

[119] O.K. Farha, I. Eryazici, N.C. Jeong, B.G. Hauser, C.E. Wilmer, A.A. Sarjeant, R.Q. Snurr, S.T. Nguyen, A.Ö. Yazaydin, J.T. Hupp, Metal-organic framework materials with ultrahigh surface areas: Is the sky the limit?, J. Am. Chem. Soc. 134 (2012) 15016-15021. doi:10.1021/ja3055639.

[120] T. Ahnfeldt, D. Gunzelmann, J. Wack, J. Senker, N. Stock, Controlled modification of the inorganic and organic bricks in an Al-based MOF by direct and post-synthetic synthesis routes, CrystEngComm. 14 (2012) 4126-4136. doi:10.1039/C2CE06620C.

[121] K.K. Tanabe, S.M. Cohen, Postsynthetic modification of metal-organic frameworks—a progress report, Chem. Soc. Rev. 40 (2011) 498-519. doi:10.1039/C0CS00031K.

[122] S. Majumdar, B. Tokay, V. Martin-Gil, J. Campbell, R. Castro-Muñoz, M.Z. Ahmad, V. Fila, Mg-MOF74/Polyvinyl acetate (PVAc) mixed matrix membranes for $\mathrm{CO}_{2}$ separation, Sep. Purif. Technol. 238 (2020) 116411. doi:https://doi.org/10.1016/j.seppur.2019.116411.

[123] J. Cravillon, C.A. Schröder, H. Bux, A. Rothkirch, J. Caro, M. Wiebcke, Formate modulated solvothermal synthesis of ZIF-8 investigated using time-resolved in situ X-ray diffraction and scanning electron microscopy, CrystEngComm. 14 (2012) 492-498. doi:10.1039/C1CE06002C.

[124] D. Eiras, Y. Labreche, L.A. Pessan, Ultem®/ZIF-8 Mixed Matrix Membranes for Gas Separation: Transport and Physical Properties, Mater. Res. 19 (2016) 220-228. doi:10.1590/1980-5373-MR-20150621.

[125] R. Semino, N.A. Ramsahye, A. Ghoufi, G. Maurin, Microscopic Model of the Metal-Organic Framework/Polymer Interface: A First Step toward Understanding the Compatibility in Mixed Matrix Membranes, ACS Appl. Mater. Interfaces. 8 (2016) 809-819. doi:10.1021/acsami.5b10150.

[126] X. Wu, W. Liu, H. Wu, X. Zong, L. Yang, Y. Wu, Y. Ren, C. Shi, S. Wang, Z. Jiang, Nanoporous ZIF-67 embedded polymers of intrinsic microporosity membranes with enhanced gas separation performance, J. Memb. Sci. 548 (2018) 309-318. doi:10.1016/j.memsci.2017.11.038.

[127] C. Ye, X. Wu, H. Wu, L. Yang, Y. Ren, Y. Wu, Y. Liu, Z. Guo, R. Zhao, Z. Jiang, Incorporating nanosized ZIF-67 to enhance selectivity of polymers of intrinsic microporosity membranes for biogas upgrading, Chem. Eng. Sci. 216 (2020) 115497. doi:10.1016/j.ces.2020.115497.

[128] L. Hao, K.S. Liao, T.S. Chung, Photo-oxidative PIM-1 based mixed matrix membranes with superior gas separation performance, J. Mater. Chem. A. 3 (2015) 17273-17281. doi:10.1039/c5ta03776j.

[129] M.R. Khdhayyer, E. Esposito, A. Fuoco, M. Monteleone, L. Giorno, J.C. Jansen, M.P. Attfield, P.M. Budd, Mixed matrix membranes based on UiO-66 MOFs in the polymer of intrinsic microporosity PIM-1, Sep. Purif. Technol. 173 (2017) 304-313. doi:10.1016/j.seppur.2016.09.036.

[130] M.Z. Ahmad, T.A. Peters, N.M. Konnertz, T. Visser, C. Téllez, J. Coronas, V. Fila, W.M. de Vos, N.E. Benes, High-pressure $\mathrm{CO}_{2} / \mathrm{CH}_{4}$ separation of $\mathrm{Zr}-\mathrm{MOF}$ based mixed matrix membranes, Sep. Purif. Technol. 230 (2020) 115858. doi:10.1016/j.seppur.2019.115858.

[131] Z. Wang, H. Ren, S. Zhang, F. Zhang, J. Jin, Polymers of intrinsic microporosity/metal-organic framework hybrid membranes with improved interfacial interaction for high-performance $\mathrm{CO}_{2}$ separation, J. Mater. Chem. A Mater. Energy Sustain. 5 (2017) 10968-10977. doi:10.1039/C7TA01773A. 
[132] Y. Wang, J. Yang, Z. Li, Z. Zhang, J. Li, Q. Yang, C. Zhong, Computational study of oxygen adsorption in metal-organic frameworks with exposed cation sites: Effect of framework metal ions, RSC Adv. 5 (2015) 33432-33437. doi:10.1039/c5ra04791a.

[133] M. Khdhayyer, A.F. Bushell, P.M. Budd, M.P. Attfield, D. Jiang, A.D. Burrows, E. Esposito, P. Bernardo, M. Monteleone, A. Fuoco, G. Clarizia, F. Bazzarelli, A. Gordano, J.C. Jansen, Mixed matrix membranes based on MIL-101 metal-organic frameworks in polymer of intrinsic microporosity PIM-1, Sep. Purif. Technol. 212 (2018) 545-554. doi:10.1016/j.seppur.2018.11.055.

[134] N. Prasetya, B.P. Ladewig, New Azo-DMOF-1 MOF as a Photoresponsive Low-Energy $\mathrm{CO}_{2}$ Adsorbent and Its Exceptional CO2/N2 Separation Performance in Mixed Matrix Membranes, ACS Appl. Mater. Interfaces. 10 (2018) 34291-34301. doi:10.1021/acsami.8b12261.

[135] Q. Shen, S. Cong, R. He, Z. Wang, Y. Jin, H. Li, X. Cao, J. Wang, B. Van der Bruggen, Y. Zhang, SIFSIX3-Zn/PIM-1 mixed matrix membranes with enhanced permeability for propylene/propane separation, J. Memb. Sci. 588 (2019) 117201. doi:10.1016/j.memsci.2019.117201.

[136] Z. Wang, S.M. Cohen, Tandem modification of metal-organic frameworks by a postsynthetic approach, Angew. Chemie - Int. Ed. 47 (2008) 4699-4702. doi:10.1002/anie.200800686.

[137] Z. Yin, S. Wan, J. Yang, M. Kurmoo, M. Zeng, Recent advances in post-synthetic modification of metal - organic frameworks: New types and tandem reactions, Coord. Chem. Rev. 378 (2019) 500-512. doi:10.1016/j.ccr.2017.11.015.

[138] S.J. Garibay, S.M. Cohen, Isoreticular synthesis and modification of frameworks with the UiO-66 topology., Chem. Commun. (Camb). 46 (2010) 7700-2. doi:10.1039/c0cc02990d.

[139] M. Kang, D.W. Kang, C.S. Hong, Post-synthetic diamine-functionalization of MOF-74 type frameworks for effective carbon dioxide separation, Dalt. Trans. 48 (2019) 2263-2270. doi:10.1039/C8DT04339F.

[140] J. Ma, Y. Ying, X. Guo, H. Huang, D. Liu, Fabrication of mixed-matrix membrane containing metalorganic framework composite with taskspecific ionic liquid for efficient $\mathrm{CO}_{2}$ separation, J. Mater. Chem. A Mater. Energy Sustain. 4 (2016) 7281-7288. doi:10.1039/C6TA02611G.

[141] G.E. Cmarik, M. Kim, S.M. Cohen, K.S. Walton, Tuning the adsorption properties of Uio-66 via ligand functionalization, Langmuir. 28 (2012) 15606-15613. doi:10.1021/la3035352.

[142] M. Kim, S.M. Cohen, Discovery, development, and functionalization of Zr-based metal-organic frameworks, CrystEngComm. 14 (2012) 4096-4104. doi:10.1039/C2CE06491J.

[143] M. Kim, J.F. Cahill, Y. Su, K.A. Prather, S.M. Cohen, Postsynthetic ligand exchange as a route to functionalization of "inert" metal-organic frameworks, Chem. Sci. 3 (2012) 126-130. doi:10.1039/c1sc00394a.

[144] S.J.D. Smith, B.P. Ladewig, A.J. Hill, C.H. Lau, M.R. Hill, Post-synthetic Ti Exchanged UiO-66 MetalOrganic Frameworks that Deliver Exceptional Gas Permeability in Mixed Matrix Membranes, Sci. Rep. 5 (2015) 7823. doi:10.1038/srep07823.

[145] T. Rodenas, M. Van Dalen, E. García-Pérez, P. Serra-Crespo, B. Zornoza, F. Kapteijn, J. Gascon, Visualizing MOF mixed matrix membranes at the nanoscale: Towards structure-performance relationships in $\mathrm{CO}_{2} / \mathrm{CH}_{4}$ separation over NH2-MIL-53(Al)@PI, Adv. Funct. Mater. 24 (2014) 249-256. doi:10.1002/adfm.201203462.

[146] J. Li, X. Zhou, J. Wang, X. Li, Two-Dimensional Covalent Organic Frameworks (COFs) for Membrane 
Separation : a Mini Review, Ind. Eng. Chem. Res. 58 (2019) 15394-15406. doi:10.1021/acs.iecr.9b02708.

[147] Y. Cheng, X. Wang, C. Jia, Y. Wang, L. Zhai, Q. Wang, D. Zhao, Ultrathin mixed matrix membranes containing two-dimensional metal-organic framework nanosheets for efficient $\mathrm{CO} 2 / \mathrm{CH} 4$ separation, J. Memb. Sci. 539 (2017) 213-223. doi:10.1016/j.memsci.2017.06.011.

[148] A. Asghar, N. Iqbal, T. Noor, Ultrasonication treatment enhances MOF surface area and gas uptake capacity, Polyhedron. 181 (2020) 114463. doi:https://doi.org/10.1016/j.poly.2020.114463.

[149] N. Tien-Binh, D. Rodrigue, S. Kaliaguine, In-situ cross interface linking of PIM-1 polymer and UiO-66$\mathrm{NH}_{2}$ for outstanding gas separation and physical aging control, J. Memb. Sci. 548 (2018) 429-438. doi:10.1016/j.memsci.2017.11.054.

[150] G. Yu, X. Zou, L. Sun, B. Liu, Z. Wang, P. Zhang, G. Zhu, Constructing Connected Paths between UiO66 and PIM-1 to Improve Membrane $\mathrm{CO}_{2}$ Separation with Crystal-Like Gas Selectivity, Adv. Mater. 31 (2019) 1-9. doi:10.1002/adma.201806853.

[151] F. Cacho-Bailo, B. Seoane, C. Téllez, J. Coronas, ZIF-8 continuous membrane on porous polysulfone for hydrogen separation, J. Memb. Sci. 464 (2014) 119-126. doi:10.1016/j.memsci.2014.03.070.

[152] E. Shamsaei, Z.X. Low, X. Lin, A. Mayahi, H. Liu, X. Zhang, J. Zhe Liu, H. Wang, Rapid synthesis of ultrathin, defect-free ZIF-8 membranes via chemical vapour modification of a polymeric support, Chem. Commun. 51 (2015) 11474-11477. doi:10.1039/c5cc03537f.

[153] Y. Liu, J. Zhang, X. Tan, High Performance of PIM-1/ZIF-8 Composite Membranes for $\mathrm{O}_{2} / \mathrm{N}_{2}$ Separation, ACS Omega. 4 (2019) 16572-16577. doi:10.1021/acsomega.9b02363.

[154] A. Fuoco, M.R. Khdhayyer, M.P. Attfield, E. Esposito, J.C. Jansen, P.M. Budd, Synthesis and transport properties of novel MOF/PIM-1/MOF sandwich membranes for gas separation, Membranes (Basel). 7 (2017). doi:10.3390/membranes7010007.

[155] D. Ugarte, A. Châtelain, W.A. de Heer, Nanocapillarity and Chemistry in Carbon Nanotubes, Science (80). 274 (1996) 1897 LP - 1899. doi:10.1126/science.274.5294.1897.

[156] D.M. Delozier, K.A. Watson, Smith Joseph G., T.C. Clancy, J.W. Connell, Investigation of Aromatic/Aliphatic Polyimides as Dispersants for Single Wall Carbon Nanotubes, Macromolecules. 39 (2006) 1731-1739. doi:10.1021/ma051826u.

[157] A.K. Geim, K.S. Novoselov, The rise of graphene, Nat. Mater. 6 (2007) 183-191. doi:10.1038/nmat1849.

[158] Y. Shin, E. Prestat, K.-G. Zhou, P. Gorgojo, K. Althumayri, W. Harrison, P.M. Budd, S.J. Haigh, C. Casiraghi, Synthesis and characterization of composite membranes made of graphene and polymers of intrinsic microporosity, Carbon $\quad$ N. $\quad$ Y. $\quad 102 \quad$ (2016) 357-366. doi:https://doi.org/10.1016/j.carbon.2016.02.037.

[159] K.S. Novoselov, V.I. Fal'ko, L. Colombo, P.R. Gellert, M.G. Schwab, K. Kim, A roadmap for graphene, Nature. 490 (2012) 192-200. doi:10.1038/nature11458.

[160] K. Althumayri, W.J. Harrison, Y. Shin, J.M. Gardiner, C. Casiraghi, P.M. Budd, P. Bernardo, G. Clarizia, J.C. Jansen, The influence of few-layer graphene on the gas permeability of the high-free-volume polymer PIM-1, Philos. Trans. R. Soc. A Math. Phys. Eng. Sci. 374 (2016) 20150031. doi:10.1098/rsta.2015.0031.

[161] O. Hölck, M. Böhning, M. Heuchel, M.R. Siegert, D. Hofmann, Gas sorption isotherms in swelling glassy polymers-Detailed atomistic simulations, J. Memb. Sci. 428 (2013) 523-532. doi:https://doi.org/10.1016/j.memsci.2012.10.023. 
[162] R.R. Nair, H.A. Wu, P.N. Jayaram, I. V Grigorieva, A.K. Geim, Unimpeded Permeation of Water Through Helium-Leak-Tight Graphene-Based Membranes, Science (80-. ). 335 (2012) 442 LP - 444. doi:10.1126/science.1211694.

[163] H. Li, Z. Song, X. Zhang, Y. Huang, S. Li, Y. Mao, H.J. Ploehn, Y. Bao, M. Yu, Ultrathin, MolecularSieving Graphene Oxide Membranes for Selective Hydrogen Separation, Science (80-. ). 342 (2013) 95 LP - 98. doi:10.1126/science.1236686.

[164] M. Chen, F. Soyekwo, Q. Zhang, C. Hu, A. Zhu, Q. Liu, Graphene oxide nanosheets to improve permeability and selectivity of PIM-1 membrane for carbon dioxide separation, J. Ind. Eng. Chem. 63 (2018) 296-302. doi:10.1016/j.jiec.2018.02.030.

[165] S. Gadipelli, Z.X. Guo, Graphene-based materials: Synthesis and gas sorption, storage and separation, Prog. Mater. Sci. 69 (2015) 1-60. doi:https://doi.org/10.1016/j.pmatsci.2014.10.004.

[166] E.M. Aliyev, M.M. Khan, A.M. Nabiyev, R.M. Alosmanov, I.A. Bunyad-zadeh, S. Shishatskiy, V. Filiz, Covalently Modified Graphene Oxide and Polymer of Intrinsic Microporosity (PIM-1) in Mixed Matrix Thin-Film Composite Membranes, Nanoscale Res. Lett. 13 (2018) 359. doi.org/10.1186/s11671-0182771-3.

[167] E. Kroke, M. Schwarz, E. Horath-Bordon, P. Kroll, B. Noll, A.D. Norman, Tri-s-triazine derivatives. Part I. From trichloro-tri-s-triazine to graphitic C3N4 structures, New J. Chem. 26 (2002) 508-512. doi:10.1039/B111062B.

[168] S.Z. Butler, S.M. Hollen, L. Cao, Y. Cui, J.A. Gupta, H.R. Gutiérrez, T.F. Heinz, S.S. Hong, J. Huang, A.F. Ismach, E. Johnston-Halperin, M. Kuno, V. V Plashnitsa, R.D. Robinson, R.S. Ruoff, S. Salahuddin, J. Shan, L. Shi, M.G. Spencer, M. Terrones, W. Windl, J.E. Goldberger, Progress, challenges, and opportunities in two-dimensional materials beyond graphene., ACS Nano. 7 (2013) 2898-2926. doi:10.1021/nn400280c.

[169] Z. Tian, S. Wang, Y. Wang, X. Ma, K. Cao, D. Peng, X. Wu, H. Wu, Z. Jiang, Enhanced gas separation performance of mixed matrix membranes from graphitic carbon nitride nanosheets and polymers of intrinsic microporosity, J. Memb. Sci. 514 (2016) 15-24. doi:10.1016/j.memsci.2016.04.019.

[170] D.F. Sanders, Z.P. Smith, R. Guo, L.M. Robeson, J.E. McGrath, D.R. Paul, B.D. Freeman, Energyefficient polymeric gas separation membranes for a sustainable future: A review, Polym. (United Kingdom). 54 (2013) 4729-4761. doi:10.1016/j.polymer.2013.05.075.

[171] C.R. Mason, M.G. Buonomenna, G. Golemme, P.M. Budd, F. Galiano, A. Figoli, K. Friess, V. Hynek, New organophilic mixed matrix membranes derived from a polymer of intrinsic microporosity and silicalite-1, Polymer (Guildf). 54 (2013) 2222-2230. doi:10.1016/j.polymer.2013.02.032.

[172] M.M. Khan, S. Shishatskiy, V. Filiz, Mixed matrix membranes of boron icosahedron and polymers of intrinsic microporosity (PIM-1) for gas separation, Membranes (Basel). 8 (2018) 1-18. doi:10.3390/membranes8010001.

[173] C. Wang, F. Guo, H. Li, J. Xu, J. Hu, H. Liu, Porous organic polymer as fillers for fabrication of defectfree PIM-1 based mixed matrix membranes with facilitating $\mathrm{CO}_{2}$-transfer chain, J. Memb. Sci. 564 (2018) 115-122. doi:10.1016/j.memsci.2018.07.018.

[174] N. Konnertz, Y. Ding, W.J. Harrison, P.M. Budd, A. Schönhals, M. Böhning, Molecular mobility and gas transport properties of nanocomposites based on PIM-1 and polyhedral oligomeric phenethyl- 
silsesquioxanes (POSS), J. Memb. Sci. 529 (2017) 274-285. doi:10.1016/j.memsci.2017.02.007.

[175] S. Zhang, Q. Yang, C. Wang, X. Luo, J. Kim, Z. Wang, Y. Yamauchi, Porous Organic Frameworks: Advanced Materials in Analytical Chemistry, Adv. Sci. 5 (2018) 1801116. doi:10.1002/advs.201801116.

[176] M. Tolinski, Overview of Fillers and Fibers, in: M.B.T.-A. for P. Tolinski (Ed.), Addit. Polyolefins, William Andrew Publishing, Oxford, 2009: pp. 93-119. doi:https://doi.org/10.1016/B978-0-8155-20511.00007-8.

[177] C. DeArmitt, Functional Fillers for Plastics, in: M.B.T.-A.P.E.H. Kutz (Ed.), Appl. Plast. Eng. Handb. Process. Mater., William Andrew Publishing, Oxford, 2011: pp. 455-468. doi:https://doi.org/10.1016/B978-1-4377-3514-7.10026-1.

[178] Z. Li, J. Kong, F. Wang, C. He, Polyhedral oligomeric silsesquioxanes (POSSs): an important building block for organic optoelectronic materials, J. Mater. Chem. C. 5 (2017) 5283-5298. doi:10.1039/C7TC01327B.

[179] W.F. Yong, K.H.A. Kwek, K.S. Liao, T.S. Chung, Suppression of aging and plasticization in highly permeable polymers, Polymer (Guildf). 77 (2015) 377-386. doi:10.1016/j.polymer.2015.09.075.

[180] T. Visser, G.H. Koops, M. Wessling, On the subtle balance between competitive sorption and plasticization effects in asymmetric hollow fiber gas separation membranes, J. Memb. Sci. 252 (2005) 265-277. doi:10.1016/j.memsci.2004.12.015.

[181] Y. Kinoshita, K. Wakimoto, A.H. Gibbons, A.P. Isfahani, H. Kusuda, E. Sivaniah, B. Ghalei, Enhanced PIM-1 membrane gas separation selectivity through efficient dispersion of functionalized POSS fillers, J. Memb. Sci. 539 (2017) 178-186. doi:10.1016/j.memsci.2017.05.072.

[182] S. Shahid, K. Nijmeijer, Performance and plasticization behavior of polymer-MOF membranes for gas separation at elevated pressures, J. Memb. Sci. 470 (2014) 166-177. doi:10.1016/j.memsci.2014.07.034.

[183] Y. Zhang, K.J. Balkus, I.H. Musselman, J.P. Ferraris, Mixed-matrix membranes composed of Matrimid ${ }^{\circledR}$ and mesoporous ZSM-5 nanoparticles, J. Memb. Sci. $325 \quad$ (2008) 28-39. doi:10.1016/j.memsci.2008.04.063.

[184] L. Yang, Z. Tian, X. Zhang, X. Wu, Y. Wu, Y. Wang, D. Peng, S. Wang, H. Wu, Z. Jiang, Enhanced CO selectivities by incorporating $\mathrm{CO}_{2}$-philic PEG-POSS into polymers of intrinsic microporosity membrane, J. Memb. Sci. 543 (2017) 69-78. doi:10.1016/j.memsci.2017.08.050.

[185] A.F. Bushell, P.M. Budd, M.P. Attfield, J.T.A. Jones, T. Hasell, A.I. Cooper, P. Bernardo, F. Bazzarelli, G. Clarizia, J.C. Jansen, Nanoporous organic polymer/cage composite membranes, Angew. Chemie - Int. Ed. 52 (2013) 1253-1256. doi:10.1002/anie.201206339.

[186] M. Mastalerz, The Next Generation of Shape-Persistant Zeolite Analogues: Covalent Organic Frameworks, Angew. Chemie Int. Ed. 47 (2008) 445-447. doi:10.1002/anie.200703871.

[187] R.W. Tilford, S.J. Mugavero III, P.J. Pellechia, J.J. Lavigne, Tailoring Microporosity in Covalent Organic Frameworks, Adv. Mater. 20 (2008) 2741-2746. doi:10.1002/adma.200800030.

[188] M. Shan, B. Seoane, E. Rozhko, A. Dikhtiarenko, G. Clet, F. Kapteijn, J. Gascon, Azine-Linked Covalent Organic Framework (COF)-Based Mixed-Matrix Membranes for $\mathrm{CO}_{2} / \mathrm{CH}_{4}$ Separation, Chem. - A Eur. J. 22 (2016) 14467-14470. doi:10.1002/chem.201602999.

[189] B.P. Biswal, H.D. Chaudhari, R. Banerjee, U.K. Kharul, Chemically Stable Covalent Organic Framework (COF)-Polybenzimidazole Hybrid Membranes: Enhanced Gas Separation through Pore Modulation, 
Chem. - A Eur. J. 22 (2016) 4695-4699. doi:10.1002/chem.201504836.

[190] X. Li, J. Hou, R. Guo, Z. Wang, J. Zhang, Constructing Unique Cross-Sectional Structured Mixed Matrix Membranes by Incorporating Ultrathin Microporous Nanosheets for Efficient $\mathrm{CO}_{2}$ Separation, ACS Appl. Mater. Interfaces. 11 (2019) 24618-24626. doi:10.1021/acsami.9b07815.

[191] X. Wu, Z. Tian, S. Wang, D. Peng, L. Yang, Y. Wu, Q. Xin, H. Wu, Z. Jiang, Mixed matrix membranes comprising polymers of intrinsic microporosity and covalent organic framework for gas separation, J. Memb. Sci. 528 (2017) 273-283. doi:10.1016/j.memsci.2017.01.042.

[192] C.H. Lau, P.T. Nguyen, M.R. Hill, A.W. Thornton, K. Konstas, C.M. Doherty, R.J. Mulder, L. Bourgeois, A.C.Y. Liu, D.J. Sprouster, J.P. Sullivan, T.J. Bastow, A.J. Hill, D.L. Gin, R.D. Noble, Ending aging in super glassy polymer membranes, Angew. Chemie - Int. Ed. 53 (2014) 5322-5326. doi:10.1002/anie.201402234.

[193] H. Zhao, L. Feng, X. Ding, Y. Zhao, X. Tan, Y. Zhang, The nitrogen-doped porous carbons/PIM mixedmatrix membranes for $\mathrm{CO}_{2}$ separation, J. Memb. Sci. 564 (2018) 800-805. doi:10.1016/j.memsci.2018.07.075.

[194] J.S. Lee, X. Wang, H. Luo, G.A. Baker, S. Dai, Facile ionothermal synthesis of microporous and mesoporous carbons from task specific ionic liquids, J. Am. Chem. Soc. 131 (2009) 4596-4597. doi:10.1021/ja900686d.

[195] R.S. Bhavsar, T. Mitra, D.J. Adams, A.I. Cooper, P.M. Budd, Ultrahigh-permeance PIM-1 based thin film nanocomposite membranes on PAN supports for $\mathrm{CO}_{2}$ separation, J. Memb. Sci. 564 (2018) 878-886. doi:10.1016/j.memsci.2018.07.089.

[196] M. Tamaddondar, A.B. Foster, M. Carta, P. Gorgojo, N.B. McKeown, P.M. Budd, Mitigation of Physical Aging with Mixed Matrix Membranes Based on Cross-Linked PIM-1 Fillers and PIM-1, ACS Appl. Mater. Interfaces. 12 (2020) 46756-46766. doi:10.1021/acsami.0c13838.

[197] A.B. Foster, M. Tamaddondar, J.M. Luque-Alled, W.J. Harrison, Z. Li, P. Gorgojo, P.M. Budd, Understanding the Topology of the Polymer of Intrinsic Microporosity PIM-1: Cyclics, Tadpoles, and Network Structures and Their Impact on Membrane Performance, Macromolecules. 53 (2020) 569-583. doi:10.1021/acs.macromol.9b02185.

[198] B. Satilmis, P.M. Budd, Selective dye adsorption by chemically-modified and thermally-treated polymers of intrinsic microporosity, J. Colloid Interface Sci. 492 (2017) 81-91. doi:https://doi.org/10.1016/j.jcis.2016.12.048.

[199] N. Du, G.P. Robertson, J. Song, I. Pinnau, S. Thomas, M.D. Guiver, Polymers of Intrinsic Microporosity Containing Trifluoromethyl and Phenylsulfone Groups as Materials for Membrane Gas Separation, Macromolecules. 41 (2008) 9656-9662. doi:10.1021/ma801858d.

[200] M. Tamaddondar, A.B. Foster, J.M. Luque-Alled, K.J. Msayib, M. Carta, S. Sorribas, P. Gorgojo, N.B. McKeown, P.M. Budd, Intrinsically Microporous Polymer Nanosheets for High-Performance Gas Separation Membranes, Macromol. Rapid Commun. 41 (2020) 2-9. doi:10.1002/marc.201900572. 